\title{
The clinical impact of glycobiology: targeting selectins, Siglecs and mammalian glycans
}

\section{Benjamin A. H. Smith $\mathbb{1}^{1}$ and Carolyn R. Bertozzi ${ }^{1,2,3 凶}$}

Abstract | Carbohydrates - namely glycans - decorate every cell in the human body and most secreted proteins. Advances in genomics, glycoproteomics and tools from chemical biology have made glycobiology more tractable and understandable. Dysregulated glycosylation plays a major role in disease processes from immune evasion to cognition, sparking research that aims to target glycans for therapeutic benefit. The field is now poised for a boom in drug development. As a harbinger of this activity, glycobiology has already produced several drugs that have improved human health or are currently being translated to the clinic. Focusing on three areas - selectins, Siglecs and glycan-targeted antibodies - this Review aims to tell the stories behind therapies inspired by glycans and to outline how the lessons learned from these approaches are paving the way for future glycobiology-focused therapeutics.

Glycoproteins

Proteins that are covalently conjugated to one or more glycans. These glycans may be either $\mathrm{N}$-linked (connected to asparagine) or O-linked (connected to serine or threonine).
'Department of Chemical \& Systems Biology and ChEM-H, Stanford School of Medicine, Stanford, CA, USA.

${ }^{2}$ Department of Chemistry, Stanford University, Stanford, CA, USA.

${ }^{3}$ Howard Hughes Medical Institute, Stanford University. Stanford, CA, USA.

$\otimes_{e-m a i l:}$

bertozzi@stanford.edu

https://doi.org/10.1038

$\$ 41573-020-00093-1$
Glycans are involved in fundamental aspects of cell and organismal biology, such as the receptor-mediated cell to cell interactions that underlie both normal and pathological processes. Indeed, the dense layer of glycans on the cell surface (the glycocalyx) can extend more than $30 \mathrm{~nm}$ from the plasma membrane on some cells ${ }^{1}$. Cell surface proteins are therefore embedded in a matrix of glycans.

The varied functions of glycans are matched by their diverse structures. Glycans can be conjugated to proteins (to form glycoproteins, proteoglycans and glycosylphosphatidylinositol (GPI)-anchored proteins) and lipids (to form glycolipids), or they can be secreted without conjugation to other macromolecules (in the form of glycosaminoglycans such as hyaluronan). In humans, glycans are primarily constructed from ten monosaccharides: glucose (Glc), galactose (Gal), $N$-acetylglucosamine (GlcNAc), $N$-acetylgalactosamine (GalNAc), fucose (Fuc), xylose (Xyl), sialic acid (Neu5Ac), glucuronic acid (GlcA), mannose (Man) and iduronic acid (IdoA). The assembly of these monosaccharides into glycans is performed by enzymes associated with the endoplasmic reticulum and Golgi apparatus. Monosaccharides are linked together through a glycosidic bond between the anomeric carbon of one sugar and a hydroxyl group of the other. The orientation of the glycosidic bond relative to the anomeric carbon ( $\alpha$ versus $\beta$ ) affects the overall shape of the glycan. Therefore, the notation for lactose, Gal $\beta 1-4 \mathrm{Glc}$, for example, refers to a galactose linked though a $\beta$-glycosidic bond to the hydroxyl group on $\mathrm{C} 4$ of glucose. Considering these factors alone, there are
20 different ways of linking together glucose and galactose in their ring forms through a glycosidic bond, 19 of which do not make lactose. Additional complexity arises from modification of glycans by sulfation, methylation, phosphorylation, acetylation and $\mathrm{O}$-acylation.

Glycosylation has three broad functions. First, some glycans form structures with unique physical properties. Second, glycans can regulate the function or properties of the entity to which they are attached, for instance by controlling protein stability or receptor dimerization. Last, certain glycans are themselves ligands for lectins, which are carbohydrate-specific receptors.

Because glycans are essential for organism health, defects in glycosylation are important contributors to human disease. However, the development of glycan-targeted therapies has been hindered by many factors, beginning with our lack of tools for understanding basic glycobiology. Research in the field hinges on accurate methods for identifying and quantifying glycans in a sample. These profiling experiments typically rely on mass spectrometry, fluorophore-conjugated lectins or antibodies. For the few glycan species with high-affinity anti-glycan antibodies, the pace of discovery is higher than for those without such reagents. However, relatively few antibodies against defined glycans are available. Mass spectrometry-based glycomics provides an inventory of glycans present in the sample, but requires liberating glycans from their underlying scaffold. As a consequence, information is limited about which glycan is attached to the particular glycosites on any given protein or lipid. Glycoproteomics is becoming 


\section{Proteoglycans \\ Glycoconjugates comprising a core protein decorated with glycosaminoglycans, which are long, linear chains of repeating disaccharides that are \\ frequently sulfated. The sugars constituting this repeating unit are characteristic of different glycosaminoglycans. \\ For instance, repeating $\mathrm{N}$-acetylgalactosamine (GalNAc) and glucuronic acid (GlcA) distinguish chondroitin sulfate, whereas heparan \\ sulfate begins as repeating \\ $\mathrm{N}$-acetylglucosamine (GlcNAc) and $\mathrm{GlcA}$ before undergoing heavy modifications, such as epimerization to IdoA and sulfation.}

\section{Catch bonds}

Bonds that prolong their lifetime in response to increased tensile forces. By contrast, the lifetime of a slip bond decreases in response to higher tension.

Leukocyte extravasation The process by which cells move from the circulation, across the blood vessel wall and into tissue parenchyma. Extravasation is a stepwise process beginning with rolling adhesion, then tight binding of leukocytes to the endothelium and, finally, diapedesis, where cells cross the endothelial barrier a viable alternative as technologies for sample preparation, database searching and data processing continue to improve $\mathrm{e}^{2,3}$.

Experiments aimed at identifying the set of ligands for a biologically relevant lectin are complicated by the nature of the interactions between lectins and their glycosylated ligands. First, monovalent interactions tend to be of low affinity; multivalent presentation of both lectin and ligand is often needed to achieve physiologically relevant binding affinities ${ }^{4}$. Second, lectins may have binding affinities that are not only higher but directed to structurally different glycans when those glycans are presented on a multivalent scaffold as compared with a monovalent interaction in solution ${ }^{5}$. Third, in vitro assays may not capture in vivo complexity; indeed, shear stress is required to observe catch bonds, which are characteristic of selectin-ligand interactions ${ }^{6}$. Last, the binding epitope on the ligand may contain both glycan and scaffold protein or lipid components. Therefore, screening fragments of glycans, proteins and lipids independently of one another for binding to a particular lectin is unlikely to identify relevant ligands. This is an important caveat to glycan array technology, in which glycans are printed on glass slides and binding is detected by incubation with fluorescently labelled lectins?.

Glycan synthesis is also a non-templated process, meaning that glycan sequences are not directly coded in the genome. Instead, glycans are produced by the coordinated activity of hundreds of biosynthetic enzymes. Therefore, a particular glycan cannot easily be genetically deleted or altered in order to explore its function. At best, pathways for glycan biosynthesis can be inhibited or engineered, and synthetic glycans on polymeric carriers can be added into a system ${ }^{8}$, leaving researchers to deconvolute the pleiotropic effects of these treatments.

Despite these difficulties, several investigators have discovered how glycans contribute to disease and have successfully converted these findings into therapies. Perhaps the best known drugs that target glycans are the influenza medications zanamivir and oseltamivir. These drugs are sialic acid mimetics that function as inhibitors of the influenza neuraminidase to prevent virion release from infected cells; their development has been reviewed ${ }^{9}$. Vaccines directed against bacterial polysaccharides are also commonplace.

Although substantial progress has been made in targeting microbial glycans, few therapies directed at human glycans have translated to the clinic. Active areas of research and development on human glycan-targeted therapeutics include the selectins, a trio of receptors involved in immune cell adhesion and homing; the Siglecs, a family of lectins that modulate immune cell activity; and vaccines and antibodies directed at mammalian glycans. This Review takes a historical perspective on these three areas of human glycobiology. Which discoveries convinced investigators that a human glycan could be therapeutically targeted? When a drug development campaign was undertaken, why did it succeed or fail? In telling the stories behind glycan-directed therapies, we hope to begin answering these questions and outline exciting areas for further research.

\section{Selectins}

The selectins are a family of calcium-dependent (C-type) lectins best known for their role in mediating immune cell adhesion to the endothelium to facilitate entry to secondary lymphoid organs and sites of inflammation. Therapies targeting selectin-ligand interactions have been inspired by the importance of selectins in mediating cell adhesion, and have been investigated in sickle cell disease, cancer cell metastasis and bone marrow transplantation.

The selectin family comprises three members, named after their expression patterns: those expressed on platelets (P-selectin), on endothelial cells (E-selectin) and on leukocytes (L-selectin). These three selectins also differ in biological activities and preferred ligands (FIG. 1). $\mathrm{L}$-selectin is constitutively expressed on all circulating leukocytes and is shed from the cell surface. E-selectin is constitutively expressed on endothelial cells in postcapillary venules of the bone marrow and skin; expression on the endothelium in other organs requires exposure to inflammatory stimuli such as tumour necrosis factor (TNF), interleukin $1 \beta$ (IL-1 $\beta$ ) and lipopolysaccharide (LPS). P-selectin is expressed by endothelial cells and activated platelets ${ }^{10}$.

Among the best described ligands for the selectins are derivatives of the fucosylated and sialylated tetrasaccharides sialyl Lewis ${ }^{\mathrm{x}}$ (sLe $^{\mathrm{x}}$, Neu5Aca2-3Gal $\beta 1-4$ (Fuca1-3) GlcNAc) and sialyl Lewis ${ }^{\mathrm{a}}$ (sLe ${ }^{\mathrm{a}}$, Neu5Aca2-3Gal $\beta 1-$ 3(Fucal-4)GlcNAc). The context in which these glycans are presented alters their affinity for any given selectin. For instance, the primary ligand for P-selectin is P-selectin glycoprotein ligand 1 (PSGL1), a homodimeric mucin decorated with sLe ${ }^{\mathrm{x}}\left(\mathrm{REFS}^{11,12}\right)$, but P-selectin also has high-affinity interactions with sulfatides, non-sialylated glycosphingolipids ${ }^{13}$ and CD24 (REF. ${ }^{14}$ ). L-selectin has a preference for binding to glycoproteins, such as CD34, glycosylation-dependent cell adhesion molecule 1 (GlyCAM1), mucosal addressin cell adhesion molecule 1 (MAdCAM1) and PSGL1, which contain sulfated sLe ${ }^{\mathrm{x}}$ incorporated into $\mathrm{N}$-linked and O-linked glycans ${ }^{15,16}$. Interestingly, both L-selectin and P-selectin display affinity for heparin and heparan sulfate, which do not contain glycans structurally related to $s \mathrm{Le}^{\mathrm{x}}$ or sLe ${ }^{\mathrm{a}}\left(\mathrm{REF}^{17}{ }^{17}\right.$. E-selectin ligands in humans include PSGL1 $\left(\right.$ REF. $\left.^{18}\right)$, haematopoietic cell E/L selectin ligand (HCELL, a sialofucosylated glycoform of CD44), CD43 (REF. ${ }^{19}$ ) and even L-selectin ${ }^{20}$, all of which contain dense glycosylation with sLe ${ }^{\mathrm{x}}$-related glycans. E-selectin also displays affinity for the glycosphingolipid VIM2 epitope, which contains internally fucosylated sialyllactosamine ${ }^{21}$. The variation within these ligand repertoires suggests that, although sLe ${ }^{\mathrm{x}}$-related glycans are important, they are not the sole determinants of selectin binding. Rather, the selectins recognize a molecular surface comprising both glycan and scaffold.

In normal physiology, the selectins are critical mediators of leukocyte circulation through secondary lymphoid tissues and recruitment to sites of inflammation. Cells flowing through the vascular compartment that are captured by selectin-ligand interactions begin rolling on endothelial cells, which is the earliest stage of leukocyte extravasation ${ }^{10}$. At secondary lymphoid tissues, 
leukocytes expressing L-selectin engage glycoproteins displayed by endothelial cells in the high endothelial venule to promote extravasation. Leukocytes are recruited to sites of inflammation because endothelial cells there upregulate expression of E-selectin and display more P-selectin, which these cells store in Weibel-Palade bodies, and activated platelets display P-selectin, which they store in a-granules. The L-selectin expressed by the gathering immune cells themselves further contributes to leukocyte adhesion and recruitment. Therefore, upregulation of selectins or their ligands directs leukocytes to particular locations: through the combinatorial display of particular selectins and their ligands, leukocyte subsets can be recruited to specific sites in the body.

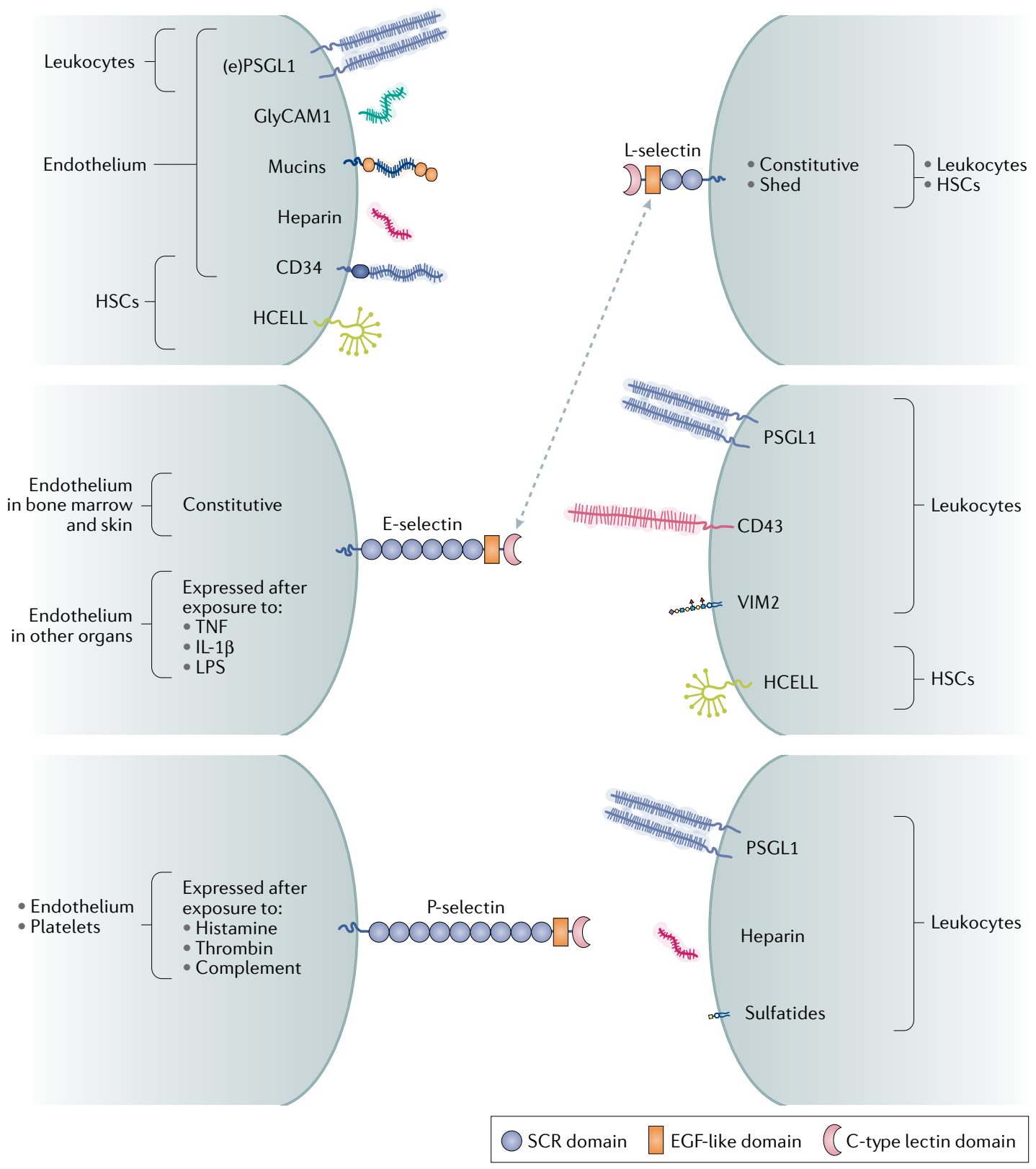

Fig. 1 Selectins and their primary ligands. In humans, selectin and selectin ligands expressed on the endothelium, platelets and other cells (shown on the left) interact with selectin and selectin ligands on leukocytes or haematopoietic stem cells (HSCs) (shown on the right). The ligands for each selectin comprise glycoproteins bearing sialofucosylated glycans that are closely related to sialyl Lewis ${ }^{x}\left(\mathrm{SL}^{\mathrm{x}}\right)$, and, in some cases, glycolipids such as VIM2 and glycosaminoglycans such as heparin. L-selectin is both constitutively expressed and shed from leukocyte cell surfaces. E-selectin and P-selectin are displayed on cells in response to inflammatory stimuli. Mucins refers to endothelial glycoproteins not otherwise depicted that function as L-selectin ligands, including mucosal addressin cell adhesion molecule 1 (MAdCAM1), podocalyxin-like protein, Sgp200, endoglycan and endomucin. E-selectin is constitutively expressed on the endothelium in the bone marrow and skin, but requires exposure to inflammatory cytokines to be expressed in other organs. The dotted arrow indicates that sLe ${ }^{\mathrm{x}}$ on L-selectin itself is a ligand for E-selectin. EGF, epidermal growth factor; (e)PSGL1, (endothelial) P-selectin glycoprotein ligand 1; GlyCAM1, glycosylation-dependent cell adhesion molecule 1; HCELL, haematopoietic cell E-/L-selectin ligand; IL-1 $\beta$, interleukin-1 $\beta$; LPS, lipopolysaccharide; SCR, short consensus repeat (Sushi domain); TNF, tumour necrosis factor. 
Discovery of selectins and ligands. Because selectinglycan interactions provide the molecular basis for recruitment of leukocytes to inflamed tissues, targeting these interactions with a therapeutic holds promise for spatially controlling the immune system. However, early investigations into selectin biology highlighted two major hurdles: glycan heterogeneity and low receptor-ligand affinity ${ }^{22}$. Pioneering work in the 1950 s established that leukocyte extravasation through high endothelial venules in the lymph node and into inflamed sites in the periphery is a tightly regulated process, dependent on cell surface carbohydrates ${ }^{23,24}$. The crucial realization that leukocyte-endothelium adhesion occurs when blood is flowing enabled the next several decades of selectin research by encouraging investigators to incorporate this shear stress into assays of selectinligand interactions ${ }^{6}$. Aided by the development of monoclonal antibody technology, the identities of the selectins were finally established when P-selectin, E-selectin and L-selectin were all cloned and described as part of the same family in 1989 (REFS ${ }^{25-27}$ ).

Animal models were quickly generated to explore the contribution of selectins to various acute and chronic inflammatory pathologies, and the results generated interest among those hoping to translate these discoveries. Among the first models tested were ischaemiareperfusion injuries ${ }^{28}$, dermal injuries ${ }^{29}$, allergen-induced inflammation ${ }^{30}$ and cobra venom-induced lung injury $^{31}$. In these models, administration of selectinimmunoglobulin chimeric decoy receptors or blocking antibodies targeting the selectins or sLe ${ }^{\mathrm{x}}$ could broadly decrease the damage caused by neutrophil entry into tissue. Models of ischaemia-reperfusion injury, in particular, produced impressive results: a P-selectin blocking antibody reduced tissue necrosis by up to $90 \%$ after ischaemia ${ }^{28}$. These results hinted that selectin inhibition may be a promising therapeutic strategy for numerous pathologies.

Pharmaceutical development could not progress, however, without an improved understanding of the glycan ligands used by selectins in vivo. In 1990, sLe ${ }^{\mathrm{x}}$ was identified as the primary binding determinant for E-selectin ${ }^{32,33}$. The resulting glycomimetic drug, Cylexin (CY-1503), comprising sLe ${ }^{\mathrm{x}} \beta$-linked to a methylprotected GalNAc, reduced neutrophilic inflammation after myocardial ischaemia in animal models ${ }^{34}$. In humans, early results showed that Cylexin prevented reperfusion injury after pulmonary thromboendarterectomy $^{35}$. Ultimately, a phase II trial (NCT00226369) (TABLE 1) found that Cylexin was not effective in reducing myocardial infarctions in infants undergoing cardiac surgery and led to cancellation of the programme. Clearly, the simple infusion of $\mathrm{sLe}^{\mathrm{x}}$ was insufficient for selectin inhibition.

Indeed, the in vitro equilibrium dissociation constant $\left(K_{\mathrm{d}}\right)$ values of the selectins for sLe ${ }^{\mathrm{x}}$ lie in the low millimolar range ${ }^{36}$. These measurements, made on free oligosaccharides, suggest weak interactions between glycan and selectin, and point towards the importance of other factors for binding in vivo. Additional information regarding selectin ligands would be necessary to enable the next generation of high-affinity inhibitors.
Small-molecule selectin inhibitors. A key insight came from more detailed studies of the interaction between P-selectin and its principal ligand, PSGL1. First, three sulfotyrosines in PSGL1 were found to be important binding determinants for P-selectin ${ }^{37}$. Soon thereafter, crystal structures of P-selectin and E-selectin in complex with sLe ${ }^{\mathrm{x}}$ and PSGL1 were solved ${ }^{38}$. The published structures demonstrated why the interaction of P-selectin with PSGL1 is decidedly higher affinity than that with the glycan alone: the three sulfotyrosines in PSGL1 create an anionic pocket that increases its affinity for P-selectin. In essence, the glycan and protein portions of PSGL1 may be considered distinct pharmacophores that both make important contributions to the interaction with P-selectin (FIG. 2). This finding was paradigmshifting because it challenged the prevailing view that lectins interact only with glycans. These structures demonstrated that the combination of glycan and scaffold provide a single epitope that is recognized by lectins such as P-selectin.

Additional NMR studies of the solution structure of $\mathrm{sLe}^{\mathrm{x}}$ bound to E-selectin highlighted the importance of contacts with the hydrogens of galactose and fucose ${ }^{39,40}$. This information was incorporated into the design of GlycoMimetics' pan-selectin inhibitor, rivipansel (GMI-1070), which retained moieties analogous to the $\mathrm{sLe}^{\mathrm{x}}$ tetrasaccharide, the carboxylic acid of sialic acid, and included a sulfated naphthalene group to mimic the sulfotyrosines in PSGL1 (REF ${ }^{41}$ ) (FIG. 3). Rivipansel bound E-selectin, P-selectin and L-selectin with micromolar affinities, was capable of inhibiting E-selectin and P-selectin-mediated leukocyte rolling and reversed vascular occlusions in a mouse model of sickle cell disease ${ }^{42}$. A phase II trial (NCT01119833) in patients with acute sickling crises demonstrated that rivipansel could decrease the time to resolution of vaso-occlusion and reduce opioid use ${ }^{43}$. The phase III trial (NCT02187003) of rivipansel in sickle cell disease failed to meet its primary end points in mid-2019, but a post hoc analysis found that patients who received the drug early after the start of pain from vaso-occlusion (within $26 \mathrm{~h}$ ) did benefit ${ }^{44}$.

Other small-molecule inhibitors that were developed to target the selectins suffered from a lack of drug-like properties, off-target effects and low binding affinities. Texas Biotechnology Corporation (later Encysive Pharmaceuticals) avoided oligosaccharide inhibitors by developing a small-molecule glycomimetic antagonist that replaced the $N$-acetyllactosamine (LacNAc) of $\mathrm{sLe}^{\mathrm{x}}$ with a biphenyl unit, substituted a carboxylic acid moiety for sialic acid and utilized mannose as a proxy for fucose ${ }^{45}$. Inspired by reports that branched sLe ${ }^{\mathrm{x}}$ structures enhanced selectin affinity, the team added an additional mannose to their structure to afford bimosiamose (TBC-1269 $)^{46}$. Bimosiamose was effective in ischaemiareperfusion injury ${ }^{47}$ and asthma model ${ }^{48}$, and later work demonstrated efficacy in psoriasis ${ }^{49}$, asthma ${ }^{50}$ and chronic obstructive pulmonary disease ${ }^{51}$. Despite these positive results, Revotar, who took over the programme, no longer appears to be developing bimosiamose.

Wyeth endeavoured to develop an orally available specific P-selectin inhibitor. Agnostic to the incorporation of carbohydrate pharmacophores in the therapeutic, 
Table 1 | Selected clinical trials of glycobiology-targeted therapeutics ${ }^{a}$

\begin{tabular}{|c|c|c|c|c|}
\hline $\begin{array}{l}\text { Therapeutic type and name; } \\
\text { manufacturer }\end{array}$ & Indication & Phase and status & Results & $\begin{array}{l}\text { Trial identifiers } \\
\text { (refs) }\end{array}$ \\
\hline \multicolumn{5}{|l|}{ Pan-selectin antagonists } \\
\hline $\begin{array}{l}\text { Small molecule } \\
\text { Cylexin (CY-1503); Cytel }\end{array}$ & $\begin{array}{l}\text { Ischaemia-reperfusion injury in } \\
\text { infant heart surgery }\end{array}$ & $\begin{array}{l}\text { Phase II/III } \\
\text { completed } 2001\end{array}$ & NR & NCT00226369 \\
\hline \multirow{3}{*}{$\begin{array}{l}\text { Small molecule } \\
\text { Rivipansel (GMI-1070); } \\
\text { GlycoMimetics }\end{array}$} & $\begin{array}{l}\text { Vaso-occlusive crisis in sickle cell } \\
\text { disease }\end{array}$ & $\begin{array}{l}\text { Phase I/Il completed } \\
2010\end{array}$ & $\begin{array}{l}\text { Well tolerated, no adverse } \\
\text { events }\end{array}$ & $\begin{array}{l}\text { NCT00911495 } \\
\left(\text { REF. }^{275}\right)\end{array}$ \\
\hline & $\begin{array}{l}\text { Vaso-occlusive crisis in sickle cell } \\
\text { disease and S- } \beta \text {-thalassaemia }\end{array}$ & $\begin{array}{l}\text { Phase Il completed } \\
2013\end{array}$ & $\begin{array}{l}\text { Trend towards reduced time to } \\
\text { vaso-occlusive crisis resolution }\end{array}$ & NCT01119833 \\
\hline & $\begin{array}{l}\text { Vaso-occlusive crisis in sickle cell } \\
\text { disease }\end{array}$ & $\begin{array}{l}\text { Phase III completed } \\
2019\end{array}$ & $\begin{array}{l}\text { Post hoc analysis showed } \\
\text { efficacy in a subset of patients }\end{array}$ & $\begin{array}{l}\text { NCT02187003 } \\
\left(\text { REF. }^{44}\right)\end{array}$ \\
\hline \multirow{3}{*}{$\begin{array}{l}\text { Small molecule } \\
\text { Bimosiamose (TBC-1269); Texas } \\
\text { Biotechnology Corporation }\end{array}$} & Psoriasis (as a cream) & $\begin{array}{l}\text { Phase II completed } \\
2009\end{array}$ & NR & NCT00823693 \\
\hline & $\begin{array}{l}\text { Ozone-induced sputum } \\
\text { neutrophilia }\end{array}$ & $\begin{array}{l}\text { Phase Il completed } \\
2010\end{array}$ & NR & NCT00962481 \\
\hline & $\begin{array}{l}\text { Chronic obstructive pulmonary } \\
\text { disease }\end{array}$ & $\begin{array}{l}\text { Phase II completed } \\
2011\end{array}$ & $\begin{array}{l}\text { Attenuates airway } \\
\text { inflammation }\end{array}$ & $\begin{array}{l}\text { NCT01108913 } \\
\text { (REFS }\end{array}$ \\
\hline $\begin{array}{l}\text { Small molecule } \\
\text { Sevuparin; Modus Therapeutics }\end{array}$ & $\begin{array}{l}\text { Vaso-occlusive crisis in sickle cell } \\
\text { disease }\end{array}$ & $\begin{array}{l}\text { Phase II completed } \\
2019\end{array}$ & NR & NCT02515838 \\
\hline \multicolumn{5}{|l|}{$P$-selectin antagonists } \\
\hline $\begin{array}{l}\text { Small molecule } \\
\text { PSI-697; Wyeth and Pfizer }\end{array}$ & Scleritis & $\begin{array}{l}\text { Phase I terminated } \\
2007\end{array}$ & NR (terminated) & NCT00367692 \\
\hline \multirow{4}{*}{$\begin{array}{l}\text { YSPSL (rPSGL-lg); Genetics } \\
\text { Institute and Wyeth }\end{array}$} & $\begin{array}{l}\text { Delayed graft function during } \\
\text { kidney allograft }\end{array}$ & $\begin{array}{l}\text { Phase I/Ila completed } \\
2007\end{array}$ & $\begin{array}{l}\text { Safe, no effect on renal } \\
\text { function }\end{array}$ & $\begin{array}{l}\text { NCT00298181 } \\
\left(\text { REF. }^{66}\right)\end{array}$ \\
\hline & $\begin{array}{l}\text { Delayed graft function during } \\
\text { kidney allograft }\end{array}$ & $\begin{array}{l}\text { Phase I/Ilb } \\
\text { completed } 2007\end{array}$ & $\begin{array}{l}\text { Attenuated biomarkers of } \\
\text { inflammation }\end{array}$ & $\begin{array}{l}\text { NCT00298168 } \\
\left(\text { REFS }^{66,277}\right)\end{array}$ \\
\hline & $\begin{array}{l}\text { Ischaemia-reperfusion injury } \\
\text { during liver allograft }\end{array}$ & $\begin{array}{l}\text { Phase Il completed } \\
2009\end{array}$ & $\begin{array}{l}\text { Safe, measures of graft } \\
\text { function trended towards } \\
\text { improvement, liver enzymes } \\
\text { normalized }\end{array}$ & $\begin{array}{l}\text { NCT00876902 } \\
\left.\text { (REF. }^{65}\right)\end{array}$ \\
\hline & $\begin{array}{l}\text { Delayed graft function during } \\
\text { liver allograft }\end{array}$ & $\begin{array}{l}\text { Phase Il completed } \\
2008\end{array}$ & NR & NCT00450398 \\
\hline \multirow{2}{*}{$\begin{array}{l}\text { Inclacumab (anti-P-selectin; } \\
\text { RO4905417); Hoffman-La Roche }\end{array}$} & Myocardial infarction & $\begin{array}{l}\text { Phase II completed } \\
2012\end{array}$ & $\begin{array}{l}\text { Reduced myocardial damage } \\
\text { (troponin I levels) in NSTEMI } \\
\text { patients }\end{array}$ & $\begin{array}{l}\text { NCT01327183 } \\
\text { (REFS } 88,278)\end{array}$ \\
\hline & $\begin{array}{l}\text { Coronary heart disease graft } \\
\text { occlusion }\end{array}$ & $\begin{array}{l}\text { Phase Il completed } \\
2013\end{array}$ & $\begin{array}{l}\text { No effect on saphenous vein } \\
\text { graft failure, possibly because } \\
\text { prior activation of P-selectin } \\
\text { pathway not evaluated }\end{array}$ & $\begin{array}{l}\text { NCT01245634 } \\
\left(\text { REF. }^{69}\right)\end{array}$ \\
\hline & $\begin{array}{l}\text { Vaso-occlusive crises in sickle } \\
\text { cell disease }\end{array}$ & $\begin{array}{l}\text { Phase Il completed } \\
2016\end{array}$ & $\begin{array}{l}\text { Reduced rate of vaso-occlusive } \\
\text { crises and time to first crisis }\end{array}$ & $\begin{array}{l}\text { NCT01895361 } \\
\left(\text { REF. }^{70}\right)\end{array}$ \\
\hline \multirow{6}{*}{$\begin{array}{l}\text { Crizanlizumab (anti-P-selectin; } \\
\text { SEG101 or SelG1); Selexys and } \\
\text { Novartis }\end{array}$} & $\begin{array}{l}\text { Vaso-occlusive crises in sickle } \\
\text { cell disease }\end{array}$ & Phase Il ongoing & Estimated completion in 2021 & NCT03264989 \\
\hline & $\begin{array}{l}\text { PK in paediatric patients with } \\
\text { sickle cell disease }\end{array}$ & Phase Il ongoing & Estimated completion in 2023 & NCT03474965 \\
\hline & $\begin{array}{l}\text { Vaso-occlusive crises in sickle cell } \\
\text { disease in adolescents and adults }\end{array}$ & Phase III ongoing & Estimated completion in 2027 & NCT03814746 \\
\hline & Sickle cell disease related priapism & Phase Il ongoing & Estimated completion in 2022 & NCT03938454 \\
\hline & $\begin{array}{l}\text { Chronic kidney disease in sickle } \\
\text { cell disease patients }\end{array}$ & Phase Il ongoing & Estimated completion in 2022 & NCT04053764 \\
\hline & $\begin{array}{l}\text { Myelofibrosis (combination } \\
\text { treatment with ruxolitinib) }\end{array}$ & Phase I/Il ongoing & Estimated completion in 2024 & NCT04097821 \\
\hline \multicolumn{5}{|l|}{ E-selectin antagonists } \\
\hline \multirow{3}{*}{$\begin{array}{l}\text { Small molecule } \\
\text { Uproleselan (GMI-1271); } \\
\text { GlycoMimetics }\end{array}$} & Deep vein thrombosis & $\begin{array}{l}\text { Phase I/II terminated } \\
2016\end{array}$ & $\begin{array}{l}\text { NR (terminated with grant } \\
\text { expiration) }\end{array}$ & NCT02744833 \\
\hline & Multiple myeloma & $\begin{array}{l}\text { Phase I completed } \\
2019\end{array}$ & NR & NCT02811822 \\
\hline & Acute myeloid leukaemia & $\begin{array}{l}\text { Phase II/III and III } \\
\text { ongoing }\end{array}$ & Estimated completion in 2023 & $\begin{array}{l}\text { NCT03616470, } \\
\text { NCT03701308 }\end{array}$ \\
\hline
\end{tabular}


Table 1 (cont.) | Selected clinical trials of glycobiology-targeted therapeutics ${ }^{a}$

\begin{tabular}{|c|c|c|c|c|}
\hline $\begin{array}{l}\text { Therapeutic type and name; } \\
\text { manufacturer }\end{array}$ & Indication & Phase and status & Results & $\begin{array}{l}\text { Trial identifiers } \\
\text { (refs) }\end{array}$ \\
\hline \multicolumn{5}{|l|}{ Siglec antibody-drug conjugates } \\
\hline \multirow{2}{*}{$\begin{array}{l}\text { Gemtuzumab } \\
\text { ozogamicin (Mylotarg; } \\
\text { anti-CD33-calicheamicin } \\
\text { conjugate); Wyeth and Pfizer }\end{array}$} & Acute myeloid leukaemia & $\begin{array}{l}\text { Phase Il completed } \\
2000\end{array}$ & $\begin{array}{l}\text { Improved survival with } \\
\text { reasonable safety profile; } \\
\text { FDA approval granted }\end{array}$ & $\begin{array}{l}\text { Trials 201, 202, } 203 \\
\text { (REFS } \\
\text { 279,280) }\end{array}$ \\
\hline & Acute myeloid leukaemia & $\begin{array}{l}\text { Phase III completed } \\
2014\end{array}$ & $\begin{array}{l}\text { No survival benefit and higher } \\
\text { rates of fatal toxicity; removed } \\
\text { from US market in } 2010\end{array}$ & $\begin{array}{l}\text { NCT00085709 } \\
\left(\text { REF. }^{281}\right)\end{array}$ \\
\hline $\begin{array}{l}\text { Inotuzumab ozogamicin (Besponsa; } \\
\text { anti-CD22-calicheamicin } \\
\text { conjugate); Pfizer }\end{array}$ & Acute lymphoblastic leukaemia & $\begin{array}{l}\text { Phase III completed } \\
2017\end{array}$ & $\begin{array}{l}\text { Improved progression-free } \\
\text { and overall survival }\end{array}$ & $\begin{array}{l}\text { NCT01564784 } \\
\left(\text { REF. }^{102}\right)\end{array}$ \\
\hline \multicolumn{5}{|l|}{ CD33 antagonists } \\
\hline \multicolumn{5}{|l|}{ AL003; Alector } \\
\hline \multicolumn{5}{|l|}{ Siglec- 8 agonists } \\
\hline \multirow[t]{2}{*}{$\begin{array}{l}\text { Monoclonal antibody } \\
\text { Lirentelimab (AK002); Allakos }\end{array}$} & $\begin{array}{l}\text { Keratoconjunctivitis, vernal } \\
\text { conjunctivitis, allergic } \\
\text { conjunctivitis }\end{array}$ & $\begin{array}{l}\text { Phase I completed } \\
2019\end{array}$ & NR & NCT03379311 \\
\hline & $\begin{array}{l}\text { Eosinophilic gastritis, } \\
\text { eosinophilic gastroenteritis }\end{array}$ & $\begin{array}{l}\text { Phase Il completed } \\
2019\end{array}$ & $\begin{array}{l}\text { Reduced gastrointestinal } \\
\text { eosinophil count and } \\
\text { symptoms in a majority of } \\
\text { patients }\end{array}$ & $\begin{array}{l}\text { NCT03496571 } \\
\left(\text { REF. }^{172}\right)\end{array}$ \\
\hline \multicolumn{5}{|l|}{ Siglec-10 agonists } \\
\hline Recombinant ligand & Severe COVID-19 & Phase III ongoing & Estimated completion in 2020 & NCT04317040 \\
\hline \multirow[t]{2}{*}{ CD24Fc; Oncolmmune } & $\begin{array}{l}\text { Immune-related adverse events } \\
\text { associated with checkpoint } \\
\text { inhibitors }\end{array}$ & $\begin{array}{l}\text { Phase I/II not yet } \\
\text { recruiting }\end{array}$ & Estimated completion in 2023 & NCT04060407 \\
\hline & Acute graft-versus-host disease & $\begin{array}{l}\text { Phase III not yet } \\
\text { recruiting }\end{array}$ & Estimated completion in 2024 & NCT04095858 \\
\hline \multicolumn{5}{|l|}{ Siglec-15 antagonists } \\
\hline $\begin{array}{l}\text { Monoclonal antibody } \\
\text { NC318; NextCure }\end{array}$ & $\begin{array}{l}\text { Metastatic solid tumours, } \\
\text { head and neck squamous cell } \\
\text { carcinoma, NSCLC, ovarian } \\
\text { cancer, triple-negative } \\
\text { breast cancer }\end{array}$ & Phase I/II ongoing & $\begin{array}{l}\text { Estimated completion in 2021; } \\
\text { NSCLC and ovarian cancer } \\
\text { cohorts will not advance after } \\
\text { interim analysis }\end{array}$ & $\begin{array}{l}\text { NCT03665285 } \\
\left(\text { REF. }^{284}\right)\end{array}$ \\
\hline \multicolumn{5}{|l|}{ Mammalian glycan vaccines } \\
\hline $\begin{array}{l}\text { Carbohydrate vaccine } \\
\text { Theratope (sTn-KLH vaccine); } \\
\text { Biomira }\end{array}$ & Breast cancer & $\begin{array}{l}\text { Phase III completed } \\
2008\end{array}$ & $\begin{array}{l}\text { No benefit to overall survival } \\
\text { or time to progression; } \\
\text { post hoc analysis showed } \\
\text { benefit when combined with } \\
\text { endocrine therapy }\end{array}$ & $\begin{array}{l}\text { NCT000003638 } \\
\text { (REFS 226,285) }\end{array}$ \\
\hline \multirow[t]{2}{*}{$\begin{array}{l}\text { MUC1 peptide plus poly-ICLC; } \\
\text { University of Pittsburgh }\end{array}$} & Colorectal adenoma & Phase Il ongoing & $\begin{array}{l}\text { Patients produced anti-MUC1 } \\
\text { lgG; adenoma recurrence } \\
\text { data pending }\end{array}$ & NCT02134925 \\
\hline & Lung carcinoma & Phase I ongoing & Estimated completion in 2020 & NCT03300817 \\
\hline
\end{tabular}


Table 1 (cont.) | Selected clinical trials of glycobiology-targeted therapeutics ${ }^{\mathrm{a}}$

\begin{tabular}{|c|c|c|c|c|}
\hline $\begin{array}{l}\text { Therapeutic type and name; } \\
\text { manufacturer }\end{array}$ & Indication & Phase and status & Results & $\begin{array}{l}\text { Trial identifiers } \\
\text { (refs) }\end{array}$ \\
\hline \multicolumn{5}{|l|}{ Mammalian glycan vaccines (cont.) } \\
\hline $\begin{array}{l}\text { Adenoviral vaccine } \\
\text { ETBX-011 (Ad5 CEA vaccine); } \\
\text { Etubics and } \mathrm{NCl}\end{array}$ & Colorectal carcinoma & $\begin{array}{l}\text { Phase I/II completed } \\
2013\end{array}$ & $\begin{array}{l}\text { Generated T cell response to } \\
\text { CEA }\end{array}$ & $\begin{array}{l}\text { NCT01147965 } \\
\left(\text { REF. }^{286}\right)\end{array}$ \\
\hline $\begin{array}{l}\text { Adenoviral vaccine } \\
\text { ETBX-011/ETBX-061/ETBX-051 } \\
\text { (Ad5 CEA/MUC1/brachyury } \\
\text { vaccine); Etubics and NCl }\end{array}$ & $\begin{array}{l}\text { Colon, breast, lung and prostate } \\
\text { cancers }\end{array}$ & Phase I ongoing & $\begin{array}{l}\text { Generated T cell response to } \\
\text { CEA, MUC } 1 \text { and brachyury }\end{array}$ & $\begin{array}{l}\text { NCT03384316 } \\
\left(\text { REF. }^{222}\right)\end{array}$ \\
\hline $\begin{array}{l}\text { Carbohydrate vaccine } \\
\text { BMS-248479 (GM2-KLH/QS-21 } \\
\text { vaccine); Bristol-Myers-Squibb }\end{array}$ & Melanoma & $\begin{array}{l}\text { Phase III terminated } \\
2007\end{array}$ & Terminated for futility & $\begin{array}{l}\text { NCT00005052 } \\
\left(\text { REF. }^{211}\right)\end{array}$ \\
\hline $\begin{array}{l}\text { Carbohydrate vaccine } \\
\text { Trivalent (GM2/GD2/GD3-KLH) } \\
\text { vaccine with OPT-821; MabVax }\end{array}$ & Metastatic sarcoma & $\begin{array}{l}\text { Phase Il completed } \\
2013\end{array}$ & $\begin{array}{l}\text { No benefit, trend towards } \\
\text { reduced progression-free } \\
\text { survival }\end{array}$ & NCT01141491 \\
\hline $\begin{array}{l}\text { Carbohydrate mimetic peptide } \\
\text { vaccine } \\
\text { P10s-PADRE vaccine; University of } \\
\text { Arkansas }\end{array}$ & Breast cancer & $\begin{array}{l}\text { Phase I completed } \\
2019\end{array}$ & $\begin{array}{l}\text { Serologic response to } L^{y} \text { and } \\
G D 2 \text { in all subjects }\end{array}$ & $\begin{array}{l}\text { NCT01390064 } \\
\left(\text { REF. }^{229}\right)\end{array}$ \\
\hline $\begin{array}{l}\text { Carbohydrate vaccine } \\
\text { GD2/GD3 lactone-KLH/OPT-821 } \\
\text { vaccine; Memorial Sloan Kettering } \\
\text { Cancer Center }\end{array}$ & Neuroblastoma & Phase I/II ongoing & Estimated completion in 2020 & $\begin{array}{l}\text { NCT00911560 } \\
\left(\text { REF. }^{231}\right)\end{array}$ \\
\hline \multicolumn{4}{|l|}{ Anti-glycan antibodies } & \\
\hline $\begin{array}{l}\text { Monoclonal antibody } \\
\text { Oregovomab (anti-MUC16/CA125; } \\
\text { B43.13); ViRexx Medical Corp }\end{array}$ & Ovarian cancer & $\begin{array}{l}\text { Phase III terminated } \\
2007\end{array}$ & $\begin{array}{l}\text { No clinical benefit as a } \\
\text { monotherapy following } \\
\text { frontline carboplatin- } \\
\text { paclitaxel treatment }\end{array}$ & $\begin{array}{l}\text { NCT00050375 } \\
\left(\text { REF. }^{287}\right)\end{array}$ \\
\hline & Ovarian neoplasms & $\begin{array}{l}\text { Phase Il completed } \\
2018\end{array}$ & $\begin{array}{l}\text { Administered with } \\
\text { carboplatin-paclitaxel } \\
\text { treatment; improved overall } \\
\text { survival, likely related to } \\
\text { increased CA125-specific } \\
\text { T cells }\end{array}$ & NCT01616303 288,289 \\
\hline & $\begin{array}{l}\text { Ovarian, fallopian tube and } \\
\text { peritoneal carcinomas }\end{array}$ & Phase III ongoing & Estimated completion in 2027 & NCT04498117 \\
\hline $\begin{array}{l}\text { Monoclonal antibody } \\
\text { BIW-8962 (anti-GM2); Kyowa }\end{array}$ & Multiple myeloma & $\begin{array}{l}\text { Phase I terminated } \\
2011\end{array}$ & Terminated for lack of efficacy & $\begin{array}{l}\text { NCT00775502 } \\
\left.\text { (REF. }{ }^{290}\right)\end{array}$ \\
\hline Hakko Kirin Pharma, Inc. & $\begin{array}{l}\text { NSCLC, small cell lung cancer, } \\
\text { mesothelioma }\end{array}$ & $\begin{array}{l}\text { Phase I/II terminated } \\
2016\end{array}$ & Terminated for lack of efficacy & NCT01898156 \\
\hline $\begin{array}{l}\text { Monoclonal antibody } \\
\text { Dinutuximab (ch14.18; anti-GD2); } \\
\text { Scripps Research Institute }\end{array}$ & Neuroblastoma & $\begin{array}{l}\text { Phase III completed } \\
2012\end{array}$ & $\begin{array}{l}\text { Improved event-free and } \\
\text { overall survival }\end{array}$ & $\begin{array}{l}\text { NCT00026312 } \\
\left(\text { REF. }^{238}\right)\end{array}$ \\
\hline
\end{tabular}


Table 1 (cont.) | Selected clinical trials of glycobiology-targeted therapeutics ${ }^{a}$

\begin{tabular}{|c|c|c|c|c|}
\hline $\begin{array}{l}\text { Therapeutic type and name; } \\
\text { manufacturer }\end{array}$ & Indication & Phase and status & Results & $\begin{array}{l}\text { Trial identifiers } \\
\text { (refs) }\end{array}$ \\
\hline \multicolumn{5}{|l|}{ Anti-glycan antibodies (cont.) } \\
\hline $\begin{array}{l}\text { Monoclonal antibody } \\
\text { MORAb-028 (anti-GD2 lgM); } \\
\text { Morphotek }\end{array}$ & Melanoma & $\begin{array}{l}\text { Phase I terminated } \\
2012\end{array}$ & $\begin{array}{l}\text { Terminated for lack of drug } \\
\text { availability }\end{array}$ & NCT01123304 \\
\hline $\begin{array}{l}\text { Monoclonal antibody } \\
\text { Ecromeximab (KW2871; anti-GD3); } \\
\text { Kyowa Hakko Kirin Pharma, Inc. }\end{array}$ & Metastatic melanoma & $\begin{array}{l}\text { Phase Il completed } \\
2014\end{array}$ & $\begin{array}{l}\text { Limited efficacy with } \\
\text { high-dose interferon, possibly } \\
\text { because tumour burdens in } \\
\text { the population studied were } \\
\text { already high }\end{array}$ & $\begin{array}{l}\text { NCT00679289 } \\
\left(\text { REF. }^{291}\right)\end{array}$ \\
\hline $\begin{array}{l}\text { Monoclonal antibody } \\
\text { BMS-986012 (anti-Fuc-GM1); } \\
\text { Bristol-Myers-Squibb }\end{array}$ & $\begin{array}{l}\text { Relapsed and refractory small } \\
\text { cell lung cancer }\end{array}$ & Phase I/Il ongoing & Estimated completion in 2020 & NCT02247349 \\
\hline $\begin{array}{l}\text { Monoclonal antibody } \\
\text { OBI-888 (anti-globo H); OBI Pharma }\end{array}$ & Solid tumours & Phase I/II ongoing & Estimated completion in 2021 & NCT03573544 \\
\hline $\begin{array}{l}\text { Antibody drug conjugate } \\
\text { OBI-999 (anti-globo H-MMAE } \\
\text { conjugate); OBI Pharma }\end{array}$ & Solid tumours & Phase I/II ongoing & Estimated completion in 2023 & NCT04084366 \\
\hline $\begin{array}{l}\text { Monoclonal antibody } \\
\text { MVT-5873 (clone 5B1 anti-CA19-9); } \\
\text { MabVax Therapeutics }\end{array}$ & Pancreatic cancer & Phase I ongoing & Estimated completion in 2020 & NCT02672917 \\
\hline $\begin{array}{l}\text { Radiolabelled monoclonal antibody } \\
\text { MVT-1075 }\left({ }^{177} \text { Lu 5B1 anti-CA19-9); }\right. \\
\text { MabVax Therapeutics }\end{array}$ & $\begin{array}{l}\text { Pancreatic cancer, tumours } \\
\text { expressing CA19-9 }\end{array}$ & Phase l ongoing & Estimated completion in 2020 & NCT03118349 \\
\hline $\begin{array}{l}\text { Radiolabelled monoclonal antibody } \\
\text { MVT-2163 ( }{ }^{89} \mathrm{Zr}-\mathrm{DFO}-5 \mathrm{~B} 1 \\
\text { anti-CA19-9) with MVT-1075 for } \\
\text { PET imaging; MabVax Therapeutics }\end{array}$ & $\begin{array}{l}\text { Pancreatic cancer, tumours } \\
\text { expressing CA19-9 }\end{array}$ & Phase l ongoing & Estimated completion in 2020 & NCT02687230 \\
\hline \multicolumn{5}{|l|}{ Anti-idiotype antibodies } \\
\hline $\begin{array}{l}\text { Monoclonal antibody } \\
\text { Abagovomab (anti-MUC16/ } \\
\text { CA125); Menarini Group }\end{array}$ & Ovarian cancer & $\begin{array}{l}\text { Phase II/III } \\
\text { terminated } 2011\end{array}$ & $\begin{array}{l}\text { Administered as maintenance } \\
\text { therapy; no clinical benefit } \\
\text { and no induction of } \\
\text { CA125-specific T cells }\end{array}$ & $\begin{array}{l}\text { NCT00418574 } \\
\left(\text { REFS }^{292,293)}\right.\end{array}$ \\
\hline $\begin{array}{l}\text { Monoclonal antibody } \\
\text { Racotumomab } \\
\text { (anti-N-glycolyl-GM3); Recombio }\end{array}$ & NSCLC & $\begin{array}{l}\text { Phase III completed } \\
2014\end{array}$ & $\begin{array}{l}\text { Increased progression-free } \\
\text { and overall survival } \\
\text { Serological response to } \\
\mathrm{N} \text {-glycolyl-GM3 }\end{array}$ & $\begin{array}{l}\text { NCT01460472 } \\
\left(\text { REF. }^{294}\right)\end{array}$ \\
\hline & $\begin{array}{l}\text { Tumours with N-glycolylated } \\
\text { gangliosides: neuroblastoma, } \\
\text { Ewing's sarcoma, Wilm's tumour, } \\
\text { retinoblastoma, glioma }\end{array}$ & $\begin{array}{l}\text { Phase I completed } \\
2014\end{array}$ & $\begin{array}{l}\text { Well tolerated, serological } \\
\text { response to } \mathrm{N} \text {-glycolyl-GM3 in } \\
\text { most patients }\end{array}$ & $\begin{array}{l}\text { NCT01598454 } \\
\left(\text { REF. }^{295}\right)\end{array}$ \\
\hline & Neuroblastoma & Phase II recruiting & Estimated completion in 2021 & NCT02998983 \\
\hline CAR cell therapies & & & & \\
\hline $\begin{array}{l}\text { Anti-GD2 CAR T; Baylor College of } \\
\text { Medicine }\end{array}$ & Neuroblastoma & Phase I ongoing & $\begin{array}{l}3 \text { of } 11 \text { patients achieved } \\
\text { completion remission; study } \\
\text { completion estimated in } 2021\end{array}$ & $\begin{array}{l}\text { NCT00085930 } \\
\left.\text { (REF. }{ }^{296}\right)\end{array}$ \\
\hline $\begin{array}{l}\text { Anti-GD2 CAR T with iCaspase } \\
\text { switch; Baylor College of Medicine }\end{array}$ & Neuroblastoma & Phase I ongoing & Estimated completion in 2030 & NCT01822652 \\
\hline $\begin{array}{l}\text { Anti-GD2 tri-virus CAR T; Baylor } \\
\text { College of Medicine }\end{array}$ & $\begin{array}{l}\text { Neuroblastoma after } \\
\text { haematopoietic stem cell } \\
\text { transplant }\end{array}$ & $\begin{array}{l}\text { Phase I completed } \\
2015\end{array}$ & $\begin{array}{l}\text { Safe, partial response in } 3 \text { of } \\
3 \text { patients }\end{array}$ & NCT01460901 \\
\hline $\begin{array}{l}\text { Anti-GD2 CAR NKT; Baylor College } \\
\text { of Medicine }\end{array}$ & Neuroblastoma & Phase I ongoing & Estimated completion 2021 & NCT03294954 \\
\hline Ad5, adenovirus serotype 5; CAR, chime & antigen receptor; $\mathrm{CE}$ & nic antigen; $\mathrm{KLH}, \mathrm{K}$ & $\begin{array}{l}\text { limpet haemocyanin; Ley, Lewisy, } \\
\text { ancer; NSTEMI, non-ST elevation } \\
\text { polyinosinic-polycytidylic acid }\end{array}$ & $\begin{array}{l}\text { UMAE, monomethyl } \\
\text { tyocardial infarction; } \\
\text { tabilized with }\end{array}$ \\
\hline
\end{tabular}



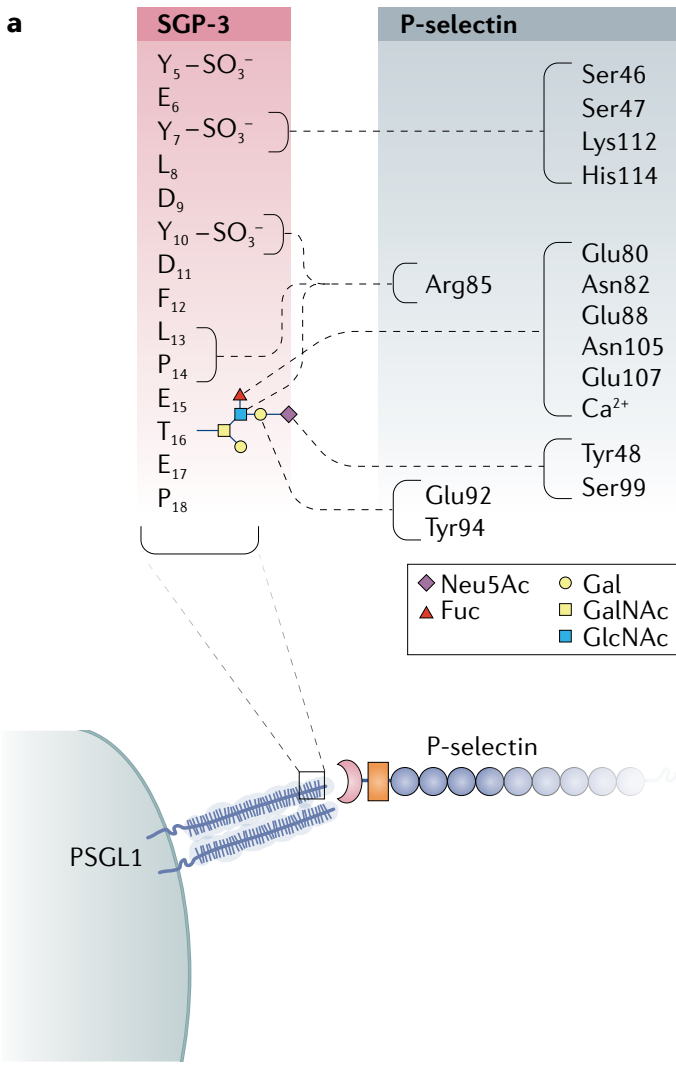

b
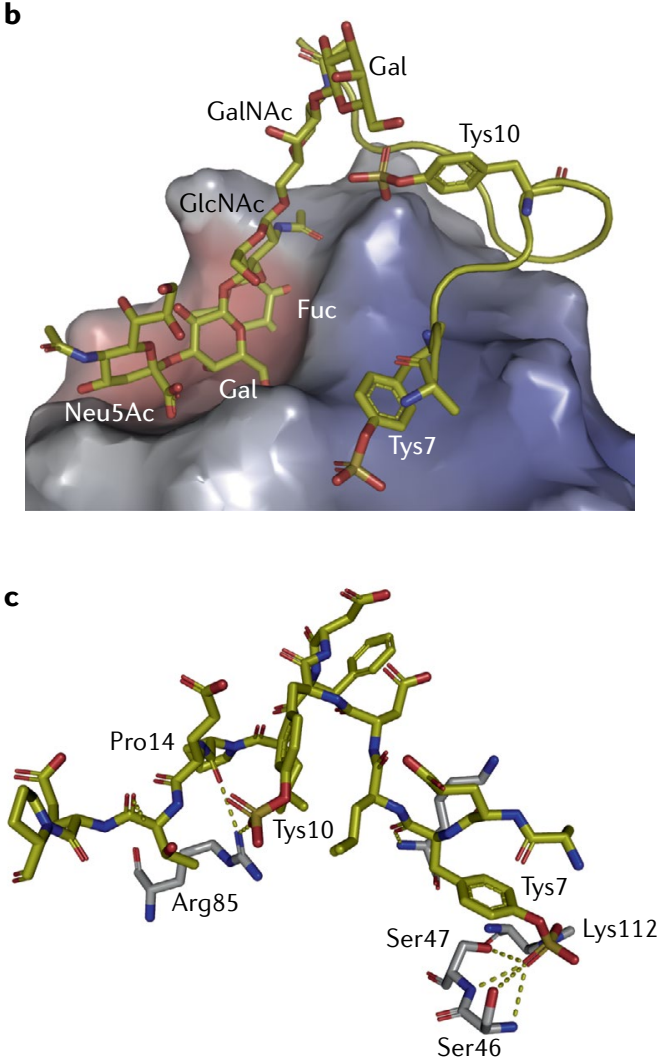

Fig. 2 | P-selectin engages both glycan and protein portions of PSGL1. P-selectin forms a complex with P-selectin glycoprotein ligand 1 (PSGL1) ${ }^{38}$. a Schematic depicting the polar contacts (dashed lines) between SGP-3, a sulfoglycopeptide derived from the amino terminus of PSGL1 (shown in the red box using single-letter amino acid codes), and P-selectin (shown in the black box using three-letter amino acid codes). The glycan attached to Thr16 is represented using the colour-coded symbol nomenclature for glycans (SNFG). Note that sulfotyrosine 5 (Tys5) was poorly resolved in the crystal structure and is therefore depicted without polar contacts. $\mathbf{b} \mid$ Crystal structure of P-selectin bound to SGP-3 (Protein Data Bank identifier: 1G1S). P-selectin has two binding surfaces: one interacts with sialyl Lewis ${ }^{x}\left(\right.$ sLe $\left.^{x}\right)$ and the other interacts with portions of the PSGL1 protein backbone. $\mathbf{c |}$ The PSGL1 protein backbone (yellow) makes key contacts with P-selectin (grey) through Pro14 and two sulfotyrosines, Tys7 and Tys10. The third sulfotyrosine that is important for the interaction, Tys 5 , was modelled as an alanine in the crystal structure. Fuc, fucose; Gal, galactose; GalNAc, $\mathrm{N}$-acetylgalactosamine; GlcNAc, $\mathrm{N}$-acetylglucosamine; Neu5Ac, $\mathrm{N}$-acetylneuraminic acid.

they used an enzyme-linked immunosorbent-based assay followed by extensive structure-activity relationship refinement to identify their lead compound, PSI-697, which was based on a tetrahydrobenzoquinoline salicylic acid scaffold ${ }^{52}$. Although PSI-697 decreased thrombosis in mice $^{53}$, it was no better than placebo in preventing thromboembolic events in smokers ${ }^{54}$. A team at Nippon Organon developed OJ-R9188, a higher affinity pan-selectin antagonist ${ }^{55,56}$ that showed efficacy in a reperfusion injury model ${ }^{57}$ but was not pursued further because it lacked drug-like properties. Modus Therapeutics developed a modified heparin, sevuparin, that maintained the interaction with P-selectin and L-selectin while avoiding binding to antithrombin III and, therefore, interference with the clotting cascade ${ }^{58}$. However, sevuparin failed to show efficacy in a phase II trial (NCT02515838) for acute vaso-occlusive crises in sickle cell disease ${ }^{59}$. Finally, the natural product efomycine $\mathrm{M}$ was believed to be a useful selectin inhibitor for treatment of inflammatory diseases $^{60}$, but was subsequently discovered to operate via selectin-independent mechanisms ${ }^{61}$.
Biologic selectin inhibitors. Knowledge of selectin ligand identities also enabled antagonism with biologics. $\mathrm{P}$-selectin inhibition using a recombinant $\mathrm{P}$-selectin ligand decreased thrombosis in non-human primate animal model ${ }^{62,63}$. These results encouraged Genetics Institute, Inc., which was acquired by Wyeth, to develop a chimeric P-selectin-immunoglobulin fusion protein, rPSGL-Ig, that was able to promote thrombolysis in porcine models of acute thrombosis and myocardial infarction ${ }^{64}$. Y's Therapeutics subsequently licensed rPSGL-Ig (YSPSL) from Wyeth/Pfizer to assess its use in improving organ allograft function because the mechanism of tissue damage in allografts involves ischaemia-reperfusion injury. Although a phase II study (NCT00876902) of liver allograft function showed that YSPSL improved liver function after transplant ${ }^{65}$, these benefits were not replicated in a phase IIa trial (NCT00298168) in renal allograft function and development was shelved ${ }^{66}$. A variant of this idea - a recently generated PSGL1 mimetic peptide - demonstrated tight binding to P-selectin with an affinity in the low nanomolar range ${ }^{67}$. 

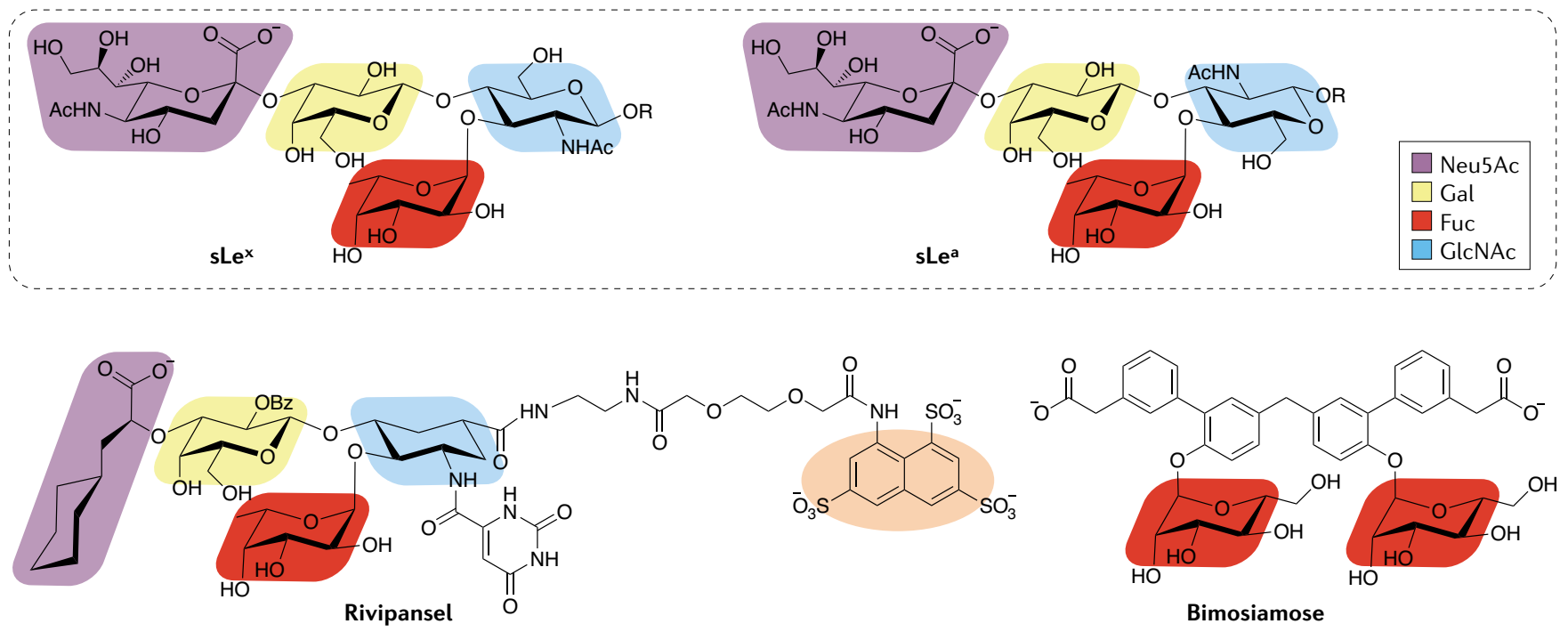

Bimosiamose
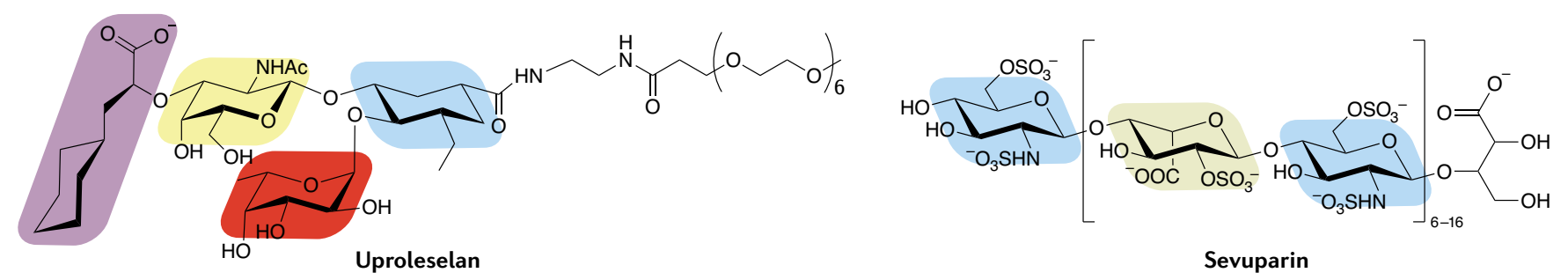

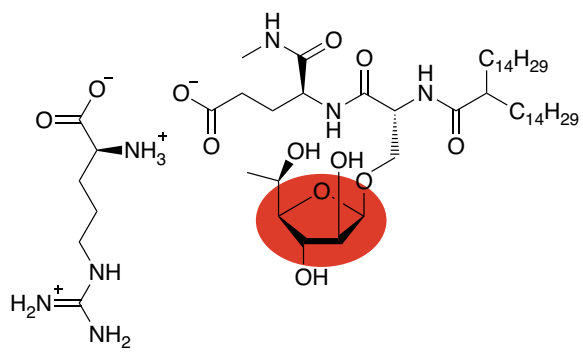

OJ-R9188

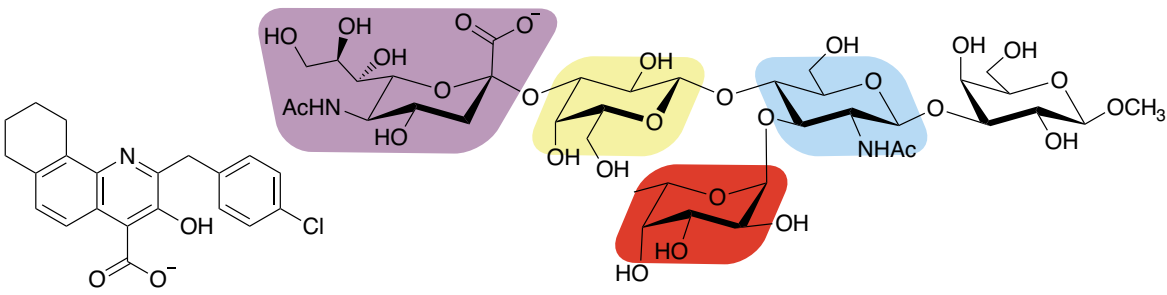

PSI-697

Cylexin

Fig. 3 | Small-molecule selectin inhibitors. The chemical structures of sialyl Lewis ${ }^{x}\left(s^{2} e^{x}\right)$ and sialyl Lewis ${ }^{a}\left(s e^{a}\right)$ are presented at the top for reference. Structural motifs within the small-molecule selectin inhibitors that have homology to the sialyl Lewis scaffolds are colour coded. The orange highlighted pharmacophore in rivipansel mimics the sulfotyrosines in P-selectin glycoprotein ligand 1 (PSGL1) that are important for the interaction with P-selectin. In sevuparin, the blue and grey shading highlights 2- $\mathrm{N}$-sulfo-6-O-sulfo-glucosamine and iduronic-2-O-sulfate, respectively, which mimic portions of heparan sulfate. In OJ-R9188, replacement of the six-membered fucose ring with fucufuranose maintained binding to E-selectin while increasing resistance to hydrolytic enzymes. Fuc, fucose; Gal, galactose; GlcNAc, N-acetylglucosamine; Neu5Ac, $N$-acetylneuraminic acid.

Selectin-blocking antibodies have shown even greater promise. Hoffmann-La Roche developed the monoclonal antibody inclaclumab as a P-selectin antagonist. In a phase II trial (NCT01327183), inclaclumab reduced myocardial damage in patients undergoing percutaneous coronary intervention for non-ST-segment elevation myocardial infarction ${ }^{68}$. However, the programme was abandoned when another phase II trial (NCT01245634) of inclaclumab in patients undergoing coronary artery bypass graft surgery showed that the drug had no benefit ${ }^{6}$. It was later discovered that both L-selectin and P-selectin are inhibited by heparin, which is the standard of care treatment for patients with myocardial infarctions. Thus, the L-selectin and P-selectin in these patients were already inhibited. Selexys opted to develop their P-selectin blocking antibody crizanlizumab (SEG101, also known as SelG1) as a prophylactic agent for vaso-occlusive crises in patients with sickle cell disease. Notably, crizanlizumab reduced the frequency of pain crises and could be administered on a dosing schedule of once every $3-4$ weeks $^{70}$. The strength of these results ${ }^{71}$ led to the acquisition of Selexys by Novartis and the FDA approval of crizanlizumab in late 2019 (REF. $\left.{ }^{72}\right)$.

Selectins in cancer. Publications in the early 1990 s showing a role for selectins in tumour cell metastasis garnered interest in targeting selectins in cancer. All members of 
the selectin family have been implicated. Ligands for L-selectin on lymphoid tissues were found to promote leukaemia and lymphoma seeding ${ }^{73}$. On colon cancer cells, the display of sialyl Lewis structures that can interact with E-selectin correlates with metastatic potential ${ }^{74}$. P-selectin expression by platelets and endothelium in the microvasculature may arrest metastatic cells ${ }^{75}$. Recently, data have corroborated and expanded these early observations: for instance, binding to P-selectin on mesothelial cells through CD24 is a major mechanism by which ovarian cancer cells metastasize ${ }^{76}$.

The application of selectin inhibitors in cancer was catalysed by the identification of E-selectin as a bone marrow homing receptor. Early work on this topic was inspired by the idea that if homing receptors exist for immune cell infiltration into the periphery, homologous mechanisms must exist for the entry of haematopoietic stem cells (HSCs) into the marrow following bone marrow transplantation. Through careful application of shear stress conditions, HSCs were found to be decorated with $\mathrm{HCELL}^{77}$. Importantly, $\mathrm{HCELL}^{-/-}$HSCs failed to home to the bone marrow whereas their HCELL ${ }^{+/+}$ counterparts entered the bone marrow niche and proliferated ${ }^{78}$. Soon thereafter, E-selectin was identified as a key regulator of HSC homeostasis ${ }^{79}$.

In a landmark discovery, leukaemia cells were found to home to regions of the bone marrow microenvironment characterized by E-selectin expression ${ }^{80}$. This discovery, along with evidence that numerous solid and blood cancers express the ligands for E-selectin, galvanized the notion that E-selectin-ligand interactions promote cancer metastasis to the bone ${ }^{81}$. In acute myeloid leukaemia (AML) in particular, the interaction of malignant cells with E-selectin promotes regeneration and resistance to chemotherapy by activating pro-survival signalling pathways ${ }^{82}$. Several pharmaceutical companies seized this opportunity to develop first in class therapies. GlycoMimetics, fresh off its rivipansel campaign, led the pack with the development of uproleselan (GMI-1271), an E-selectin-specific inhibitor ${ }^{83}$. A phase I/II trial of uproleselan in combination with chemotherapy for AML showed promise ${ }^{84}$, leading to the initiation of a phase III trial (NCT03616470) with results expected in late 2023. The finding that uproleselan also disrupts the tumour microenvironment in multiple myeloma ${ }^{85}$ launched a phase I trial (NCT02811822) that was ultimately halted due to low patient recruitment.

Recent data have shed mechanistic light on the contribution of E-selectin to bone marrow metastasis. E-selectin expression by the vasculature was found to regulate breast cancer cell entry into, but not retention by, the bone marrow niche ${ }^{86}$. Interactions with E-selectin were also found to promote mesenchymal-epithelial transition and activate WNT signalling, implying that targeting these networks, such as with the WNT inhibitor LF3, may indirectly interfere with E-selectin interactions in cancer $^{87}$.

New aspects of PSGL1 biology are poised to enter the immuno-oncology arena. Reports that PSGL1 modulates antigen-presenting cell and $\mathrm{T}$ cell activity have existed in the literature for years without coalescing on a clear mechanism ${ }^{88}$, although signalling cascades downstream of PSGL1 crosslinking appear to be involved ${ }^{89}$. Along these lines, Verseau is developing a PSGL1 blocking antibody as a macrophage checkpoint inhibitor ${ }^{90}$. V-type immunoglobulin domain-containing suppressor of T cell activation (VISTA), a B7 family protein expressed on activated lymphocytes and some myeloid populations, binds PSGL1 in an sLe ${ }^{\mathrm{x}}$-independent but sulfotyrosine-dependent manner ${ }^{91}$. Importantly, a VISTA blocking antibody reversed immune cell inhibition and promoted tumour rejection in a mouse model of MC38 colorectal adenocarcinoma ${ }^{91}$.

Prospects for selectin-targeted therapies. Early efforts to harness selectin inhibition as a therapeutic modality focused on cardiovascular disease and travelled a rocky road to success. Positive outcomes from selectin inhibition in cancer, as showcased by trials of uproleselan in AML, have reinvigorated the field and encouraged other efforts to target selectins. These approaches include nanoparticles decorated with P-selectin ligands for targeted drug delivery ${ }^{92}$, and chimeric antigen receptor (CAR) $\mathrm{T}$ cells with enforced expression of sLe $\mathrm{e}^{\mathrm{x}}$ to boost E-selectin ligand display and increase infiltration into the marrow ${ }^{93}$.

Despite early failures, selectin inhibitors may still prove useful for vascular disease. Identifying an appropriate patient population will be central to demonstrating efficacy. Indeed, it is likely that patients were already selectin-inhibited by heparin in the phase II trial that showed no benefit of inclaclumab administration during coronary artery bypass graft surgery. Likewise, the phase III trial of rivipansel for vaso-occlusive crises in sickle cell disease included patients who received the drug days after the onset of pain; the post hoc analysis of this trial suggests that early selectin inhibition is necessary for efficacy ${ }^{44}$. Biologics such as crizanlizumab benefit from long half-lives, meaning that patients can receive doses less frequently, and that outcomes such as the incidence of vaso-occlusive crises, rather than the time to vaso-occlusive crisis resolution in a hospitalized setting, as was monitored for rivipansel, could be monitored. Potential catalysts for selectin inhibitors include GlycoMimetics' new E-selectin antagonist, GMI-1687, which displays a $K_{\mathrm{d}}$ value in the low nanomolar range and can be administered subcutaneously, and uproleselan, trials of which will report in 2023 (REF ${ }^{94}$ ).

Efforts to inhibit selectins with small molecules have certainly experienced turbulence. Nevertheless, these endeavours have laid the foundation for future drug development campaigns, including suggesting that fragment-based screening may be a particularly fruitful modality for discovering novel inhibitors of glycan binding proteins.

\section{Siglecs}

The Siglecs are a family of receptors expressed by most immune cell types. Siglec ligands comprise proteins and lipids adorned with glycans containing sialic acid ('sialylated') ${ }^{95}$ (FIG. 4). Due to their homology to the immunoglobulin superfamily, the Siglecs are considered I-type lectins. Structurally, they comprise an aminoterminal V-set domain that binds sialylated glycans 
a Human Siglecs

Conserved Siglecs

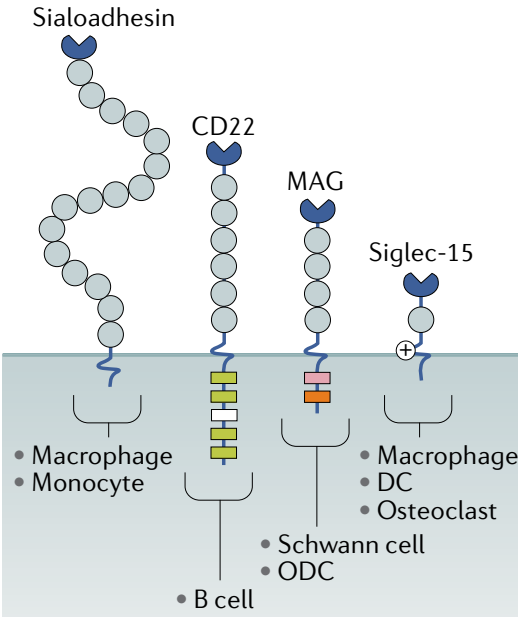

\section{b Mouse Siglecs}

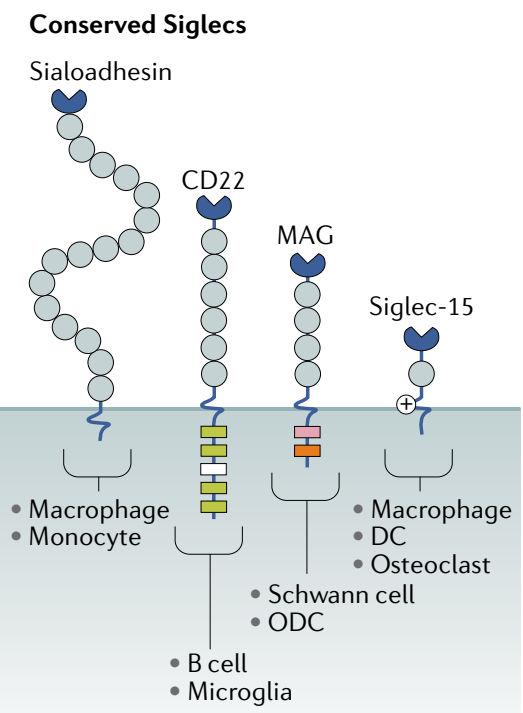

\section{c Immunoreceptors for comparison}

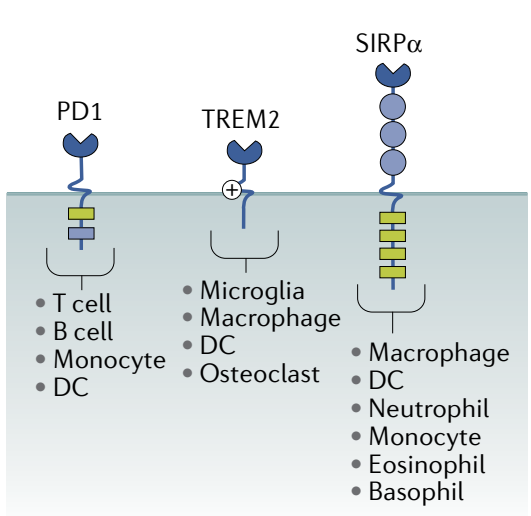

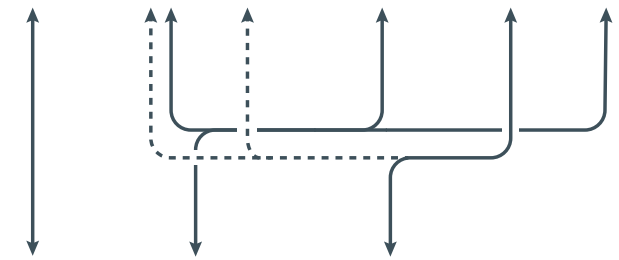

CD33-related Siglecs
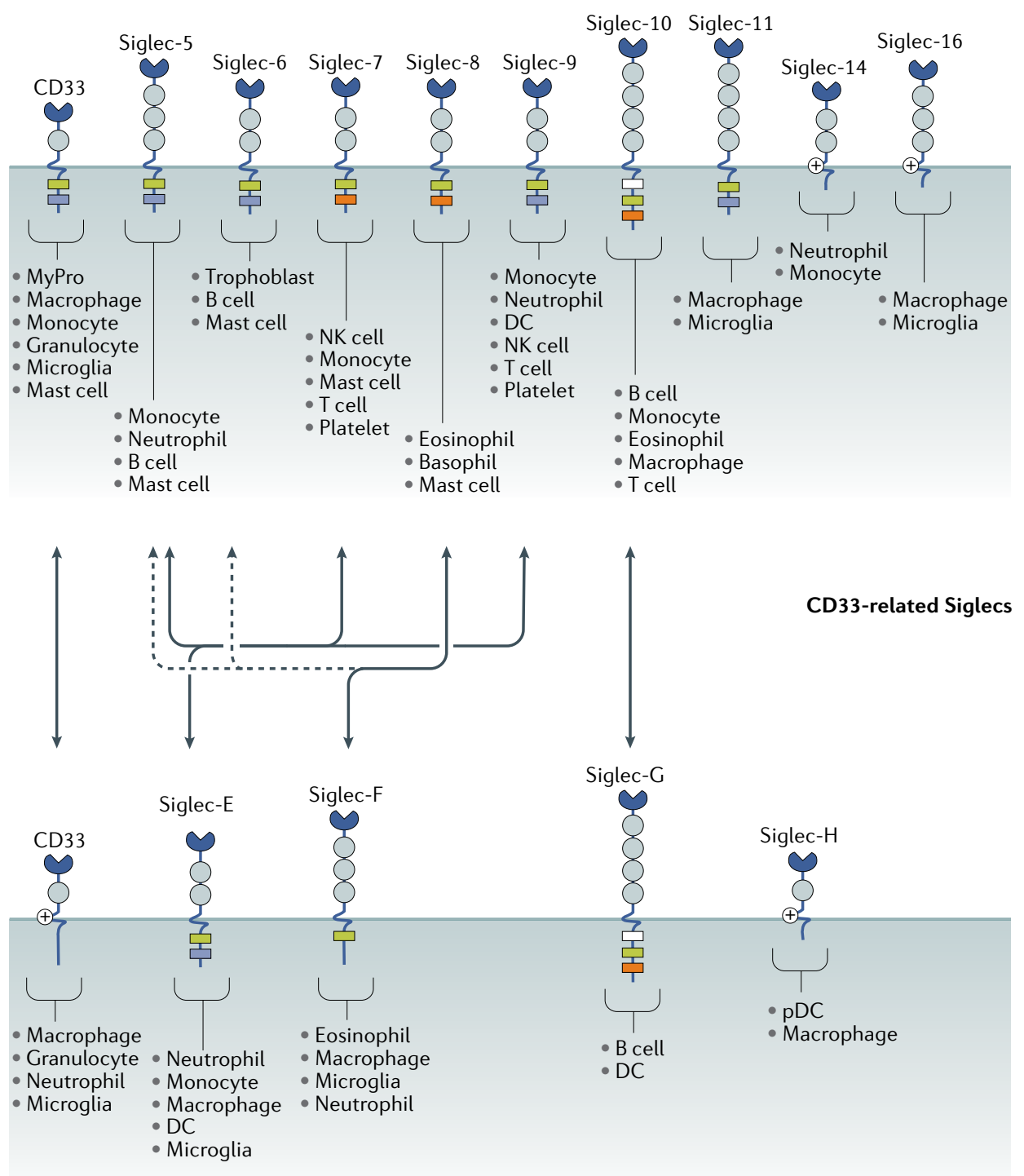

\section{d Signalling cascades}

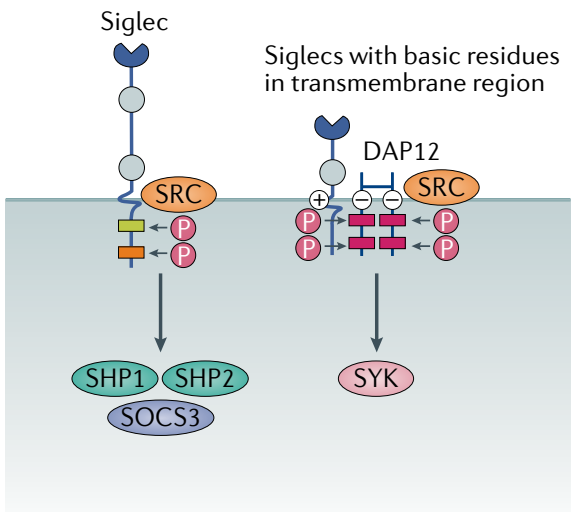

( Immunoglobulin-like $V$ set domain Immunoglobulin-like C2 set domain Immunoglobulin-like $\mathrm{C} 1$ set domain $\square$ ITIM

$\square$ ITSM

$\square$ ITIM-like

$\square$ GRB2 binding motif

$\square$ ITAM

$\square \quad$ FYN kinase site

$\oplus \ominus$ Basic/acidic residues 
4 Fig. 4 | Siglecs and downstream signalling. a,b | Protein domains of all members of the human (part a) and mouse (part b) Siglec families. The Siglecs can be broadly divided into the conserved Siglecs (sialoadhesin, CD22, myelin associated glycoprotein (MAG) and Siglec-15) and the CD33-related (CD33r) Siglecs that have diverged more recently on the evolutionary timescale. Cell types that express each Siglec are indicated. Doubleheaded arrows show functional orthologues among CD33r Siglecs. Murine Siglec-E is considered the functional orthologue of human Siglec-5, Siglec-7 and Siglec-9. Siglec-F is the functional paralogue of human Siglec-8, although it is an orthologue of human Siglec- 5 and Siglec- 6 (dashed line). Siglec- $\mathrm{G}$ is the functional orthologue of human Siglec-10. Human Siglec-XII lacks the arginine essential for sialic acid binding and is non-functional. Chimpanzee Siglec-13 was deleted in humans. Signalling domains in the cytoplasmic tails of each protein are depicted as coloured boxes. The immunoreceptor tyrosine-based inhibitory motif (ITIM) sequence is [I/L/V]xYxx[L/V], the ITIM-like sequence is [D/E]YxE[V/I][R/K], the immunoreceptor tyrosine-based switch motif (ITSM) sequence is $\mathrm{Tx} Y \mathrm{xx}[\mathrm{V} / \mathrm{I}]$, the growth factor receptor-bound protein 2 (GRB2) SH2 binding motif is $\mathrm{YxNx}$ and the FYN kinase site is RxxS. Other non-consensus motif tyrosines, such as in murine CD33 and Siglec-F, are not depicted. The GRB2-binding motif in Siglec-10 and Siglec-G is contained within an ITIM. Siglec expression patterns are indicated according to independent reports in the literature. Recent data also suggest that murine T cells express Siglec- $\mathrm{E}^{130}$ and Siglec- $-\mathrm{G}^{297}$, and that murine platelets express Siglec- $\mathrm{E}^{137}$. c| Domain organization and signalling motifs of other immune cell receptors with known roles in immune modulation, illustrated for comparison. $\mathbf{d}$ | Siglecs with ITIMs and ITIMlike signalling motifs may be phosphorylated by SRC family kinases, thereby enabling the recruitment of the protein phosphatases SRC homology region 2 domain-containing phosphatase 1 (SHP1) and SHP2. The ITIM domains in CD33 and Siglec-7 have also been shown to recruit suppressor of cytokine signaling 3 (SOCS3). Siglecs with basic residues in their transmembrane domain enable interactions with the scaffold protein DNAX-activation protein 12 (DAP12). DAP12 contains four immunoreceptor tyrosinebased activation motif (ITAM) domains that, when phosphorylated by SRC family kinases, lead to SYK activation. Figure inspired by REF. ${ }^{298}$. DC, dendritic cell; MyPro, myeloid progenitor; NK cell, natural killer cell; ODC, oligodendrocyte; P, phosphate; $\mathrm{pDC}$, plasmacytoid dendritic cell; SIRPa, signal regulatory protein- $\alpha$.

followed by several immunoglobulin-like domains, a transmembrane domain and, finally, a carboxy-terminal cytoplasmic tail bearing activating or inhibitory signalling motifs. Broadly, the Siglecs may be divided into two families: the conserved Siglecs, including sialoadhesin (Siglec-1), CD22 (Siglec-2), myelin-associated glycoprotein (MAG; Siglec-4) and Siglec-15; and the remaining CD33-related (CD33r) Siglecs that vary substantially from species to species. The diversity among the CD33r Siglecs is believed to have come from a recent gene duplication event and the subsequent loss of Siglec genes from each mammalian lineage. In total, there are 14 known functional Siglecs in humans (of which 10 are CD33r Siglecs) and 9 in mice (of which 5 are CD33r Siglecs).

There are few therapies targeting Siglec glycobiology currently in clinical trials. However, a recent explosion of data implicating Siglecs in cancer, infectious diseases and neuroscience has made this area one of the most dynamic and active in glycobiology.

Siglecs as cell markers. In a manner similar to the selectins, the discovery of sialoadhesin was stimulated by questions regarding cell adhesion. Sialoadhesin was identified as a prominent mediator of macrophage adhesion to bone marrow ${ }^{96}$. Soon thereafter, CD22 was identified as a B cell marker and a participant in cell-cell interactions ${ }^{97}$. CD33 (Siglec-3) was found as a myeloid lineage marker ${ }^{98}$, and MAG was recognized as an oligodendrocyte identifier ${ }^{99}$. This early work on the Siglecs was united by a common thread: identifying useful cell markers.
Indeed, the expression patterns of the Siglecs have enabled therapies targeted to defined cell populations (FIG. 5). For instance, the antibody-drug conjugate (ADC) gemtuzumab ozogamicin (Mylotarg) comprises a monoclonal antibody against CD33 coupled to calicheamicin, a potent DNA-damaging agent, and is FDA-approved for treatment of $\mathrm{AML}^{100}$. Other anti-CD33 ADCs, such as SGN33A and IMGN779, are in the pipeline ${ }^{101}$. CD22 on $\mathrm{B}$ cell leukaemias and lymphomas is the target of several ADCs, such as inotuzumab ozogamicin (Besponsa) ${ }^{102}$ and pinatuzumab vedotin ${ }^{103}$. Antibodies against CD22 and CD33 are also being used to make bispecific antibodies and CAR T cells for treatment of these haematopoietic neoplasms $s^{104,105}$. Liposomes decorated with sialoadhesin ligands have been engineered to selectively deliver antigen to macrophages ${ }^{106}$, and nanoparticles bearing a high-affinity CD22 ligand could effectively direct doxorubicin to B cell lymphoma cells ${ }^{107}$. In these cases, the Siglecs are primarily regarded as targeting moieties.

Siglecs mediate immune homeostasis. Functionally, the Siglecs are important mediators of immune homeostasis. This biology is enabled by the presence of either immunoreceptor tyrosine-based inhibitory motifs (ITIMs), related immunoreceptor tyrosine-based switch motifs or ITIM-like sequences in the cytoplasmic tails of most Siglecs. Alternatively, in a minority of Siglecs, a basic residue in the transmembrane region couples to the immunoreceptor tyrosine-based activation motif containing adaptor protein DAP12 to initiate signalling. Typically, Siglecs inhibit immune cell activation by recruiting SHP family phosphatases to their ITIM or ITIM-like domains, which suppresses other signalling pathways. Those Siglecs that engage DAP12 transmit activating signals. Sialoadhesin has neither ITIM sequences nor DAP12 binding sites, and is therefore likely to play less of a role in signalling than in adhesion. Siglec activity is associated with immune cell killing, pathogen clearance and cytokine production, and has thus been linked to numerous inflammatory diseases and phenotypes.

As the best studied Siglec, CD22, provides a useful model for understanding Siglec biology. The discovery that CD22 bound to sialylated ligands led to hypotheses that it played a role in cell adhesion ${ }^{108}$. However, CD22 also negatively regulates the $\mathrm{B}$ cell receptor, raising the possibility that it suppresses B cells and tempers humoral immunity ${ }^{109}$. Experiments intended to validate this concept produced conflicting results. As expected, CD22 knockout mice exhibited increased reactivity to self-antigen and reduced tolerance ${ }^{110,111}$. However, knocking out $S T 6 G A L 1$, the sialyltransferase responsible for manufacturing sialylated ligands for CD22, produced $\mathrm{B}$ cells with substantially less reactivity ${ }^{112}$. The paradox was resolved with the finding that CD22 interacts not only with sialosides on target cells in trans but also in cis with sialosides on the membrane of the same B cell ${ }^{113}$. Indeed, CD22 interacts with a2,6-linked sialosides on neighbouring CD22 molecules, thereby sequestering itself away from the $\mathrm{B}$ cell receptor in homo-oligomers ${ }^{114}$. According to this model, recently supported by crystal structures ${ }^{115}$, interaction of a B cell with sialylated 
self-antigen provides contacts for CD22 in trans that disperse nano-clusters and permit CD22 association with and inhibition of the $\mathrm{B}$ cell receptor. In addition, CD22 is an endocytic receptor that is continually internalized and recycled to the surface ${ }^{116}$. Therefore, Siglec activity in general is governed by several parameters, including the availability of cis and trans interactors, the relative affinity for and density of any given ligand, and the rate of internalization and recycling. This remarkable complexity is a hurdle for pharmaceutical development.

Siglecs engage tumour sialic acids. The Siglecs are potentially attractive targets for cancer immunotherapy alongside established checkpoint proteins such as
PD1, CTLA4 and SIRPa ${ }^{117}$. Indeed, the presence of ITIM domains in the cytoplasmic tail of many Siglecs alongside their expression on many immune cell subtypes is reminiscent of members of the $\mathrm{B} 7$ family of regulatory immune receptors, such as PD1.

The first hints that sialic acids are important in tumorigenesis came from studies in the 1960s, in which increased sialic acid content was observed on malignant cells ${ }^{118}$ and desialylated tumours exhibited reduced engraftment in in vivo models ${ }^{119}$. Negative results from subsequent human trials, in which sialidase-treated autologous tumour cells were administered as adjuvant immunotherapies, and a lack of mechanistic understanding dampened excitement for targeting tumour
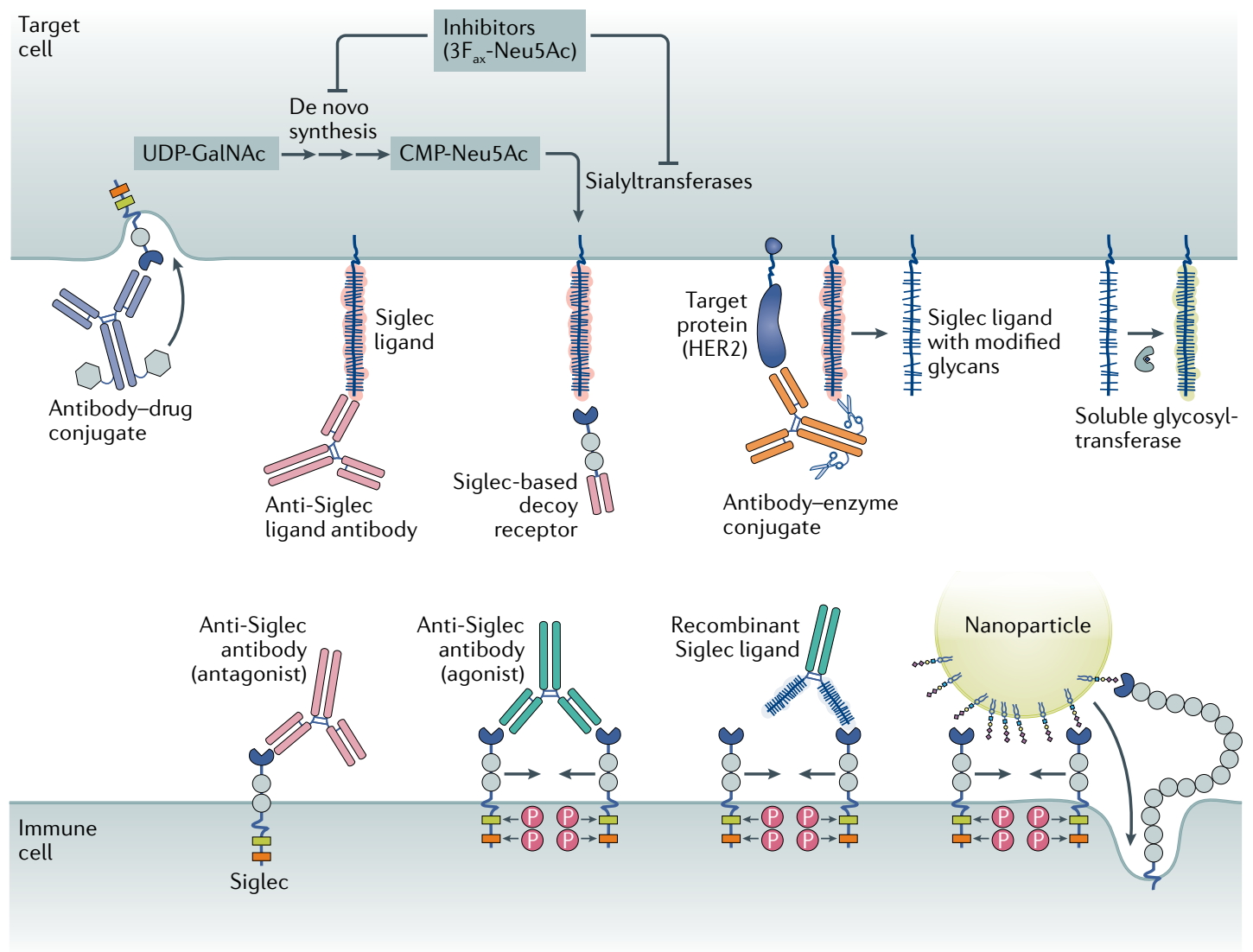

Fig. 5 | Modalities for Siglec-targeted therapies. Antibody-drug conjugates target the Siglecs (CD22 and CD33) that are expressed by cancers, including acute myeloid leukaemia and B cell lymphomas. Anti-Siglec antibodies can either agonize or antagonize Siglec activity. Siglec-blocking antibodies can function as antagonists by preventing ligand binding, but many serve as mild agonists by promoting dimerization. Siglec agonist antibodies can dampen immune cell activity and promote apoptosis. Siglec ligand-blocking antibodies antagonize Siglec function via competitive binding to the Siglec ligand. Recombinant Siglec ligands, shown here as a recombinant glycoprotein fused to an antibody Fc domain, could theoretically act as either receptor agonists or antagonists, likely depending on their ability to cluster Siglecs. Siglec-based decoy receptors comprising a soluble Siglec protein bind to and block the set of ligands for any given Siglec. Therefore, they may antagonize Siglec activity when ligand identities are unclear or diverse. Antibody-enzyme conjugates comprise antibodies directed to target cell-specific antigens conjugated to a glycocalyx editing enzyme such as a sialidase. In the case of an antibody-sialidase conjugate, removal of sialic acid destroys Siglec ligands, thereby antagonizing immune cell Siglecs. Glycosyltransferases in circulation or administered therapeutically may use nucleotide sugars released from platelets to alter the glycocalyx by creating or destroying Siglec binding sites. Nanoparticles such as liposomes bearing Siglec ligands may agonize Siglecs via aggregation or serve as a means for targeted payload delivery. Finally, small-molecule inhibitors, such as the fluorinated sialic acid analogue $3 \mathrm{~F}_{\text {ax }}-\mathrm{Neu} 5 \mathrm{Ac}^{154}$, of de novo sialic acid synthesis, or the sialyltransferases, the enzymes responsible for linking sialic acid to nascent glycoproteins and glycolipids, may reduce the sialic acid content of the glycocalyx and destroy Siglec ligands. CMP-Neu5Ac, cytidine monophosphate$\mathrm{N}$-acetyl-neuraminic acid; HER2, human epidermal growth factor receptor 2 (also known as ERBB2); P, phosphate; UDP-GalNAc, uridine diphosphate-N-acetyl-galactosamine. 
sialic acids ${ }^{120}$. The observation that desialylated fibrosarcoma cells proliferated slower than their fully sialylated counterparts only in immunocompetent, and not irradiated, mice ${ }^{121}$ reinvigorated the field and clearly established that tumour sialic acids play a role in immune evasion. The Siglecs have emerged as likely mediators of this effect ${ }^{95}$.

Although the association of hypersialylation with cancer was evident, the mechanistic details were opaque. Ligands for Siglec-7 and Siglec-9 were found on various human cancers, and removing sialic acids from cancer cells increased their susceptibility to cytotoxicity from natural killer cells ${ }^{122}$. Because natural killer cells have a demonstrated role in the early stages of tumorigenesis, natural killer cell activity towards Siglec-7 and Siglec- 9 may be an important determinant of tumour engraftment. As a complementary approach, our group synthesized glycopolymers displaying sialylated glycans as mucin mimetics. By decorating tumours with these polymers and observing their ability to protect cells from being killed by natural killer cells, we provided evidence that natural killer cells are directly inhibited by tumour sialosides and that blocking Siglec-7 on natural killer cells removes this inhibition ${ }^{123}$.

The case for Siglec-mediated immune evasion mounted. Siglec-9, which is broadly expressed on neutrophils, natural killer cells, monocytes, dendritic cells, macrophages and subsets of T cells, also garnered attention. Siglec-9 ligands are upregulated on carcinomas of different histological subtypes and the rs16988910 SNP in Siglec-9 correlates with improved survival of non-small cell lung cancer patients, although only in the short term $(<2 \text { years })^{124}$. This study also found that tumours bearing Siglec-9 ligands inhibit neutrophil activation and, surprisingly, prevent macrophage M2 polarization. The function of Siglecs on macrophages is not well defined, as stimulating macrophages with a Siglec-9 ligand comprising the mucin MUC1 decorated with truncated O-glycans polarized these cells towards an immunosuppressive M2 phenotype ${ }^{125}$. M2 polarization in macrophages in this experimental set-up did not go through the SHP phosphatases, as occurs with most ITIM-containing Siglec signalling, but instead was directed by PI3K activation and calcium influx ${ }^{125}$. Additional functions for Siglecs on innate immune cells were identified in mouse models of lung adenocarcinoma, in which tumours are infiltrated by neutrophils bearing Siglec-F (a murine homologue to human Siglec-5 and Siglec-8) that remodel the immune microenvironment to promote tumour growth ${ }^{126}$.

Although Siglecs are not expressed on naive human $\mathrm{T}$ cells ${ }^{127}$, recent evidence suggests that $\mathrm{T}$ cells do express, and are negatively regulated by, Siglec-5, Siglec-7, Siglec-9 and Siglec-10 in certain contexts ${ }^{128,129}$. A key study found that tumour-infiltrating lymphocytes express Siglec-9 and exhibit increased cytotoxicity against MC38 cells that lack sialic acids (GNE-null) or following treatment with a Siglec-9 blocking antibody fragment ${ }^{130}$. In the same study, mice with subcutaneous MC38 tumours demonstrated improved survival when they lacked Siglec-E, the mouse homologue of human Siglec-9, or when their Siglec-E locus was engineered to replace the inhibitory cytoplasmic domain of Siglec-E with the activating motifs of Siglec-16 (REF. ${ }^{130}$ ). Regulation of T cell activity by Siglec- 9 was also found in melanoma ${ }^{131}$.

Microbiology has also provided evidence of Siglec-mediated immune evasion. Neutrophils are inhibited by capsular sialic acids on group B Streptococcus (GBS) strains via Siglec-5 and Siglec-9 (REFS ${ }^{132,133}$ ). GBS also inhibits natural killer cell sentinel activity by engaging Siglec-7 through sialic acid-independent contacts with the $\beta$-protein of $\mathrm{GBS}^{134}$. Hyaluronan in the capsule of group A Streptococcus, as well as host hyaluronan, inhibits neutrophils via Siglec-9 (REF. ${ }^{135}$ ). Intriguingly, hyaluronan also has a recognized role in shaping the tumour microenvironment in breast, prostate, ovarian and lung cancers ${ }^{136}$. Even the Siglecs on platelets are exploited by pathogens. $\alpha 2,3$-Linked capsular sialic acids on GBS promote virulence by binding platelet Siglec-9 and inhibiting degranulation ${ }^{137}$. Given the intense selective pressure exerted by the immune system, it seems likely that pathogens and cancers might converge on similar strategies to avoid detection and clearance.

Our understanding of the mechanisms behind Siglec-mediated immune evasion is rapidly improving. Siglec-10, known previously only as a promoter of $\mathrm{B}$ cell homeostasis, recently garnered attention as a negative regulator of macrophage-mediated phagocytosis. Siglec-10 functions in parallel to the SIRPa-CD47 axis by binding to its ligand, CD24, on breast and ovarian cancer cells ${ }^{138}$. The CD24 blocking antibody developed in that study enhanced phagocytosis of CD24-positive tumour cells and could be developed into a new cancer immunotherapy.

The guiding hypothesis on Siglecs in cancer has been that immune cells bearing Siglecs are inhibited upon binding to their sialoside ligands on target cells. This proposition was recently upended by the discovery that Siglec-15, which contains a DAP12 binding site and is considered a conserved Siglec, is present on both tumour-infiltrating myeloid cells and tumour cells. In human cancers, Siglec-15 is abundant and mutually exclusive with PDL1 across various tumour types; mouse models show that high Siglec-15 levels increase tumour growth and decrease $\mathrm{T}$ cell infiltration ${ }^{139}$. The identity of the Siglec-15 ligand has not been elucidated, and it is not clear whether Siglec-15 on the tumour or infiltrating antigen-presenting cells are responsible for these effects. Nevertheless, evidence that treatment with a Siglec-15 blocking antibody decreased tumour burdens launched a phase I/II trial (NCT03665285) of the anti-Siglec-15 antibody, NC318, that is currently ongoing.

Identification of Siglec ligands. If Siglecs are analogous to checkpoint proteins, then what are their tumour cell ligands - the functional analogues of PDL1 and CD47? Likewise, what transcriptional and metabolic programmes are active in tumour cells that lead to Siglec ligand expression? This information may provide clues for how to interfere with the sialoside-Siglec axis of immune evasion, and inform potential therapy options for patients. The Siglec ligands used by healthy cells to support normal physiology and homeostasis may also be different from those observed in pathological states 
such as cancer ${ }^{140}$. Moreover, any given Siglec may bind various ligands with high affinity. For instance, Siglec-7 has high affinity for both the sialylated ganglioside GD3 (REF ${ }^{141}$ ) and N-linked disialyl Lewis ${ }^{\mathrm{a}}$ in the normal colonic epithelium ${ }^{142}$. The heavily glycosylated protein galectin 3-binding protein (LGALS3BP) is one Siglec-9 ligand on cancer ${ }^{143}$, but several other physiological ligands such as MUC1 (REF. ${ }^{125}$ ), disialyl Lewis ${ }^{\mathrm{a} / \mathrm{c}}$ (REF. ${ }^{140}$ ) and gangliosides ${ }^{144}$ have been described. Analogous to the manner in which both glycan and protein portions of PSGL1 form a molecular surface recognized by P-selectin, Siglec ligands are likely defined by particular glycans and the context in which they are presented. In support of this notion, paired immunoglobulin-like type 2 receptor- $\alpha$ (PILR $\alpha$ ) and PILR $\beta$ are receptors that modulate immune cell function, interact with sialic acid and have Siglec-like folds ${ }^{145}$. A crystal structure of PILRa in complex with a mucin glycopeptide revealed critical contacts to both the $O$-glycan and peptide backbone ${ }^{146}$.

Glycan array data generated by flowing recombinant lectins over collections of glycans printed onto glass slides provide a useful starting point for understanding these interactions, but do not adequately recapitulate the presentation of glycans in the context of particular protein and lipid scaffolds or capture the complexity of Siglec-ligand interactions on the native cell surface ${ }^{147}$. Multivalent Siglec-Fc constructs have recently improved the detection of Siglec ligands on cells and tissues ${ }^{148}$. Other approaches to identify Siglec ligands include proximity labelling and glycan library screening against Siglec reporter cells $\mathrm{s}^{149-151}$. Strategies to manipulate Siglec-ligand interactions based on metabolic glycoengineering are useful tools to study Siglec function ${ }^{152}$. Additional approaches to elucidate natural Siglec ligands and the mechanisms leading to their production are nevertheless needed.

Siglec-targeted therapies for cancer. Therapies can either target the Siglec or inhibit the Siglec ligand (FIG. 5). The most straightforward approach is to create a Siglec blocking antibody, and several companies are pursuing this strategy ${ }^{153}$ (see below). One obstacle is the challenge of identifying purely blocking antibodies that do not agonize the Siglec via dimerization. A second strategy is to remove the Siglec ligand. When the ligand is known, it may be blocked: for example, anti-CD24 antibodies were used to prevent interactions with Siglec-10 and promote tumour phagocytosis ${ }^{138}$. For Siglecs with poorly characterized ligands, blockade is not an option. Instead, Siglec interactions can be inhibited by complete desialylation. For example, treating B16F10 melanoma with peracetyl- $3 \mathrm{~F}_{\mathrm{ax}}-\mathrm{Neu} 5 \mathrm{Ac}^{154}$, an inhibitor of sialylation, reduced growth and migratory capacity in vivo ${ }^{155}$.

Our group adopted the complementary strategy of targeted degradation. We engineered antibody-enzyme conjugates comprising an antibody directed against a tumour antigen such as HER2 and a broad-acting sialidase capable of complete target cell desialylation. The first-generation antibody enzyme conjugate, consisting of an anti-HER2 antibody (trastuzumab) conjugated to a bacterial sialidase, removed Siglec ligands on breast cancer cells, boosting natural killer cell antibody-dependent cellular cytotoxicity against resistant breast cancer lines in vitro ${ }^{156}$. Second-generation antibody enzyme conjugates were designed to improve biocompatibility and stability in vivo by utilizing a human neuraminidase and transitioning from acid-labile aminooxy linker chemistry to a more secure linker synthesized via Pictet-Spengler ligation ${ }^{157}$. Palleon Pharmaceuticals was formed on the back of these results, and has further developed reagents to analyse and edit the cancer cell glycocalyx.

Whereas sialidases are an obvious choice to remove Siglec ligands, other glycocalyx-modifying enzymes may present therapeutic opportunities. For instance, bacterial mucinases can cleave the cancer-associated mucins MUC1 and MUC16 (REF. ${ }^{158}$ ). One major advantage of using broad-acting hydrolases to remodel the glycocalyx is that the ligands for several Siglecs may all be targeted simultaneously using a single therapeutic. Infusion of soluble glycosyltransferases could also theoretically take advantage of activated nucleotide sugars released by platelets at sites of inflammation to remodel the glycocalyx in situ ${ }^{159}$.

Siglecs in autoimmunity and inflammation. The Siglecs control inflammation in various pathologies ranging from autoimmunity and allergy to sepsis. Siglec agonism via antibodies, recombinant ligands, nanoparticles or liposomes could combat harmful inflammatory responses in a targeted manner.

Liposomes or nanoparticles decorated with synthetic Siglec ligands engage and induce the clustering of the relevant Siglec, and in some cases induce the Siglec to localize near an activating receptor and thereby oppose its activity. As described above, B cells deficient in CD22 and Siglec-G (a homologue of human Siglec-10) are hyperactive, leading to autoimmune phenotypes in mice ${ }^{110}$. This inhibitory activity of CD22 could be harnessed to prevent deleterious B cell responses. For instance, liposomes decorated with both antigen and CD22 ligands induced apoptosis of defined B cell populations, showcasing the potential of Siglec agonism as a therapy ${ }^{160}$. Likewise, liposomes bearing an allergen and a high-affinity CD33 ligand suppressed IgE-mediated activation of mast cells ${ }^{161}$. Surprisingly, targeting Siglecs in this manner even holds promise for sepsis, in which the multifactorial aetiology has left doctors with only blunt tools, such as corticosteroids, for treatment. In mouse models of sepsis, dendritic cell Siglec-G reduced gut inflammation ${ }^{162}$ and neutrophil Siglec-E protected against acute lung inflammation ${ }^{163}$. Nanoparticles decorated with a2,8-linked disialic acid functioned as Siglec agonists and improved survival in mouse models of sepsis and acute respiratory distress syndrome ${ }^{164}$.

Recombinant Siglec ligands also show potential as Siglec agonists. The best example of this approach comes from the growing recognition of Siglec-10 as an important regulator of innate immune responses. In particular, dendritic cell Siglec-10 reduced responses to damage-associated molecular patterns by interacting with CD24 (REF. ${ }^{165}$ ). Subsequent research found that recombinant CD24 could engage Siglec-G to prevent deleterious inflammation in a mouse model of 
5xFAD mouse model A mouse model for Alzheimer disease. 5xFAD mice express human amyloid protein precursor (APP) and presenilin 1 (PSEN1) along with five mutations in these genes linked to Alzheimer pathology. graft-versus-host disease ${ }^{166}$. This finding pushed OncoImmune to develop soluble CD24, presented as a dimer via conjugation to an immunoglobulin Fc domain $(\mathrm{CD} 24 \mathrm{Fc})$, as a Siglec-10 agonist. CD24Fc is currently being tested in phase III trials for the prevention of acute graft-versus-host disease (NCT04095858) and inflammation associated with severe COVID-19 (NCT04317040), and a phase I/II trial (NCT04060407) for immune-related adverse events associated with checkpoint inhibitor therapy. Siglec-10 agonism may also prove useful in the adaptive immune system, in which the interaction of Siglec-10 on T cells with soluble glycosylated CD52 has been found to protect mice from type 1 diabetes ${ }^{167}$.

Antibody-based Siglec agonists have developed alongside the recognition that Siglecs comprise an important node for eosinophil and mast cell regulation. An agonist antibody targeting murine Siglec-F reduced eosinophilic inflammation and tissue remodelling ${ }^{168}$. In humans, eosinophil apoptosis is promoted by Siglec- 8 agonism $^{169}$ and mast cells are suppressed by Siglec-7 and Siglec- 8 activity ${ }^{170,171}$. These findings led Allakos to develop lirentelimab (AK002), a monoclonal antibody recently shown to be effective in treating eosinophilic gastritis and duodenitis ${ }^{172}$, that is currently being tested in several additional phase II and III clinical trials for other allergic conditions such as chronic urticaria (NCT03436797) and eosinophilic gastroenteritis (NCT03664960).

Siglecs in neuroimmune homeostasis. Sialic acids are critical regulators of phagocyte homeostasis in the brain, where they are abundantly incorporated into gangliosides and $\alpha 2,8$-linked polysialic acids, which are linked to glycoproteins such as neural cell adhesion molecule (NCAM). The observation that polysialic acids bind to Siglec-11, coupled with the recognition of high Siglec-11 expression on microglia, inspired the hypothesis that glial Siglec-11 protects neurons from toxicity ${ }^{173}$. Indeed, treatment with the Siglec-11 ligand polysialic acid neutralized phagocyte activity and inhibited the macrophage oxidative burst on LPS exposure ${ }^{174}$. These findings were extended when aberrant phagocyte activation in age-related macular degeneration was subsequently discovered to be mediated, at least in part, by reduced sialylation and increased complement activation ${ }^{175}$.

Broader interest by the neurodegeneration community was piqued when CD33 appeared on the shortlist of genes significantly associated with Alzheimer disease and neurodegeneration across multiple genome-wide association studies ${ }^{176-178}$. Neuroimaging studies confirmed the association of CD33 variants (rs3826656 and rs3865444), which increase expression of CD33 $\left(\mathrm{REFS}^{179,180}\right)$, with reduced volumes of the amygdala and hippocampus in amyloid- $\beta(\mathrm{A} \beta)$-positive patients, particularly in the prodromal stages of Alzheimer disease ${ }^{181,182}$. Furthermore, the frequency of CD33-positive microglia correlates with the $\mathrm{A} \beta$ plaque burden in patients, CD33 directly inhibits $A \beta$ uptake by microglia and $C D 33$ inactivation mitigates disease ${ }^{183}$. CD33-targeting antibodies are undergoing phase I clinical trials (NCT03822208) at Alector (TABLE 1).
Recent failures of several A $\beta$-targeted therapies have forced the field to take a hard look at the amyloid hypothesis for Alzheimer disease, but Siglec-targeted therapies continue to hold promise ${ }^{184}$. Genetic deletion of CD33 produces a signature of microglial homeostasis, improves pathology in the 5xFAD mouse model and engages in crosstalk with TREM2, which is encoded by a gene whose loss is associated with an increased risk of Alzheimer disease ${ }^{185}$. CD22 also made a surprise entrance into the neurodegeneration space. Formerly thought to be B cell-specific, CD22 is also expressed on aged and damage-associated microglia in mice. Treatment of aged mice with a CD22 blocking antibody boosted microglia-mediated clearance of $A \beta$ and $\alpha$-synuclein, and, remarkably, improved cognitive function ${ }^{186}$. Siglecs clearly play a key role in defining the neuroimmune microenvironment, but the jury is still out on whether therapeutic inhibition of this axis can reverse pathology in humans.

Outlook for Siglec-directed therapies. Currently, the only FDA-approved Siglec-targeted therapies are ADCs against CD22 and CD33, which use the Siglec as a tumour-specific antigen to identify target cells. Moving forward, it is likely that the importance of the Siglecs in regulating inflammation in normal physiology and disease will be increasingly recognized as our understanding of Siglec biology improves. Clustering is a key principle to consider when developing therapies that modulate Siglec activity. Dimerization is generally agonistic, as crosslinking antibodies that target ITIM domaincontaining Siglecs inhibit immune cell activity. Likewise, glycomimetic Siglec ligands displayed on a multivalent scaffold, such as a nanoparticle, liposome or polymer, can aggregate Siglecs and act as receptor agonists ${ }^{187}$. Similar to the manner in which CD22 localization near the B cell receptor inhibits signalling, enforced localization of an ITIM domain-containing Siglec near a protein with a cytoplasmic immunoreceptor tyrosine-based activation motif domain - for example, using a bispecific antibody - could inhibit particular signalling cascades. Antibodies, single-chain variable fragments (scFvs) or high-affinity glycomimetic ligands that do not aggregate Siglecs are more likely to function as antagonists. The apparent requirement for Siglec aggregation to promote agonism must be balanced against induced internalization $^{188}$, which is the mechanism of action for intracellular delivery of cargo-bearing liposomes decorated with Siglec ligands ${ }^{107}$, and an antagonistic antibody targeting Siglec-15 on osteoclasts ${ }^{189}$.

Perhaps the greatest need in this area is a catalogue of biologically relevant ligands for each Siglec and the glycoproteomics and glycolipidomics tools to detect them on tissues of interest. Several therapies directed at Siglec function are nevertheless in advanced development by biotechnology and pharmaceutical companies, many of which will move towards clinical trials. Based on patent literature, in addition to those already mentioned, Innate Pharma's Siglec neutralizing antibodies for cancer, Medimmune's anti-Siglec-15 antibody for leukaemia, Alethia's anti-Siglec-15 antibody for osteogenesis imperfecta, Octapharma AG’s Siglec-modulating 


\section{REVIEWS}

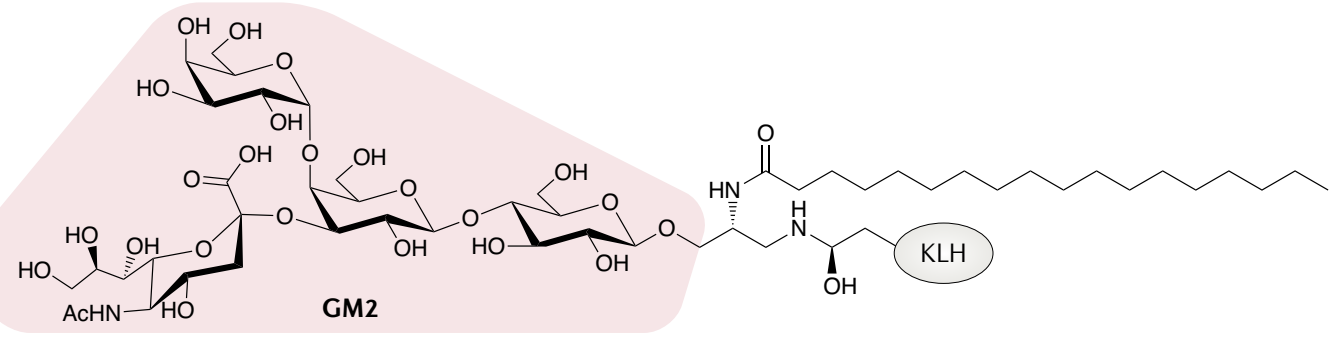

GM2-KLH

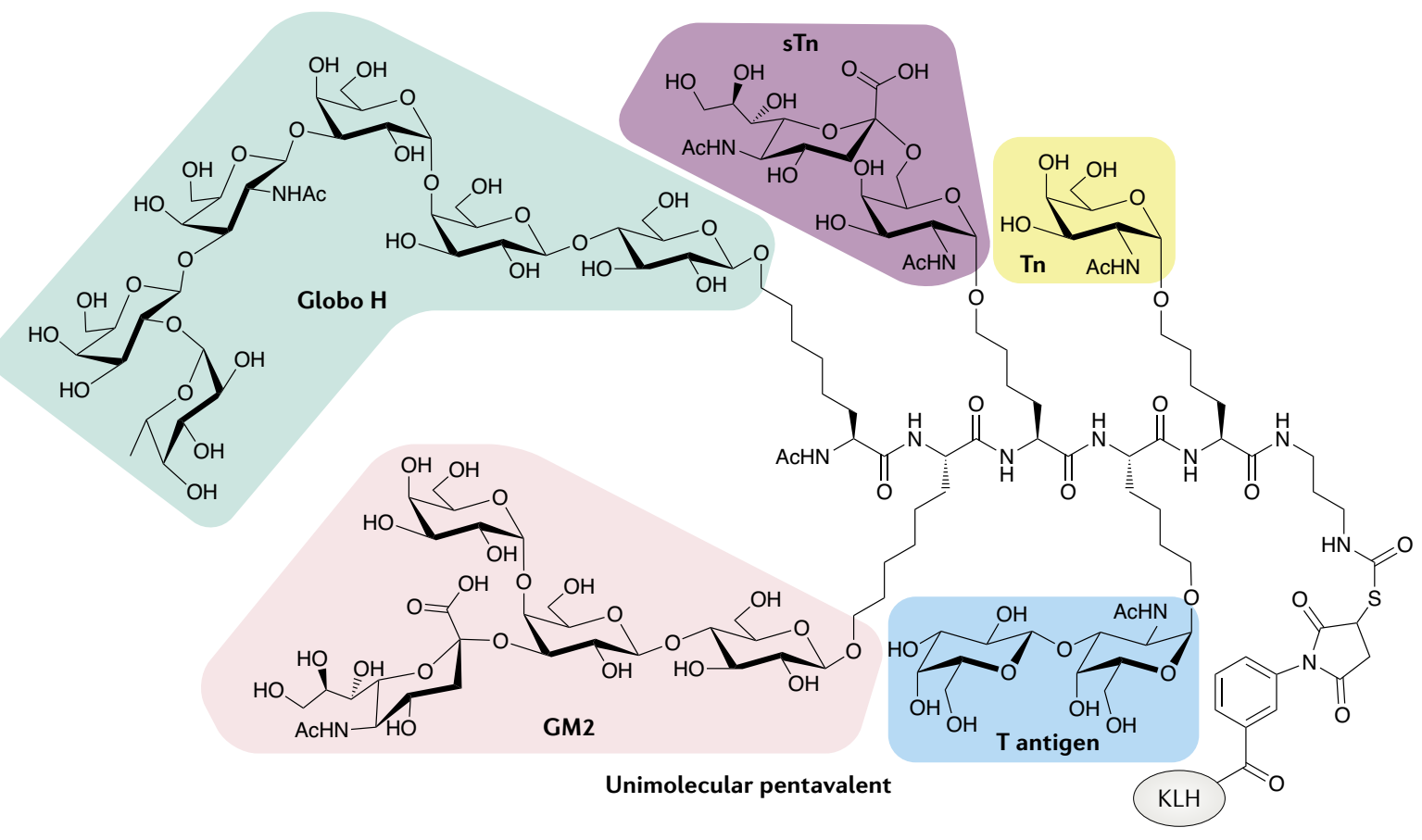

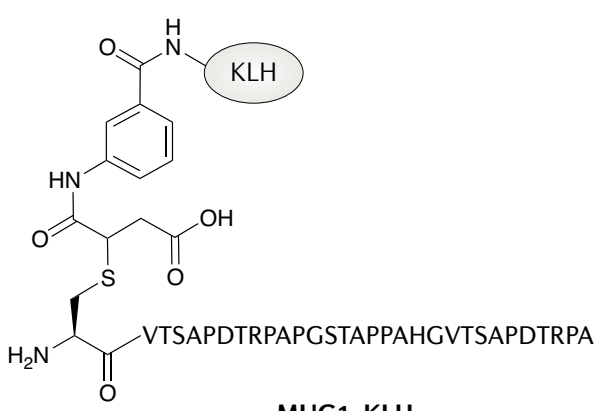

MUC1-KLH

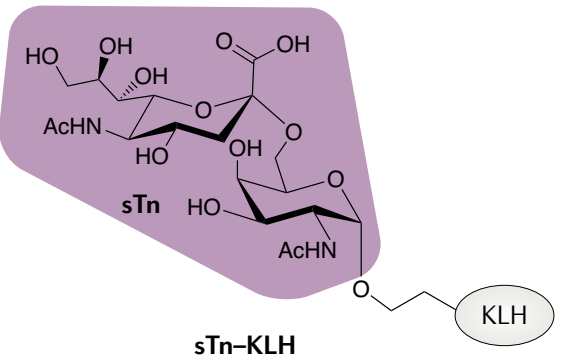

sTn-KLH

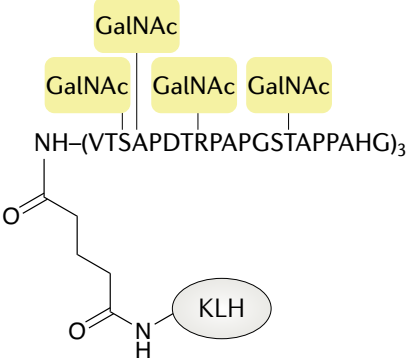

MUC1 Tn-KLH
WRYTAPVHLGDG - PADRE

P10s (Lewis $/$ GD2 mimic)-PADRE

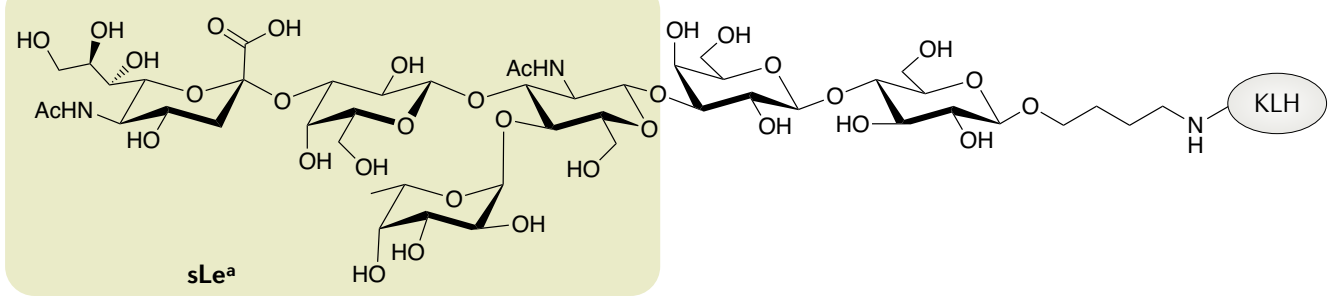

sLe ${ }^{a-K L H}$ 
4 Fig. 6 | Tumour-associated carbohydrate antigen vaccines. Vaccines targeting tumourassociated carbohydrates have evolved from unimolecular vaccines comprising single glycans conjugated to a carrier protein (usually keyhole limpet haemocyanin (KLH)) into more complex multivalent vaccines in which multiple glycans are linked together on a single scaffold. Although glycolipids have been popular targets, some vaccines target mucin-associated glycans. Pharmacophores representing key glycans in each vaccine are shaded in colour. The vaccines depicted include GM2-KLH ${ }^{210}$, a unimolecular pentavalent immunogen $^{228}$, MUC1-KLH ${ }^{218}$, sTn-KLH ${ }^{299}$, MUC1 Tn-KLH ${ }^{248}$, P10s-PADRE ${ }^{229}$ and sLe ${ }^{a}-$ $\mathrm{KLH}^{255}$. Tn denotes a single $\mathrm{O}$-GalNAc. GalNAc, $\mathrm{N}$-acetylgalactosamine; MUC1, mucin 1; PADRE, pan-HLA DR binding epitope; sLe ${ }^{a}$, sialyl Lewisa; sTn, sialyl-Tn.

glycopeptides, Cellectis' Siglec null CAR T cells and Onkimmune's Siglec null natural killer cell therapies are all worth watching.

\section{Glycan-targeted antibodies, vaccines}

Glycans can be neoantigens that are useful for diagnosis and therapy of cancer and other inflammatory diseases. Indeed, glycans can be convenient targets, and many common vaccines target the polysaccharides displayed by pathogens, such as Pneumovax and Prevnar for Streptococcus pneumoniae, Menactra and Menomune for Neisseria meningitidis and Synflorix for Haemophilus influenzae. Nevertheless, most therapeutic antibodies target proteins. The reason for this is not the lack of suitable glycan neoantigens but, rather, practicality. Three main challenges confront the use of mammalian glycans as therapeutic targets. First, tolerance must be broken because many of these glycans are expressed during embryonic development or are present on normal adult tissue at low levels. Second, stimulation of an efficient response to a glycan immunogen requires a functional population of marginal zone $\mathrm{B}$ cells or conjugation to protein because the glycan alone is considered a $\mathrm{T}$ cell-independent antigen and does not stimulate a robust $\mathrm{T}$ cell response ${ }^{190}$. Last, producing complex glycans is a synthetic challenge.

These hurdles can be, and have been, overcome. As antibodies targeting glycans are developed, we must keep in mind that antibodies are themselves glycosylated. The glycoforms decorating the Fc domains of IgG regulate binding to $\mathrm{Fc} \gamma$ receptors, thereby modulating antibody effector functions and contributing to inflammatory pathologies ${ }^{191}$. Glycosylation is an important consideration when developing a new therapeutic antibody, and antibodies can be glycoengineered (reviewed elsewhere ${ }^{192}$ ).

In this section, we review glycan neoantigens in cancer and strategies deployed to target them, including vaccines, monoclonal antibodies and CAR T cells.

Glycosylation is a hallmark of disease. Altered glycosylation is a hallmark of disease ${ }^{193,194}$. In numerous inflammatory conditions, patients develop antibodies to carbohydrate epitopes, and these antibodies are potential biomarkers. For instance, anti-glycan antibodies have been detected that are characteristic of multiple sclerosis $^{195}$ or Crohn's disease ${ }^{196}$. Patients with systemic sclerosis have antibodies directed against sulfated LacNAc. In this population, sulfation in particular was found to be critical for immunogenicity, suggesting more broadly that the glycans against which these diagnostic antibodies are directed may contribute to disease pathogenesis ${ }^{197}$. Dysregulated glycosylation is particularly characteristic of cancer. Indeed, tumour-associated glycoproteins have utility as biomarkers to monitor cancer progression and response to therapy. For instance, the ovarian tumour marker CA125 is a mucin (MUC16) decorated with high mannose-type $N$-glycans ${ }^{198}$, the colon cancer marker carcinoembryonic antigen (CEA) is a sialofucosylated GPI-anchored protein ${ }^{199}$ and the pancreatic cancer biomarker CA19-9 is sLe conjugated to highly glycosylated bottlebrush-shaped proteins known as mucins ${ }^{200}$.

In all cases, pathological glycosylation is a direct result of dysregulated metabolic pathways. Common motifs are reversion to an embryonic state, glycan truncation and extended branching ${ }^{201}$. Although most mammalian cells display O-linked glycans that have been elaborated from their simple GalNAc base to longer and more complex architectures, mucinous carcinomas frequently display short, truncated glycans. In many of these cases, glycan truncation has been linked to mutations in COSMC ${ }^{202}$, a chaperone necessary for folding of glycoprotein- $N$-acetylgalactosamine 3- $\beta$-galactosyltransferase 1 (C1GALT1). Cancers also frequently display more high mannose-type $\mathrm{N}$-linked glycans produced from increased branching ${ }^{203}$. We are only beginning to fully understand the functional consequences of altered glycosylation in health and disease, but these phenotypes have been linked to immune evasion, metastasis, cell survival and growth factor receptor signalling.

Tumour vaccines. The rationale for a tumour vaccine is to harness the power of the immune system to identify and eliminate malignant cells bearing certain antigens. To target mammalian glycans in practice, strategies for breaking self-tolerance and encouraging a $\mathrm{T}$ cell response have ranged from administration of multivalent antigens, conjugation of glycans to immunogenic carrier proteins such as keyhole limpet haemocyanin $(\mathrm{KLH})$ and addition of vaccine adjuvants such as QS-21 (REF. ${ }^{204}$ ).

Development of vaccines against tumour-associated carbohydrates stems from the observation that the gangliosides GM2 and GD2 were among the most commonly recognized antigens in patients' sera following administration of a whole-cell melanoma vaccine as adjuvant immunotherapy ${ }^{205-207}$. A GM2-specific vaccine was prepared by isolating the ganglioside from natural sources. This GM2 was poorly immunogenic in isolation, although a combination with Bacillus Calmette-Guérin stimulated antibody production in melanoma patients and improved disease-free survival ${ }^{208}$. The duration of response and antibody titres were nevertheless low, thus spurring the replacement of Bacillus Calmette-Guérin with KLH and the addition of the adjuvant QS-21 in an attempt to augment IgG titres ${ }^{209,210}$ (FIC. 6). Unfortunately, in a phase III trial (NCT00005052) of GM2-KLH with QS-21 in patients with stage II melanoma, the vaccine lacked efficacy and the trial was stopped ${ }^{211}$. Although the study's authors surmise that the vaccination schedule was ineffective, it is possible that the monovalent GM2 used in the trial was unable to stimulate a vigorous 
immune response. One simple contributor to the failure was the low percentage of patients who developed high antibody titres against GM2.

Vaccines against other carbohydrate antigens were propelled by improved methods for organic synthesis of glycans. Low abundance of some tumour-associated carbohydrate antigens in natural sources coupled with the challenges of purifying a glycan of interest from heterogeneous mixtures hampered isolation of material from natural sources. These new synthetic methodologies, namely glycal assembly, enabled the creation of KLH conjugate vaccines against the glycolipid globo $\mathrm{H}$ in breast cancer ${ }^{212}$, fucosyl-GM1 (Fuc-GM1) in small cell lung cancer ${ }^{213}$ and Lewis ${ }^{\mathrm{y}}\left(\mathrm{Le}^{\mathrm{y}}\right)$ in ovarian cancer ${ }^{214}$. The efficacy of these vaccines was mixed. In order for a carbohydrate-based vaccine to be an effective therapy, it must consistently generate high titres of high-affinity anti-glycan antibodies in patients, and these monomeric vaccines tended to produce only moderate IgM and poor IgG titres in immunized patients. For instance, a phase II/III trial (NCT01516307) of the globo H vaccine in breast cancer patients did not improve progressionfree survival but did offer a benefit to patients who developed high IgG titres ${ }^{215}$. A phase III trial (NCT03562637) of the same vaccine in triple-negative breast cancer is currently underway.

Even vaccines capable of inducing high IgG titres are not guaranteed success. The mucin MUC1 is differentially glycosylated in cancer, which makes it an attractive target ${ }^{216}$. In preparing their MUC1 peptide$\mathrm{KLH}$ conjugate for use in breast cancer, one group was inspired by the notion that truncating the glycans on cancer-associated MUC1 (REF. ${ }^{217}$ ) might lead to greater exposure of the peptide backbone, and therefore left all of the glycans off their immunogen. Although this strategy generated high IgM and IgG titres, the ability of these antibodies to bind tumour MUC1 in vivo was limited ${ }^{218}$. Another MUC1 peptide, administered in conjunction with the TLR3 agonist poly-ICLC ${ }^{219}$, is in clinical trials for the prevention of colorectal adenoma and lung cancer. Although preliminary results (NCT02134925) suggest that the vaccine generates anti-MUC1 antibodies, the capacity for this immune memory to prevent disease progression is unknown ${ }^{220}$. Etubics is pursuing a complementary strategy in which colon and breast cancer patients are administered modified adenovirus coding for tumour-associated antigens, including MUC1 and $\mathrm{CEA}^{221}$. The vaccine appears to generate $\mathrm{T}$ cells that are reactive to MUC1 and CEA (NCT03384316), although in vitro analysis suggests that the MUC1 produced by the virus is not glycosylated and its efficacy in reducing disease remains to be seen ${ }^{222}$.

MUC1 decorated with sialyl-Tn (sTn), a truncated O-glycan comprising Neu5Aca2-6GalNAc, could predict prognosis in ovarian cancer, which inspired an sTn-KLH conjugate vaccine (Theratope) ${ }^{223}$. In breast cancer patients, Theratope promoted the generation of anti-sTn antibodies ${ }^{224}$, and the presence of these antibodies correlated with improved survival ${ }^{225}$. Ultimately, a phase III trial (NCT00003638) of Theratope revealed no benefit in metastatic breast cancer patients despite high IgG titres in patients receiving the vaccine ${ }^{226}$. One possible explanation for failure is that patient eligibility was not determined by tumour sTn expression.

Glycan multivalency may be the most promising path forward. A heptavalent vaccine comprising a mixture of carbohydrate-KLH conjugates induced a moderate humoral response ${ }^{227}$, and a second-generation pentavalent vaccine comprising the glycan portions of globo $\mathrm{H}$, GM2, Tn (a single $O$-GalNAc), sTn and T antigen (Gal $\beta 1-3$ GalNAc) linked together on a single scaffold increased IgG titres to these antigens in a recent phase I trial (NCT01248273) ${ }^{228}$. Taking an alternative approach, a vaccine comprising a carbohydrate mimetic peptide conjugated to the pan-HLA DR binding epitope (PADRE) peptide $\mathrm{T}$ cell agonist generated antibodies against both $\mathrm{Le}^{\mathrm{y}}$ antigen and GD2, and had a potential benefit for breast cancer patients in a phase I trial (NCT01390064) 229,230 . A bivalent vaccine comprising GD2 and GD3, stabilized as lactones, conjugated to $\mathrm{KLH}$ and injected in combination with the immunostimulants OPT-821 (a QS-21 equivalent) and $\beta$-glucan (a Mac-1 ligand), is the subject of an ongoing phase II trial (NCT00911560) for high-risk neuroblastoma ${ }^{231}$. Going full circle, whole-cell vaccines, the ultimate in multivalency, were again recently shown to generate antibodies against carbohydrate antigens, although they are likely only effective when the glycan neoantigen is expressed at very high levels ${ }^{232}$.

Glycan-directed passive immunotherapy. Therapies based on anti-glycan antibodies avoid many of the challenges facing active immunotherapy. Among the first anti-glycan therapeutics to be successfully translated to the clinic was the anti-GD2 antibody dinutuximab, currently FDA-approved for treatment of high-risk paediatric neuroblastoma ${ }^{233}$. The lead molecule that eventually produced dinutuxumab was not created with a glycan in mind, however; the primary goal was to develop any antibody specific to neuroblastoma. Two independent groups immunized mice with human whole-cell neuroblastomas, isolated B cell clones and screened for reactivity against neuroblastoma antigen $s^{234-236}$. Remarkably, the most selective and highest-affinity antibodies isolated by each group targeted the disialoganglioside GD2, highlighting the prevalence of gangliosides on cancer and the utility of targeting tumour glycans. Humanization of one of these clones yielded the ch14.18 antibody, which became dinutuximab ${ }^{237}$. A landmark phase III (NCT02641782) trial of ch14.18 in paediatric neuroblastoma revealed that GD2-targeted immunotherapy improved overall survival ${ }^{238}$.

Likewise, other promising anti-glycan antibodies have emerged to complement the carbohydrate vaccine programmes described above. The common ganglioside GM1 has only been detected in its fucosylated form in small cell lung cancer, and this has garnered interest in using Fuc-GM1 monoclonal antibodies in this disease. However, Fuc-GM1-KLH conjugate vaccines generated only a low-affinity IgM response in patients ${ }^{239}$. Nevertheless, data suggesting that Fuc-GM1 antibodies could inhibit tumour engraftment in mice and promote complement dependent cytotoxicity ${ }^{240}$ led Bristol-Myers Squibb to develop a fully human anti-Fuc-GM1 antibody 
(BMS-986012) for use in small cell lung cancer ${ }^{241}$. Results from the clinical trial (NCT02247349) were expected in late 2020. Similarly, antibodies directed against globo $\mathrm{H}$ inhibit angiogenesis and promote antibody-dependent cellular cytotoxicity against globo $\mathrm{H}$-positive tumours of various backgrounds ${ }^{242,243}$. These results encouraged a phase I/II trial (NCT03573544) of the globo H antibody OBI-888 and a phase I/II trial (NCT04084366) of OBI999, an ADC based on the same antibody ${ }^{244}$, in patients with solid tumours. Both trials are underway.

Among glycoproteins, the mucin MUC1 has perhaps received the most attention as a target for cancer immunotherapy. In mucinous adenocarcinomas, MUC1 is abundantly expressed and aberrantly O-glycosylated with short glycans including sTn, Tn and T antigen. These MUC1 glycoforms are not displayed on healthy tissue $^{245}$, and their expression correlates with adverse outcomes in numerous tumours ${ }^{246,247}$. A potent and specific monoclonal antibody, 5E5, was isolated from mice immunized with MUC1 Tn glycopeptide-KLH conjugates $^{248}$. Intriguingly, the MUC1 epitopes recognized by $5 \mathrm{E} 5$ and other $\mathrm{B}$ cell clones isolated from these mice map to the same tandem repeat region, suggesting the existence of immunodominant glycopeptides ${ }^{249}$. The 5E5 anti-Tn-MUC1 antibody bound to human breast cancer lines and induced antibody-dependent cellular cytotoxicity.

The broad and selective expression of Tn-MUC1 on cancer made it an attractive target in attempts to generate a universal CAR $T$ therapy with utility in various tumour types. Using the $5 \mathrm{E} 5$ antibody as a starting point, one group generated a Tn-MUC1 CAR T cell that demonstrated efficacy in mouse models of leukaemia and disseminated pancreatic cancer ${ }^{250}$. CAR T cells against the disialoganglioside GD2 have also advanced to human trials in neuroblastoma ${ }^{251}$. Indeed, GD2-targeted CAR $\mathrm{T}$ cells can cross the blood-brain barrier, thereby permitting the treatment of aggressive cancers such as midline gliomas ${ }^{252}$.

Theranostics. As additional glycan neo-epitopes are identified, one of the most promising avenues for translation of these findings comes from the field of theranostics, in which a diagnostic tool is paired to a therapy. Pancreatic ductal adenocarcinoma is an aggressive tumour that is exceptionally lethal, partially because it is diagnosed late. CA19-9 (mucin decorated with sLe ${ }^{a}$ ) is the most highly expressed tumour antigen on pancreatic ductal adenocarcinoma and its display on breast and colon cancer correlates with more aggressive tumours ${ }^{253,254}$. sLe $^{\mathrm{a}}$ was packaged into a KLH conjugate vaccine and administered to metastatic breast cancer patients (NCT00470574), with results expected in 2021 $\left(R^{2} F^{255}\right)$. Anti-glycan antibodies were isolated from one of the patients receiving the experimental vaccine and validated for binding to CA19-9 (REF. ${ }^{256}$ ). A phase I trial (NCT02672917) of one of these antibodies (5B1; MVT5873 ) in CA19-9-positive malignancies is ongoing. To facilitate monitoring of CA19- $9^{+}$tumours in vivo, Lewis and colleagues adapted the 5B1 antibody into a probe for positron emission tomography ${ }^{257}$ and near-infrared fluorescent optical imaging (NCT02687230) ${ }^{258}$. Recently, they used a tetrazine ligation between $\mathrm{a}^{225} \mathrm{Ac}$ radioligand and a trans-cyclooctene-labelled anti-CA19-9 antibody to transform the diagnostic antibody into a potent a-particle-emitting radiotherapeutic ${ }^{259}$. Results from a phase I trial (NCT03118349) on a matching $\beta$-particleemitting ${ }^{177} \mathrm{Lu}$-labelled version of the antibody (MVT$1075)^{260}$ are expected soon. As additional highly specific anti-glycan antibodies are generated, theranostics may be a rapid way of translating discoveries to the clinic and validating targets by ensuring that only patients most likely to benefit from a therapy are treated.

\section{Outlook}

The human glycome is dynamic and the functions encoded by its structures are poorly understood. The glycome contains a wealth of information that correlates with cell and organism status, and, in many cases, particular glycans also perform essential functions. Uncovering this information, integrating it with existing data and collating it into useful models is a formidable task. Nevertheless, a cadre of persevering glycobiologists has already produced several drug candidates and shown that the field is ripe to produce more (FIG. 7). Although outside the scope of this Review, one exciting area to watch is galectin biology. The galectins are a family of $\beta$-galactoside binding proteins involved in diverse aspects of cell physiology, and several galectin-targeted therapies have entered clinical trials for indications including cancer, cardiovascular disease and fibrotic disease (reviewed elsewhere ${ }^{261,262}$ ).

Major challenges still remain. Most importantly, we do not yet have a full portrait of the glycome in health and disease. Improvements in our ability to detect altered glycosylation will catalyse the development of glycan-targeted therapeutics and increase the number of useful glycan biomarkers. A necessary first step already being taken is to develop a greater appreciation for the 'dark matter' of biology, including everything outside DNA, RNA and proteins ${ }^{263}$. Indeed, awareness that glycans decorate many medically relevant biomolecules is burgeoning, as is recognition that even those molecules that have already been the subject of hundreds of clinical trials, such as PDL1, are glycosylated ${ }^{264}$. GlyGen, GlyCosmos and glycan profiling and array data from the Consortium for Functional Glycomics are extremely valuable resources, and are not yet complete. We should strive to generate comprehensive information on glycosylation of proteins and lipids across various tissues, cell types and disease states that can be put at the fingertips of all biologists so that answering a question about glycosylation is no more difficult than looking up a gene expression data set.

How can we work towards this goal? A robust method for sequencing glycans and simultaneously identifying their point of attachment, whether to a particular site on a protein or a specific lipid, would advance the field substantially. In the absence of a technology for glycan sequencing, the next-best option for glycan and glycosite identification is mass spectrometry-based glycoproteomics. Glycoproteomics can provide detailed portraits of the glycans on a few predefined proteins, but cannot yet be used to reliably survey and quantify 


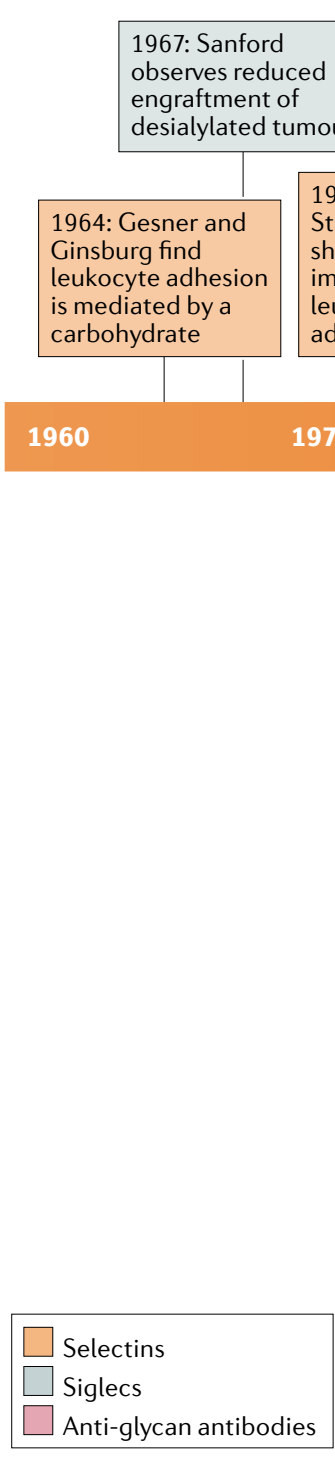

1976: Woodruff and Stamper discover shear conditions are important for leukocyte-endothelium adhesion

\begin{tabular}{|l|}
\hline $\begin{array}{l}\text { 2000: HCELL first } \\
\text { characterized }\end{array}$ \\
\hline 2000: Crystal structures \\
of P-selectin in complex \\
with PSGL1 reveal \\
the importance of sulfo- \\
tyrosine
\end{tabular}

1991: sLe ${ }^{x}$ identified as the primary binding determinant for E-selectin

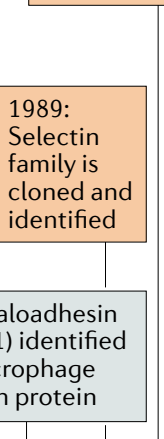

1997: Tumour sialic acids demonstrated to promote cancer growth via immunoediting

1995: CD22

(Siglec-2) found to inhibit B cell activation via SHP phosphatases
1986: Siaload (Siglec-1) identified as a macrophage adhesion protein
2008: HCELL found to govern HSC trafficking to the bone marrow

2008: GWAS link SNPs in CD33 to Alzheimer disease

2005: Leukaemia found to home to E-selectin-positive regions of bone marrow

2005: Regulation of CD22 activity by homomultimeric clustering observed

\begin{tabular}{|l|}
\hline $\begin{array}{l}\text { 2001: Key } \\
\text { clinical trial } \\
\text { of Cylexin } \\
\text { shows no } \\
\text { benefit }\end{array}$ \\
\hline
\end{tabular}

2019: Crizanlizumab approved by the FDA

2019: Phase I trial of AL003 (anti-CD33)

launched

\section{7: Gemtuzumab} ozogamicin approved again

016: Phase I trial of AK002

(anti-Siglec-8) launched

\section{5: Rivipanse} reduces opioid use in a phase II trial in sickle cell patients

\section{1: rPSGL-lg}

(YSPL) shows mixed

results in phase II

trials for liver and

renal allograft

\section{0}

1979: Anti-GM2
antibodies found in
patients administered
whole melanoma cell
vaccines

1988: CD22 (Siglec-2) and
CD33 (Siglec-3) identified as cell lineage markers

1994: QS-21 identified as a useful adjuvant for glycan-based vaccines

\begin{tabular}{l}
$\mid \begin{array}{l}\text { 1990: Anti-GD2 } \\
\text { antibody } \\
\text { ch14.18 } \\
\text { developed }\end{array}$ \\
\hline iglec-2) and \\
identified \\
QSarkers \\
yseful adjuvant \\
ycan-based \\
nes
\end{tabular}$$
\text { }
$$

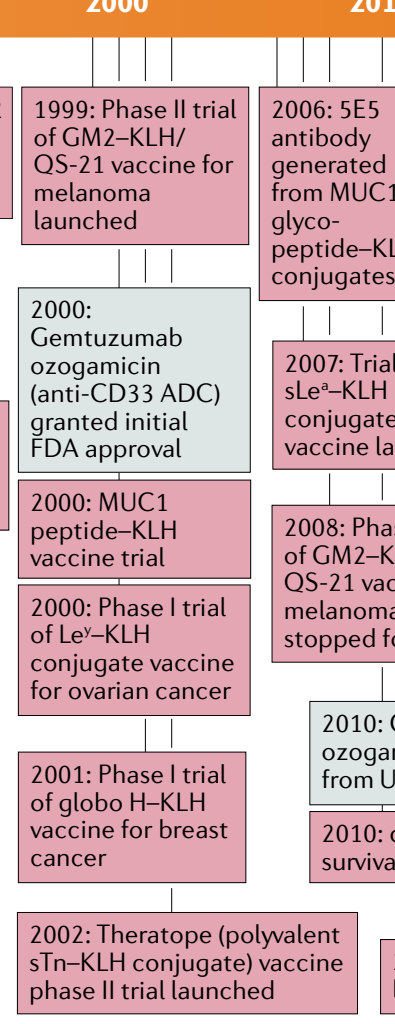

Fig. 7 | Timeline of key developments in translational glycobiology. Important events that have catalysed biological discovery and drug development are highlighted for each thread of this Review. Tn denotes a single O-GaINAc. ADC, antibody-drug conjugate; CAR, chimeric antigen receptor; GalNAc, $\mathrm{N}$-acetylgalactosamine; GWAS, genome-wide association studies; HCELL, haematopoietic cell E-/L-selectin ligand; HSC, haematopoietic stem cell; KLH, keyhole limpet haemocyanin; Ley, Lewis`; MUC1, mucin 1; PSGL1, P-selectin glycoprotein ligand 1; rPSGL-lg, recombinant PSGL1 fused to immunoglobulin; SHP, SRC homology region 2 domain-containing phosphatase; SNP, single-nucleotide polymorphism; sLe ${ }^{a}$, sialyl Lewis ${ }^{\mathrm{a}}$; sLe ${ }^{\mathrm{x}}$, sialyl Lewis; sTn, sialyl-Tn; TIL, tumour-infiltrating lymphocyte.

the entire glycoproteome. Advances in glycomics and glycoproteomics have made analyses more robust, reproducible and feasible on small sample quantities, but single-cell analysis is currently out of reach. Indeed, radical simplification of the glycome with SimpleCell technology, which requires engineering cells to express only a single glycan, has been the only way to map glycosites on a proteome-wide scale ${ }^{265,266}$. 
Increased availability of reagents for glycan detection will also accelerate biological discovery. In addition to the mammalian vaccination strategies discussed above, high-affinity anti-glycan antibodies have been generated in lamprey ${ }^{267}$ and avian ${ }^{268}$ hosts. Glycan processing enzymes can be converted into binding reagents, as has been done by Lecten $\mathrm{z}^{269}$. Plant or microbial lectins could also be evolved for high specificity to a particular glycan of interest.

The most obvious application of the resultingly increased understanding of glycobiology will be biomarker discovery. We are also likely to discover novel biology as we develop richer, more detailed data sets. For example, we are sure to find more examples of glycans that are important modulators of protein function and drivers of disease $\mathrm{e}^{270}$. Ligand discovery for glycan-binding proteins such as the Siglecs and galectins is a particularly fertile area for translational medicine. Chip-based glycan arrays have enabled the screening of lectins against large libraries of synthetic glycans. Laser-based array synthesis technology is an important advance in this area as it enables on-chip glycopeptide syntheses at defined densities $^{271}$. Cell-based glycan arrays go a step further, as lectin binding is observed on a native lipid bilayer, at appropriate glycan densities and in the context of other proteins ${ }^{272,273}$. Cell-based arrays also hold promise for unravelling the non-templated nature of glycan synthesis and glycosyltransferase function when paired with glycoproteomics analyses. As genome-wide CRISPR screens become increasingly common for identification of novel biology, we are certain to see 'glycogenes' implicated in more areas.

Among the most promising therapeutic agents in the pipeline are biologics targeting glycan binding proteins, such as the P-selectin blocking antibody crizanlizumab and NextCure's Siglec-15 blocking antibody. These agents benefit from the ease of manufacturing and favourable pharmacokinetics of monoclonal antibodies, while avoiding the challenges of targeting glycans directly. For glycan or lectin blocking reagents, the most effective designs will recognize that glycan and protein together make a continuous molecular surface that is read by glycan binding proteins (as occurs in the P-selectin-PSGL1 interaction). Finally, the development of glycomimetics with drug-like properties will be advanced by structure-guided design incorporating multiple fragments and binding sites, an approach that was recently showcased ${ }^{274}$. The groundwork has been laid for an exciting expansion of therapeutic opportunities in glycobiology.

Published online 18 January 2021
1. Martinez-Palomo, A., Braislovsky, C. \& Bernhard, W. Ultrastructural modifications of the cell surface and intercellular contacts of some transformed cell strains. Cancer Res. 29, 925-937 (1969).

2. Woo, C. M. et al. Development of IsoTaG a chemical glycoproteomics technique for profiling intact $\mathrm{N}$ - and $\mathrm{O}$-glycopeptides from whole cell proteomes. J. Proteome Res. 16, 1706-1718 (2017).

3. Riley, N. M., Malaker, S. A., Driessen, M. D \& Bertozzi, C. R. Optimal dissociation methods differ for $\mathrm{N}$ - and $\mathrm{O}$-glycopeptides. J. Proteome Res. 19 3286-3301 (2020).

4. Varki, A. Biological roles of glycans. Glycobiology 27 , 3-49 (2017).

5. Liang, R. et al. Polyvalent binding to carbohydrates immobilized on an insoluble resin. Proc. Natl Acad. Sci. USA 94, 10554-10559 (1997).

6. Stamper, H. B. Jr. \& Woodruff, J. J. Lymphocyte homing into lymph nodes: in vitro demonstration of the selective affinity of recirculating lymphocytes for high-endothelial venules. J. Exp. Med. 144, 828-833 (1976).

This report highlights the importance of catch bonds in selectin-ligand interactions and establishes the shear stress-based assay that enabled the next several decades of research on selectins.

7. Godula, K. \& Bertozzi, C. R. Density variant glycan microarray for evaluating cross-linking of mucin-like glycoconjugates by lectins. J. Am. Chem. Soc. 134 15732-15742 (2012).

8. Rabuka, D., Forstner, M. B., Groves, J. T. \& Bertozzi, C. R Noncovalent cell surface engineering: incorporation of bioactive synthetic glycopolymers into cellular membranes. J. Am. Chem. Soc. 130, 5947-5953 (2008).

9. von Itzstein, M. The war against influenza: discovery and development of sialidase inhibitors. Nat. Rev. Drug Discov. 6, 967-974 (2007)

10. McEver, R. P. Selectins: initiators of leucocyte adhesion and signalling at the vascular wall. Cardiovasc. Res. 107, 331-339 (2015)

11. Sako, D. et al. Expression cloning of a functional glycoprotein ligand for P-selectin. Cell 75, 1179-1186 (1993).

12. Norgard, K. E. et al. Characterization of a specific ligand for P-selectin on myeloid cells. A minor glycoprotein with sialylated O-linked oligosaccharides. J. Biol. Chem. 268, 12764-12774 (1993).
13. Aruffo, A., Kolanus, W., Walz, G., Fredman, P. \& Seed, B. CD62/P-selectin recognition of myeloid and tumor cell sulfatides. Cell 67, 35-44 (1991).

14. Aigner, S. et al. CD24, a mucin-type glycoprotein, is a ligand for P-selectin on human tumor cells. Blood $\mathbf{8 9}$ 3385-3395 (1997)

15. Imai, Y., Lasky, L. A. \& Rosen, S. D. Sulphation requirement for GlyCAM-1, an endothelial ligand for L-selectin. Nature 361, 555-557 (1993).

16. McEver, R. P. \& Zhu, C. Rolling cell adhesion. Annu. Rev. Cell Dev. Biol. 26, 363-396 (2010).

17. Norgard-Sumnicht, K. E., Varki, N. M. \& Varki, A Calcium-dependent heparin-like ligands for L-selectin in nonlymphoid endothelial cells. Science 261, 480-483 (1993).

18. Berg, E. L. et al. The cutaneous lymphocyte antigen is a skin lymphocyte homing receptor for the vascular lectin endothelial cell-leukocyte adhesion molecule 1. J. Exp. Med. 174, 1461-1466 (1991).

19. Fuhlbrigge, R. C., King, S. L., Sackstein, R. \& Kupper, T. S. CD43 is a ligand for E-selectin on CLA human T cells. Blood 107, 1421-1426 (2006).

20. Morikis, V. A. et al. Selectin catch-bonds mechanotransduce integrin activation and neutrophil arrest on inflamed endothelium under shear flow. Blood 130, 2101-2110 (2017).

21. Nimrichter, L. et al. E-selectin receptors on human leukocytes. Blood 112, 3744-3752 (2008).

22. Sackstein, R. Fulfilling Koch's postulates in glycoscience: HCELL, GPS and translational glycobiology. Glycobiology 26, 560-570 (2016).

23. Gowans, J. L. The recirculation of lymphocytes from blood to lymph in the rat. J. Physiol. 146, 54-69 (1959).

24. Gesner, B. M. \& Ginsburg, V. Effect of glycosidases on the fate of transfused lymphocytes. Proc. Natl Acad. Sci. USA 52, 750-755 (1964).

25. Bevilacqua, M. P., Stengelin, S., Gimbrone, M. A. Jr. $\&$ Seed, B. Endothelial leukocyte adhesion molecule 1 an inducible receptor for neutrophils related to complement regulatory proteins and lectins. Science 243, 1160-1165 (1989)

26. Johnston, G. I., Cook, R. G. \& McEver, R. P. Cloning of GMP-140, a granule membrane protein of platelets and endothelium: sequence similarity to proteins involved in cell adhesion and inflammation. Cell $\mathbf{5 6}$ 1033-1044 (1989).

27. Camerini, D., James, S. P., Stamenkovic, I. \& Seed, B. Leu-8/TQ1 is the human equivalent of the Mel-14 lymph node homing receptor. Nature $342,78-82$ (1989).
28. Winn, R. K Liggitt, D Vedder, N. B, Paulson, J. C. \& Harlan, J. M. Anti-P-selectin monoclonal antibody attenuates reperfusion injury to the rabbit ear. J. Clin. Invest. 92, 2042-2047 (1993).

29. Mulligan, M. S. et al. Role of endothelial-leukocyte adhesion molecule 1 (ELAM-1) in neutrophil-mediated lung injury in rats. J. Clin. Invest. 88, 1396-1406 (1991).

30. Gundel, R. H. et al. Endothelial leukocyte adhesion molecule-1 mediates antigen-induced acute airway inflammation and late-phase airway obstruction in monkeys. J. Clin. Invest. 88, 1407-1411 (1991).

31. Mulligan, M. S., Watson, S. R., Fennie, C. \& Ward, P. A Protective effects of selectin chimeras in neutrophilmediated lung injury. J. Immunol. 151, 6410-6417 (1993).

32. Walz, G., Aruffo, A., Kolanus, W., Bevilacqua, M. $\&$ Seed, B. Recognition by ELAM-1 of the sialyl-Le $\mathrm{e}^{\mathrm{x}}$ determinant on myeloid and tumor cells. Science $\mathbf{2 5 0}$ 1132-1135 (1990).

33. Phillips, M. L. et al. ELAM-1 mediates cell adhesion by recognition of a carbohydrate ligand, sialyl-Le ${ }^{x}$. Science 250, 1130-1132 (1990).

34. Buerke, M. et al. Sialyl Lewis ${ }^{\mathrm{x}}$-containing oligosaccharide attenuates myocardial reperfusion injury in cats. J. Clin. Invest. 93, 1140-1148 (1994).

35. Kerr, K. M. et al. The use of cylexin (CY-1503) in prevention of reperfusion lung injury in patients undergoing pulmonary thromboendarterectomy. Am. J. Respir. Crit. Care Med. 162, 14-20 (2000).

36. Poppe, L., Brown, G. S., Philo, J. S., Nikrad, P. V. \& Shah, B. H. Conformation of sLe $\mathrm{e}^{x}$ tetrasaccharide free in solution and bound to E-, P-, and L-selectin. J. Am. Chem. Soc. 119, 1727-1736 (1997).

37. Leppänen, A., White, S. P., Helin, J., McEver, R. P. $\&$ Cummings, R. D. Binding of glycosulfopeptides to P-selectin requires stereospecific contributions of individual tyrosine sulfate and sugar residues. J. Biol. Chem. 275, 39569-39578 (2000).

38. Somers, W. S., Tang, J., Shaw, G. D. \& Camphausen, R. T. Insights into the molecular basis of leukocyte tethering and rolling revealed by structures of P- and E-selectin bound to SLe ${ }^{\mathrm{x}}$ and PSGL-1. Cell 103, 467-479 (2000).

This study presents the crystal structure of P-selectin and E-selectin in complex with PSGL1, revealing how both glycan and protein portions of PSGL1 together form a molecular surface recognized by the selectins. 
39. Scheffler, K. et al. Application of homonuclear 3D NMR experiments and 1D analogs to study the conformation of sialyl Lewis ${ }^{\mathrm{x}}$ bound to E-selectin. J. Biomol. NMR 9, 423-436 (1997).

40. Rinnbauer, M. et al. Epitope mapping of sialyl Lewis ${ }^{x}$ bound to E-selectin using saturation transfer difference NMR experiments. Glycobiology 13 435-443 (2003).

41. Ernst, B. \& Magnani, J. L. From carbohydrate leads to glycomimetic drugs. Nat. Rev. Drug Discov. 8 661-677 (2009).

42. Chang, J et al. GMI-1070 a novel pan-selectin antagonist, reverses acute vascular occlusions in sickle cell mice. Blood 116, 1779-1786 (2010).

43. Telen, M. J. et al. Randomized phase 2 study of GMI-1070 in SCD: reduction in time to resolution of vaso-occlusive events and decreased opioid use. Blood 125, 2656-2664 (2015).

44. Dampier, C. D. et al. Efficacy and safety of rivipansel (GMI-1070) in the treatment of vaso-occlusive crisis in hospitalized patients with sickle cell disease: results from the RESET phase 3 study. J. Sickle Cell Dis. Hemoglobinopathies 7, 26-29 (2020).

45. Kogan, T. P. et al. Rational design and synthesis of small molecule, non-oligosaccharide selectin inhibitors: (a-d-mannopyranosyloxy)biphenylsubstituted carboxylic acids. J. Med. Chem. 38 4976-4984 (1995)

46. Kogan, T. P. et al. Novel synthetic inhibitors of selectinmediated cell adhesion: synthesis of 1,6-bis[3 (3-carboxymethylphenyl)-4-(2-a-d-mannopyranosyloxy) phenyl]hexane (TBC1269). J. Med. Chem. 41 , 1099-1111 (1998)

47. Palma-Vargas, J. M. et al. Small-molecule selectin inhibitor protects against liver inflammatory response after ischemia and reperfusion. J. Am. Coll. Surg. 185 365-372 (1997)

48. Abraham, W. M. et al. Selectin blockade prevents antigen-induced late bronchial responses and airwa hyperresponsiveness in allergic sheep. Am. J. Respir. Crit. Care Med. 159, 1205-1214 (1999).

49. Friedrich, $\mathrm{M}$. et al. Pan-selectin antagonism improves psoriasis manifestation in mice and man Arch. Dermatol. Res. 297, 345-351 (2006).

50. Beeh, K. M. et al. Bimosiamose, an inhaled smallmolecule pan-selectin antagonist, attenuates late asthmatic reactions following allergen challenge in mild asthmatics: a randomized, double-blind, placebo-controlled clinical cross-over-trial. Pulm Pharmacol. Ther. 19, 233-241 (2006).

51. Watz, H. et al. Inhaled pan-selectin antagonist bimosiamose attenuates airway inflammation in COPD. Pulm. Pharmacol. Ther. 26, 265-270 (2013).

52. Kaila, N. et al. 2-(4-Chlorobenzyl)-3-hydroxy-7,8,9, 10-tetrahydrobenzo[ $H]$ quinoline-4-carboxylic acid (PSI-697): identification of a clinical candidate from the quinoline salicylic acid series of P-selectin antagonists. J. Med. Chem. 50, 40-64 (2007)

53. Myers, D. D. Jr. et al. Decreased venous thrombosis with an oral inhibitor of P selectin. J. Vasc. Surg. 42 329-336 (2005)

54. Japp, A. G. et al. Effect of PSI-697, a novel P-selectin inhibitor, on platelet-monocyte aggregate formation in humans. J. Am. Heart Assoc. 2, e006007 (2013).

55. Ikegami-Kuzuhara, A., Yoshinaka, T., Ohmoto, H., Inoue, Y. $\&$ Saito, T. Therapeutic potential of a nove synthetic selectin blocker, OJ-R9188, in allergic dermatitis. Br. J. Pharmacol. 134, 1498-1504 (2001)

56. Hiramatsu, Y. et al. Studies on selectin blockers. 6. Discovery of homologous fucose sugar unit necessary for E-selectin binding. J. Med. Chem. 41 2302-2307 (1998).

57. Yoshimura, T. et al. A novel selectin blocker alleviates oxidative stress of lung reperfusion injury. J. Surg. Res. 101, 91-98 (2001)

58. Telen, M. J. et al. Sevuparin binds to multiple adhesive ligands and reduces sickle red blood cell-induced vaso-occlusion. Br. J. Haematol. 175, 935-948 (2016).

59. BioSpace. Modus Therapeutics announces the results of its global, randomized, placebo-controlled phase 2 clinical trial evaluating sevuparin for the management of acute vaso-occlusive crisis (VOC) in patients with sickle cell disease (SCD). BioSpace https://www. biospace.com/article/-modus-therapeutics-announcesthe-results-of-its-global-randomized-placebocontrolled-phase-2-clinical-trial-evaluating-sevuparinfor-the-management-of-acute-vaso-occlusive-crisisvoc-in-patients-with-sickle-cell-disease-scd-/ (2019).

60. Schön, M. P. et al. Efomycine M, a new specific inhibitor of selectin, impairs leukocyte adhesion and alleviates cutaneous inflammation. Nat. Med. 8 366-372 (2002).

61. von Bonin, A. et al. Efomycine M: an inhibitor of selectins? Nat. Med. 12, 873; author reply 873-874 (2006).

62. Myers, D. et al. New and effective treatment of experimentally induced venous thrombosis with anti-inflammatory rPSGL-Ig. Thromb. Haemost. 87, 374-382 (2002)

63. Myers, D. D. Jr. et al. P-selectin antagonism causes dose-dependent venous thrombosis inhibition. Thromb. Haemost. 85, 423-429 (2001).

64. Kumar, A., Villani, M. P., Patel, U. K., Keith, J. C. Jr $\S$ Schaub, R. G. Recombinant soluble form of PSGL-1 accelerates thrombolysis and prevents reocclusion in a porcine model. Circulation 99, 1363-1369 (1999).

65. Busuttil, R. W. et al. rPSGL-lg for improvement of early liver allograft function: a double-blind, placebocontrolled, single-center phase II study. Am. J. Transpl. 11, 786-797 (2011)

66. Gaber, A. O. et al. YSPSL (rPSGL-Ig) for improvement of early renal allograft function: a double-blind, placebo-controlled, multi-center phase lla study. Clin. Transplant. 25, 523-533 (2011)

67. Krishnamurthy, V. R. et al. Glycopeptide analogues of PSGL-1 inhibit P-selectin in vitro and in vivo. Nat. Commun. 6, 6387 (2015)

68. Tardif, J.-C. et al. Effects of the P-selectin antagonist inclacumab on myocardial damage after percutaneous coronary intervention for non-ST-segment elevation myocardial infarction: results of the SELECT-ACS trial. J. Am. Coll. Cardiol. 61, 2048-2055 (2013).

69. Stähli, B. E. et al. Effects of P-selectin antagonist inclacumab in patients undergoing coronary artery bypass graft surgery: SELECT-CABG trial. J. Am. Coll. Cardiol. 67, 344-346 (2016).

70. Ataga, K. I. et al. Crizanlizumab for the prevention of pain crises in sickle cell disease. N. Engl. J. Med. 376 429-439 (2017).

71. Kutlar, A. et al. Effect of crizanlizumab on pain crises in subgroups of patients with sickle cell disease: a SUSTAIN study analysis. Am. J. Hematol. 94, 55-61 (2019).

72. US Food and Drug Administration. FDA approves crizanlizumab-tmca for sickle cell disease (FDA, 2019).

73. Michie, S. A., Streeter, P. R., Bolt, P. A., Butcher, E. C. $\&$ Picker, L. J. The human peripheral lymph node vascular addressin. An inducible endothelial antigen involved in lymphocyte homing. Am. J. Pathol. 143 1688-1698 (1993).

74. Sawada, R., Tsuboi, S. \& Fukuda, M. Differential E-selectin-dependent adhesion efficiency in sublines of a human colon cancer exhibiting distinct metastatic potentials. J. Biol. Chem. 269, 1425-1431 (1994).

75. Stone, J. P. \& Wagner, D. D. P-selectin mediates adhesion of platelets to neuroblastoma and small cell lung cancer. J. Clin. Invest. 92, 804-813 (1993).

76. Carroll, M. J et al. Alternatively-activated macrophages upregulate mesothelial expression of $\mathrm{P}$-selectin to enhance adhesion of ovarian cancer cells Cancer Res. 78, 3560-3573 (2018).

77. Dimitroff, C. J., Lee, J. Y., Fuhlbrigge, R. C. $\&$ Sackstein, R. A distinct glycoform of CD44 is an L-selectin ligand on human hematopoietic cells. Proc. Natl Acad. Sci. USA 97, 13841-13846 (2000).

78. Sackstein, R. et al. Ex vivo glycan engineering of CD44 programs human multipotent mesenchymal stromal cell trafficking to bone. Nat. Med. 14, 181-187 (2008).

79. Winkler, I. G. et al. Vascular niche E-selectin regulates hematopoietic stem cell dormancy, self renewal and chemoresistance Nat Med 18, 1651-1657 (2012).

80. Sipkins, D. A. et al. In vivo imaging of specialized bone marrow endothelial microdomains for tumour engraftment. Nature 435, 969-973 (2005).

This study is the first to reveal how E-selectin ligands on leukaemia promote homing to the bone marrow.

81. Porquet, N. et al. Survival advantages conferred to colon cancer cells by E-selectin-induced activation of the PI3K-NFkB survival axis downstream of Death receptor-3. BMC Cancer 11, 285 (2011).

82. Barbier, V. et al. Endothelial E-selectin inhibition improves acute myeloid leukaemia therapy by disrupting vascular niche-mediated chemoresistance. Nat. Commun. 11, 2042 (2020).

83. Chien, S. et al. A novel small molecule E-selectin inhibitor GMI-1 271 blocks adhesion of AML blasts to E-selectin and mobilizes blood cells in Nodscid IL2 $\mathrm{Rgc}^{-1-}$ mice engrafted with human AML. Blood $120,4092(2012)$
84. DeAngelo, D. J. et al. High E-selectin ligand expression contributes to chemotherapy-resistance in poor risk relapsed and refractory $(R / R)$ acute myeloid leukemia (AML) patients and can be overcome with the addition of uproleselan. Blood 134, 2690 (2019).

85. Muz, B. et al. Inhibition of E-selectin (GMI-1271) or E-selectin together with CXCR4 (GMI-1359) re-sensitizes multiple myeloma to therapy. Blood Cancer J. 9, 68 (2019).

86. Price, T. T. et al. Dormant breast cancer micrometastases reside in specific bone marrow niches that regulate their transit to and from bone. Sci. Transl. Med. 8 , 340ra73 (2016)

87. Esposito, M. et al. Bone vascular niche E-selectin induces mesenchymal-epithelial transition and Wnt activation in cancer cells to promote bone metastasis. Nat. Cell Biol. 21, 627-639 (2019).

88. Tinoco, R. \& Bradley, L. M. Targeting the PSGL-1 pathway for immune modulation. Immunotherapy $\mathbf{9}$, 785-788 (2017)

89. Urzainqui, A. et al. Functional role of P-selectin glycoprotein ligand $1 / P$-selectin interaction in the generation of tolerogenic dendritic cells. J. Immunol. 179, 7457-7465 (2007)

90. Tong, A. Armed with Langer tech and $\$ 50 \mathrm{M}$, Verseau hails new checkpoint drugs unleashing macrophages against cancer. Endpoints News https://endpts.com armed-with-langer-tech-and-50m-verseau-hailsnew-checkpoint-drugs-unleashing-macrophagesagainst-cancer/ (2019).

91. Johnston, R. J. et al. VISTA is an acidic $\mathrm{pH}$-selective ligand for PSGL-1. Nature 574, 565-570 (2019).

92. Shamay, Y. et al. P-selectin is a nanotherapeutic delivery target in the tumor microenvironment. Sci. Transl. Med. 8, 345ra87 (2016).

93. Mondal, N. et al. Distinct human $\alpha(1,3)$ fucosyltransferases drive Lewis-X/sialyl Lewis-X assembly in human cells. J. Biol. Chem. 293 7300-7314 (2018).

94. Peterson, J. et al. A novel and potent inhibitor of E-selectin, GMI-1687, attenuates thrombus formation and augments chemotherapeutic intervention of AML in preclinical models following subcutaneous administration. Blood 132, 4678-4678 (2018).

95. Macauley, M. S., Crocker, P. R. \& Paulson, J. C. Siglec-mediated regulation of immune cell function in disease. Nat. Rev. Immunol. 14, 653-666 (2014).

96. Crocker, P. R. \& Gordon, S. Properties and distribution of a lectin-like hemagglutinin differentially expressed by murine stromal tissue macrophages. J. Exp. Med. 164, 1862-1875 (1986)

97. Boué, D. R. \& Lebien, T. W. Structural characterization of the human B lymphocyte-restricted differentiation antigen CD22. Comparison with CD21 (complement receptor type 2/Epstein-Barr virus receptor) J. Immunol. 140, 192-199 (1988).

98. Simmons, D \& Seed, B. Isolation of a cDNA encoding CD33, a differentiation antigen of myeloid progenitor cells. J. Immunol. 141, 2797-2800 (1988).

99. Sternberger, N. H., Quarles, R. H., Itoyama, Y. $\&$ Webster, H. D. Myelin-associated glycoprotein demonstrated immunocytochemically in myelin and myelin-forming cells of developing rat. Proc. Natl Acad. Sci. USA 76, 1510-1514 (1979).

100. Selby, C., Yacko, L. R. \& Glode, A. E. Gemtuzumab ozogamicin: back again. J. Adv. Pract. Oncol. 10 68-82 (2019).

101. Walter, R B Investigational CD33-targeted therapeutics for acute myeloid leukemia. Expert Opin. Investig. Drugs 27, 339-348 (2018).

102. Kantarjian, H. M. et al. Inotuzumab ozogamicin versus standard therapy for acute lymphoblastic leukemia. N. Engl. J. Med. 375, 740-753 (2016).

103. Morschhauser, F. et al. Polatuzumab vedotin or pinatuzumab vedotin plus rituximab in patients with relapsed or refractory non-Hodgkin lymphoma: final results from a phase 2 randomised study (ROMULUS) Lancet Haematol. 6, e254-e265 (2019).

104. Fry, T. J. et al. CD22-targeted CAR T cells induce remission in B-ALL that is naive or resistant to CD19-targeted CAR immunotherapy. Nat. Med. 24 20-28 (2018)

105. Kenderian, S. S. et al. CD33-specific chimeric antigen receptor T cells exhibit potent preclinical activity against human acute myeloid leukemia. Leukemia $\mathbf{2 9}$ 1637-1647 (2015).

106. Chen, W. C. et al. Antigen delivery to macrophages using liposomal nanoparticles targeting sialoadhesin CD169. PLOS ONE 7, e39039 (2012).

107. Chen, W. C. et al. In vivo targeting of B-cell lymphoma with glycan ligands of CD22. Blood 115, 4778-4786 (2010). 
108. Sgroi, D., Varki, A., Braesch-Andersen, S \& Stamenkovic, I. CD22, a B cell-specific immunoglobulin superfamily member, is a sialic acid-binding lectin. J. Biol. Chem. 268, 7011-7018 (1993).

109. Doody, G. M. et al. A role in B cell activation for CD22 and the protein tyrosine phosphatase SHP. Science 269, 242-244 (1995). This report establishes that $C D 22$ is a negative regulator of $B$ cell function.

110. Jellusova, J., Wellmann, U., Amann, K., Winkler, T. H. \& Nitschke, L. CD22 $\times$ Siglec-G double-deficient mice have massively increased B1 cell numbers and develop systemic autoimmunity. J. Immunol. 184, 3618-3627 (2010).

111. Nitschke, L., Carsetti, R., Ocker, B., Köhler, G. \& Lamers, M. C. CD22 is a negative regulator of B-cell receptor signalling. Curr. Biol. 7, 133-143 (1997).

112. Collins, B. E., Smith, B. A., Bengtson, P. \& Paulson, J. C. Ablation of CD22 in ligand-deficient mice restores B cell receptor signaling. Nat. Immunol. 7, 199-206 (2006).

113. Müller, J. et al. CD22 ligand-binding and signaling domains reciprocally regulate $\mathrm{B}$-cell $\mathrm{Ca}^{2+}$ signaling. Proc. Natl Acad. Sci. USA 110, 12402-12407 (2013).

114. Han, S., Collins, B. E., Bengtson, P. \& Paulson, J. C. Homomultimeric complexes of CD22 in B cells revealed by protein-glycan cross-linking. Nat. Chem Biol. 1, 93-97 (2005)

115. Ereño-Orbea, J. et al. Molecular basis of human CD22 function and therapeutic targeting. Nat. Commun. 8 764 (2017).

116. O'Reilly, M. K., Tian, H. \& Paulson, J. C. CD22 is a recycling receptor that can shuttle cargo between the cell surface and endosomal compartments of B cells. J. Immunol. 186, 1554-1563 (2011).

117. Marin-Acevedo, J. A. et al. Next generation of immune checkpoint therapy in cancer: new developments and challenges. J. Hematol. Oncol. 11, 39 (2018).

118. Ruhenstroth-Bauer, G. et al. Zur Bedeutung der Neuraminsäuren in der Zellmembran für das Wachstum maligner Zellen [German]. Z. Krebsforsch 65, 37-43 (1962).

119. Sanford, B. H. An alteration in tumor histocompatibility induced by neuraminidase Transplantation 5, 1273-1279 (1967).

120. Gray, B. N., Walker, C., Andrewartha, L., Freeman, S \& Bennett, R. C. Controlled clinical trial of adjuvant immunotherapy with BCG and neuraminidase-treated autologous tumour cells in large bowel cancer. J. Surg Oncol. 40, 34-37 (1989).

121. Cohen, M. et al. Sialylation of 3-methylcholanthreneinduced fibrosarcoma determines antitumor immune responses during immunoediting. J. Immunol. 185 , 5869-5878 (2010).

This report is among the first to provide definitive evidence that tumour sialic acid promotes evasion from immune surveillance.

122. Jandus, C. et al. Interactions between Siglec-7/9 receptors and ligands influence NK cell-dependent tumor immunosurveillance. J. Clin. Invest. 124 1810-1820 (2014).

This analysis of human tumour samples by lectin immunohistochemistry reveals a widespread display of ligands for Siglec-7 and Siglec-9 across various tissues of origin, suggesting that these Siglecs may be broadly important regulators of anti-tumour immunity.

123. Hudak, J. E., Canham, S. M. \& Bertozzi, C. R. Glycocalyx engineering reveals a Siglec-based mechanism for NK cell immunoevasion. Nat. Chem. Biol. 10, 69-75 (2014).

124. Läubli, H. et al. Engagement of myelomonocytic Siglecs by tumor-associated ligands modulates the innate immune response to cancer. Proc. Natl Acad. Sci. USA 111, 14211-14216 (2014).

125. Beatson, R. et al. The mucin MUC1 modulates the tumor immunological microenvironment through engagement of the lectin Siglec-9. Nat. Immunol. 17 1273 (2016)

126. Engblom, C. et al. Osteoblasts remotely supply lung tumors with cancer-promoting SiglecFhigh neutrophils. Science 358, eaal5081 (2017).

127. Nguyen, D. H., Hurtado-Ziola, N., Gagneux, P. \& Varki, A. Loss of Siglec expression on T lymphocytes during human evolution. Proc. Natl Acad. Sci. USA 103, 7765-7770 (2006).

128. Ikehara, Y., Ikehara, S. K. \& Paulson, J. C. Negative regulation of T cell receptor signaling by Siglec- 7 (p70/AIRM) and Siglec-9. J. Biol. Chem. 279 43117-43125 (2004).
129. Vuchkovska, A. \& Iwashima, M. Siglec 5 - a nove checkpoint receptor in T cells. J. Immunol. 204 78.11-78.11 (2020)

130. Stanczak, M. A. et al. Self-associated molecular patterns mediate cancer immune evasion by engaging Siglecs on T cells. J. Clin. Invest. 128, 4912-4923 (2018). This report identifies Siglec-9 as a checkpoint on tumour-infiltrating lymphocytes that contributes to tumorigenesis. The authors present elegant experiments where the inhibitory cytoplasmic domain of Siglec is exchanged with an activating domain to reverse the effects they observe, thereby highlighting the importance of Siglecs in regulating the immune response.

131. Haas, Q. et al. Siglec-9 regulates an effector memory $\mathrm{CD}^{+} \mathrm{T}$-cell subset that congregates in the melanoma tumor microenvironment. Cancer Immunol. Res. 7 707-718 (2019)

132. Carlin, A. F. et al. Molecular mimicry of host sialylated glycans allows a bacterial pathogen to engage neutrophil Siglec-9 and dampen the innate immune response. Blood 113, 3333-3336 (2009).

133. Ali, S. R. et al. Siglec-5 and Siglec-14 are polymorphic paired receptors that modulate neutrophil and amnion signaling responses to group B Streptococcus. J. Exp. Med. 211, 1231-1242 (2014).

134. Fong, J. J. et al. Siglec-7 engagement by GBS $\beta$-protein suppresses pyroptotic cell death of natural killer cells. Proc. Natl Acad. Sci. USA 115, 10410-10415 (2018).

135. Secundino, I. et al. Host and pathogen hyaluronan signal through human Siglec-9 to suppress neutrophil activation. J. Mol. Med. 94, 219-233 (2016).

136. Chanmee, T., Ontong, P. \& Itano, N. Hyaluronan: a modulator of the tumor microenvironment. Cancer Lett. 375, 20-30 (2016).

137. Uchiyama, S. et al. Dual actions of group B Streptococcus capsular sialic acid provide resistance to platelet-mediated antimicrobial killing. Proc. Natl Acad. Sci. USA 116, 7465-7470 (2019).

138. Barkal, A. A. et al. CD24 signalling through macrophage Siglec-10 is a target for cancer immunotherapy. Nature 572, 392-396 (2019).

139. Wang, J. et al. Siglec-15 as an immune suppresso and potential target for normalization cance immunotherapy. Nat. Med. 25, 656-666 (2019).

140. Miyazaki, K. et al. Colonic epithelial cells express specific ligands for mucosal macrophage immunosuppressive receptors Siglec-7 and -9 . J. Immunol. 188, 4690-4700 (2012).

141. Nicoll, G. et al. Ganglioside GD3 expression on target cells can modulate NK cell cytotoxicity via Siglec-7dependent and -independent mechanisms. Eur. $J$. Immunol. 33, 1642-1648 (2003).

142. Miyazaki, K. et al. Loss of disialyl Lewis ${ }^{\text {a }}$, the ligand for lymphocyte inhibitory receptor sialic acid-binding immunoglobulin-like lectin-7 (Siglec-7) associated with increased sialyl Lewis ${ }^{\text {a }}$ expression on human colon cancers. Cancer Res. 64, 4498-4505 (2004).

143. Läubli, H. et al. Lectin galactoside-binding soluble 3 binding protein (LGALS3BP) is a tumor-associated immunomodulatory ligand for CD33-related Siglecs. J. Biol. Chem. 289, 33481-33491 (2014).

144. Yu, H. et al. Siglec-8 and Siglec-9 binding specificities and endogenous airway ligand distributions and properties. Glycobiology 27, 657-668 (2017).

145. Lu, Q. et al. PILRa and PILR $\beta$ have a siglec fold and provide the basis of binding to sialic acid. Proc. Natl Acad. Sci. USA 111, 8221-8226 (2014).

146. Kuroki, K. et al. Structural basis for simultaneous recognition of an $\mathrm{O}$-glycan and its attached peptide of mucin family by immune receptor PILRa. Proc. Natl Acad. Sci. USA 111, 8877-8882 (2014).

147. Mende, M. et al. Multivalent glycan arrays. Faraday Discuss. 219, 9-32 (2019).

148. Rodrigues, E. et al. A versatile soluble siglec scaffold for sensitive and quantitative detection of glycan ligands. Nat. Commun. 11, 5091 (2020).

149. Chang, L. et al. Identification of Siglec ligands using a proximity labeling method. J. Proteome Res. 16, 3929-3941 (2017).

150. Rillahan, C. D., Schwartz, E., McBride, R., Fokin, V. V. $\&$ Paulson, J. C. Click and pick: identification of sialoside analogues for Siglec-based cell targeting. Angew. Chem. Int. Ed. Engl. 51, 11014-11018 (2012)

151. Suematsu, R. et al. Identification of lipophilic ligands of Siglec5 and -14 that modulate innate immune responses. J. Biol. Chem. 294, 16776-16788 (2019).

152. Büll, C. et al. Steering Siglec-sialic acid interactions on living cells using bioorthogonal chemistry. Angew. Chem. Int. Ed. Engl. 56, 3309-3313 (2017).
153. Bénac, O. et al. Preclinical development of first-in-class antibodies targeting Siglec-9 immune checkpoint for cancer immunotherapy [abstract 2713]. Cancer Res. 78, 2713 (2018)

154. Rillahan, C. D. et al. Global metabolic inhibitors of sialyl- and fucosyltransferases remodel the glycome. Nat. Chem. Biol. 8, 661-668 (2012).

155. Büll, C. et al. Targeting aberrant sialylation in cancer cells using a fluorinated sialic acid analog impairs adhesion, migration, and in vivo tumor growth Mol. Cancer Ther. 12, 1935-1946 (2013).

156. Xiao, H., Woods, E. C., Vukojicic, P. \& Bertozzi, C. R. Precision glycocalyx editing as a strategy for cancer immunotherapy. Proc. Natl Acad. Sci. USA 113, 10304-10309 (2016).

157. Gray, M. A. et al. Targeted glycan degradation potentiates the anticancer immune response in vivo. Nat. Chem. Biol. 16, 1376-1384 (2020).

158. Malaker, S. A. et al. The mucin-selective protease StcE enables molecular and functional analysis of human cancer-associated mucins. Proc. Natl Acad. Sci. USA 116, 7278-7287 (2019).

159. Manhardt, C. T., Punch, P. R., Dougher, C. W. L. \& Lau, J. T. Y. Extrinsic sialylation is dynamically regulated by systemic triggers in vivo. J. Biol. Chem. 292, 13514-13520 (2017)

160. Macauley, M. S. et al. Antigenic liposomes displaying CD22 ligands induce antigen-specific B cell apoptosis. J. Clin. Invest. 123, 3074-3083 (2013).

161. Duan, S. et al. CD33 recruitment inhibits IgE-mediated anaphylaxis and desensitizes mast cells to allergen. J. Clin. Invest. 129, 1387-1401 (2019).

162. Chen, G.-Y. et al. Amelioration of sepsis by inhibiting sialidase-mediated disruption of the CD24-SiglecC interaction. Nat. Biotechnol. 29, 428-435 (2011).

163. McMillan, S. J. et al. Siglec-E is a negative regulator of acute pulmonary neutrophil inflammation and suppresses CD 11 b $\beta 2$-integrin-dependent signaling. Blood 121, 2084-2094 (2013)

164. Spence, S. et al. Targeting Siglecs with a sialic acid-decorated nanoparticle abrogates inflammation. Sci. Transl. Med. 7, 303ra140 (2015).

165. Chen, G.-Y., Tang, J., Zheng, P. \& Liu, Y. CD24 and Siglec-10 selectively repress tissue damage-induced immune responses. Science 323, 1722-1725 (2009).

166. Toubai, T. et al. Siglec-G-CD24 axis controls the severity of graft-versus-host disease in mice. Blood 123, 3512-3523 (2014).

167. Bandala-Sanchez, E. et al. T cell regulation mediated by interaction of soluble CD52 with the inhibitory receptor Siglec-10. Nat. Immunol. 14, 741-748 (2013).

168. Song, D. J. et al. Anti-Siglec-F antibody reduces allergen-induced eosinophilic inflammation and airway remodeling. J. Immunol. 183, 5333-5341 (2009).

169. Nutku, E., Hudson, S. A. \& Bochner, B. S. Mechanism of Siglec-8-induced human eosinophil apoptosis: role of caspases and mitochondrial injury. Biochem. Biophys. Res. Commun. 336, 918-924 (2005).

170. Mizrahi, S., Gibbs, B. F., Karra, L., Ben-Zimra, M. $\&$ Levi-Schaffer, F. Siglec-7 is an inhibitory receptor on human mast cells and basophils. J. Allergy Clin. Immunol. 134, 230-233 (2014).

171. Yokoi, H. et al. Inhibition of FceRI-dependent mediator release and calcium flux from human mast cells by sialic acid-binding immunoglobulin-like lectin 8 engagement. J. Allergy Clin. Immunol. 121, 499-505.e1 (2008)

172. Dellon, E. S. et al. Anti-Siglec-8 antibody for eosinophilic gastritis and duodenitis. N. Engl. J. Med 383, 1624-1634 (2020)

173. Wang, Y. \& Neumann, H. Alleviation of neurotoxicity by microglial human Siglec-11. J. Neurosci. 30 3482-3488 (2010).

174. Shahraz, A. et al. Anti-inflammatory activity of low molecular weight polysialic acid on human macrophages. Sci. Rep. 5, 16800 (2015).

175. Karlstetter, M. et al. Polysialic acid blocks mononuclear phagocyte reactivity, inhibits complement activation, and protects from vascular damage in the retina. EMBO Mol. Med. 9, 154-166 (2017).

176. Bertram, L. et al. Genome-wide association analysis reveals putative Alzheimer's disease susceptibility loci in addition to APOE. Am. J. Hum. Genet. 83 623-632 (2008)

177. Hollingworth, P. et al. Common variants at ABCA7, MS4A6A/MS4A4E, EPHA1, CD33 and CD2AP are associated with Alzheimer's disease. Nat. Genet. 43, 429-435 (2011) 
178. Naj, A. C. et al. Common variants at MS4A4/MS4A6E, CD2AP CD33 and EPHA 1 are associated with late-onset Alzheimer's disease. Nat. Genet. 43, 436-441 (2011)

179. Malik, M. et al. CD33 Alzheimer's risk-altering polymorphism, CD33 expression, and exon 2 splicing. J. Neurosci. 33, 13320-13325 (2013).

180. Bradshaw, E. M. et al. CD33 Alzheimer's disease locus: altered monocyte function and amyloid biology. Nat. Neurosci. 16, 848-850 (2013).

181. Chauhan, G. et al. Association of Alzheimer's disease GWAS loci with MRI markers of brain aging. Neurobiol. Aging 36, 1765.e7-1765.e16 (2015).

182. Wang, Y.-J. et al. Effects of CD33 variants on neuroimaging biomarkers in non-demented elders. J. Alzheimers Dis. 68, 757-766 (2019).

183. Griciuc, A. et al. Alzheimer's disease risk gene CD33 inhibits microglial uptake of amyloid $\beta$. Neuron 78 , 631-643 (2013)

184. Panza, F. et al. Are antibodies directed against amyloid- $\beta(A \beta)$ oligomers the last call for the $A \beta$ hypothesis of Alzheimer's disease? Immunotherapy 11, 3-6 (2019).

185. Griciuc, A. et al. TREM2 acts downstream of CD33 in modulating microglial pathology in Alzheimer's disease. Neuron 103, 820-835.e7 (2019).

186. Pluvinage, J. V. et al. CD22 blockade restores homeostatic microglial phagocytosis in ageing brains. Nature 568, 187-192 (2019).

187. Delaveris, C., Chiu, S., Riley, N. \& Bertozzi, C. Modulation of immune cell reactivity with cis-binding Siglec agonist. Preprint at ChemRxiv https:// doi.org/10.26434/chemrxiv.12598655.v1 (2020).

188. Walter, R. B. et al. ITIM-dependent endocytosis of CD33-related Siglecs: role of intracellular domain, tyrosine phosphorylation, and the tyrosine phosphatases, Shp1 and Shp2. J. Leukoc. Biol. 83, 200-211 (2008)

189. Stuible, M. et al. Mechanism and function of monoclonal antibodies targeting Siglec-15 for therapeutic inhibition of osteoclastic bone resorption. J. Biol. Chem. 289, 6498-6512 (2014).

190. Speiser, D. E. et al. Self antigens expressed by solid tumors do not efficiently stimulate naive or activated T cells: implications for immunotherapy. J. Exp. Med. 186, 645-653 (1997).

191. Wang, T. T. in FC Mediated Activity of Antibodies: Structural and Functional Diversity (eds Ravetch, J. V. \& Nimmerjahn, F.) 63-75 (Springer, 2019).

192. Mastrangeli, R., Palinsky, W. \& Bierau, H. Glycoengineered antibodies: towards the nextgeneration of immunotherapeutics. Glycobiology 29, 199-210 (2019).

193. Dube, D. H. \& Bertozzi, C. R. Glycans in cancer and inflammation - potential for therapeutics and diagnostics. Nat. Rev. Drug Discov. 4, 477-488 (2005).

194. Pinho, S. S. \& Reis, C. A. Glycosylation in cancer: mechanisms and clinical implications. Nat. Rev. Cancer 15, 540-555 (2015).

195. Dotan, N., Altstock, R. T., Schwarz, M. \& Dukler, A. Anti-glycan antibodies as biomarkers for diagnosis and prognosis. Lupus 15, 442-450 (2006).

196. Dotan, I. et al. Antibodies against laminaribioside and chitobioside are novel serologic markers in Crohn's disease. Gastroenterology 131, 366-378 (2006)

197. Grader-Beck, T. et al. Antibodies recognising sulfated carbohydrates are prevalent in systemic sclerosis and associated with pulmonary vascular disease. Ann. Rheum. Dis. 70, 2218-2224 (2011).

198. Kui Wong, N. et al. Characterization of the oligosaccharides associated with the human ovarian tumor marker CA125. J. Biol. Chem. 278 , 28619-28634 (2003).

199. Hammarström, S. The carcinoembryonic antigen (CEA) family: structures, suggested functions and expression in normal and malignant tissues. Semin. Cancer Biol. 9, 67-81 (1999).

200. Magnani, J. L., Steplewski, Z., Koprowski, H. \& Ginsburg, V. Identification of the gastrointestinal and pancreatic cancer-associated antigen detected by monoclonal antibody 19-9 in the sera of patients as a mucin Cancer Res. 43, 5489-5492 (1983).

201. Kim, Y. J. \& Varki, A. Perspectives on the significance of altered glycosylation of glycoproteins in cancer. Glycoconj. J. 14, 569-576 (1997).

202. Sun, X., Ju, T. \& Cummings, R. D. Differential expression of Cosmc, T-synthase and mucins in Tn-positive colorectal cancers. BMC Cancer 18, 827 (2018).

203. Lau, K. S. et al. Complex N-glycan number and degree of branching cooperate to regulate cell proliferation and differentiation. Cell 129, 123-134 (2007).
204. Feng, D., Shaikh, A. S. \& Wang, F. Recent advance in tumor-associated carbohydrate antigens (TACAs)based antitumor vaccines. ACS Chem. Biol. 11 850-863 (2016)

205. Irie, R. F., Giuliano, A. E. \& D. L. Morton. Oncofetal antigen: a tumor-associated fetal antigen immunogenic in man. J. Natl Cancer Inst. 63 (1979).

This article is the first to demonstrate that adjuvant immunotherapy with a whole-cell melanoma vaccine elicited antibodies against oncofetal antigens that were later shown to be GD2 and GM2.

206. Cahan, L. D. et al. Identification of a human neuroectodermal tumor antigen (OFA-I-2) as ganglioside GD2. Proc. Natl Acad. Sci. USA 79 7629-7633 (1982).

207. Tai, T., Paulson, J C C Cahan, L. D. \& Irie, R. F. Ganglioside GM2 as a human tumor antigen (OFA-I-1) Proc. Natl Acad. Sci. USA 80, 5392-5396 (1983).

208. Livingston, P. O. et al. Improved survival in stage III melanoma patients with GM2 antibodies: a randomized trial of adjuvant vaccination with $\mathrm{GM} 2$ ganglioside. J. Clin. Oncol. 12, 1036-1044 (1994).

209. Helling, F. et al. GD3 vaccines for melanoma: superior immunogenicity of keyhole limpet hemocyanin conjugate vaccines. Cancer Res. 54, 197-203 (1994)

210. Helling, F. et al. GM2-KLH conjugate vaccine: increased immunogenicity in melanoma patients after administration with immunological adjuvant QS-21. Cancer Res. 55, 2783-2788 (1995).

211. Eggermont, A. M. M. et al. Adjuvant ganglioside GM2-KLH/QS-21 vaccination versus observation after resection of primary tumor $>1.5 \mathrm{~mm}$ in patients with stage II melanoma: results of the EORTC 1896 randomized phase III trial. J. Clin. Oncol. 31, 3831-3837 (2013).

212. Gilewski, T. et al. Immunization of metastatic breast cancer patients with a fully synthetic globo $\mathrm{H}$ conjugate: a phase I trial. Proc. Natl Acad. Sci. USA 98, 3270-3275 (2001)

213. Krug, L. M. et al. Vaccination of patients with small-cell lung cancer with synthetic fucosyl GM-1 conjugated to keyhole limpet hemocyanin. Clin. Cancer Res. 10, 6094-6100 (2004).

214. Sabbatini, P. J. et al. Immunization of ovarian cance patients with a synthetic Lewis ${ }^{y}$-protein conjugate vaccine: a phase 1 trial. Int. J. Cancer 87, 79-85 (2000).

215. Huang, C.-S. et al. Randomized phase II/III trial of active immunotherapy with OPT-822/OPT-821 in patients with metastatic breast cancer. J. Clin. Orthod. 34, 1003-1003 (2016)

216. Hull, S. R. et al. Oligosaccharide differences in the DF3 sialomucin antigen from normal human milk and the BT-20 human breast carcinoma cell line. Cancer Commun. 1, 261-267 (1989).

217. Lloyd, K. O., Burchell, J., Kudryashov, V., Yin, B. W. \& Taylor-Papadimitriou, J. Comparison of O-linked carbohydrate chains in MUC-1 mucin from normal breast epithelial cell lines and breast carcinoma cell lines. Demonstration of simpler and fewer glycan chains in tumor cells. J. Biol. Chem. 271 33325-33334 (1996)

218. Gilewski, T. et al. Vaccination of high-risk breast cancer patients with mucin-1 (MUC1) keyhole limpet hemocyanin conjugate plus QS-21. Clin. Cancer Res. 6. 1693-1701 (2000).

219. Kimura, T. et al. MUC1 vaccine for individuals with advanced adenoma of the colon: a cancer immunoprevention feasibility study. Cancer Prev. Res. 6, 18-26 (2013)

220. Finn, O. J. et al. Abstract CT236: randomized, double-blind, placebo-controlled trial of preventative MUC1 vaccine in patients with newly diagnosed advanced adenomas: results from one-year booster Cancer Res. 79, CT236 (2019).

221. Gabitzsch, E. S. et al. The generation and analyses of a novel combination of recombinant adenovirus vaccines targeting three tumor antigens as an immunotherapeutic. Oncotarget 6, 31344-31359 (2015).

222. Gatti-Mays, M. E. et al. A phase I trial using a multitargeted recombinant adenovirus 5 (CEA/MUC 1/ Brachyury)-based immunotherapy vaccine regimen in patients with advanced cancer. Oncologist 25, 479.e899 (2020).

223. Kobayashi, H., Terao, T. \& Kawashima, Y. Serum sialyl $\mathrm{Tn}$ as an independent predictor of poor prognosis in patients with epithelial ovarian cancer. J. Clin. Oncol. 10, 95-101 (1992)

224. MacLean, G. D. et al. Immunization of breast cancer patients using a synthetic sialyl-Tn glycoconjugate plus
Detox adjuvant. Cancer Immunol. Immunother. 36, 215-222 (1993).

225. MacLean, G. D., Reddish, M. A., Koganty, R. R. \& Longenecker, B. M. Antibodies against mucinassociated sialyl-Tn epitopes correlate with survival of metastatic adenocarcinoma patients undergoing active specific immunotherapy with synthetic STn vaccine. J. Immunother. Emphasis Tumor Immunol. 19, 59-68 (1996)

226. Miles, D. et al. Phase III multicenter clinical trial of the sialyl-TN (STn)-keyhole limpet hemocyanin (KLH) vaccine for metastatic breast cancer. Oncologist 16 1092-1100 (2011).

227. Sabbatini, P. J. et al. Pilot study of a heptavalent vaccine-keyhole limpet hemocyanin conjugate plus QS21 in patients with epithelial ovarian, fallopian tube, or peritoneal cancer. Clin. Cancer Res. 13 4170-4177 (2007).

228. O'Cearbhaill, R. E. et al. A phase I study of unimolecular pentavalent (Globo-H-GM2-sTn-TF$\mathrm{Tn}$ ) immunization of patients with epithelial ovarian, fallopian tube, or peritoneal cancer in first remission. Cancers 8, 46 (2016)

229. Hutchins, L. F. et al. Targeting tumor-associated carbohydrate antigens: a phase I study of a carbohydrate mimetic-peptide vaccine in stage IV breast cancer subjects. Oncotarget 8, 99161-99178 (2017).

230. Kieber-Emmons, T. et al. Vaccination with carbohydrate peptide mimotopes promotes anti-tumor responses. Nat. Biotechnol. 17, 660-665 (1999).

231. Kushner, B. H. et al. Phase I trial of a bivalent gangliosides vaccine in combination with $\beta$-glucan for high-risk neuroblastoma in second or later remission. Clin. Cancer Res. 20, 1375-1382 (2014).

232. Xia, L., Schrump, D. S. \& Gildersleeve, J. C. Whole-cell cancer vaccines induce large antibody responses to carbohydrates and glycoproteins. Cell Chem. Biol. 23 1515-1525 (2016).

233. Ploessl, C., Pan, A., Maples, K. T. \& Lowe, D. K. Dinutuximab: an anti-GD2 monoclonal antibody for high-risk neuroblastoma. Ann. Pharmacother. 50 416-422 (2016)

234. Cheung, N. K. et al. Monoclonal antibodies to a glycolipid antigen on human neuroblastoma cells. Cancer Res. 45, 2642-2649 (1985).

235. Saito, M., Yu, R. K. \& Cheung, N. K. Ganglioside GD2 specificity of monoclonal antibodies to human neuroblastoma cell. Biochem. Biophys. Res. Commun 127, 1-7 (1985).

236. Mujoo, K., Cheresh, D. A., Yang, H. M. \& Reisfeld, R. A Disialoganglioside GD2 on human neuroblastoma cells: target antigen for monoclonal antibodymediated cytolysis and suppression of tumor growth. Cancer Res. 47, 1098-1104 (1987)

237. Mueller, B. M., Romerdahl, C. A., Gillies, S. D. \& Reisfeld, R. A. Enhancement of antibody-dependent cytotoxicity with a chimeric anti-GD2 antibody. J. Immunol. 144, 1382-1386 (1990).

238. Yu, A. L. et al. Anti-GD2 antibody with GM-CSF, interleukin-2, and isotretinoin for neuroblastoma N. Engl. J. Med. 363, 1324-1334 (2010).

239. Dickler, M. N. et al. Immunogenicity of a fucosylGM1-keyhole limpet hemocyanin conjugate vaccine in patients with small cell lung cancer. Clin. Cancer Res. 5, 2773-2779 (1999)

240. Brezicka, F. T., Holmgren, J., Kalies, I. \& Lindholm, L. Tumor-cell killing by mAbs against fucosyl GM 1 , a ganglioside antigen associated with small-cell lung carcinoma. Int. J. Cancer 49, 911-918 (1991).

241. Ponath, P. et al. A novel, fully human anti-fucosyl-GM antibody demonstrates potent in vitro and in vivo antitumor activity in preclinical models of small cell lung cancer. Clin. Cancer Res. 24, 5178-5189 (2018).

242. Cheng, J.-Y. et al. Globo-H ceramide shed from cancer cells triggers translin-associated factor X-dependent angiogenesis. Cancer Res. 74, 6856-6866 (2014).

243. Chen, Y.-C. et al. Abstract 544: Anti-tumor efficacy and potential mechanism of action of a novel therapeutic humanized anti-Globo $\mathrm{H}$ antibody, OBI-888. Cancer Res. 79, 544-544 (2019).

244. Yang, M.-C. et al. Abstract 4815: Novel Globo H targeting antibody-drug conjugate with binding specificity and anti-tumor efficacy in multiple cancer types. Cancer Res. 79, 4815-4815 (2019).

245. Ju, T. et al. Human tumor antigens Tn and sialy $\mathrm{Tn}$ arise from mutations in Cosmc. Cancer Res. 68, 1636-1646 (2008).

246. Ohno, S. et al. Expression of Tn and sialyl-Tn antigens in endometrial cancer: its relationship with tumorproduced cyclooxygenase-2, tumor-infiltrated lymphocytes and patient prognosis. Anticancer Res. 26, 4047-4053 (2006). 
247. Itzkowitz, S. Colon carcinogenesis in inflammatory bowel disease: applying molecular genetics to clinical practice. J. Clin. Gastroenterol. 36, S70-S74 (2003).

248. Sørensen, A. L. et al. Chemoenzymatically synthesized multimeric Tn/STn MUC1 glycopeptides elicit cancerspecific anti-MUC1 antibody responses and override tolerance. Glycobiology 16, 96-107 (2006). This paper systematically tests and synthesizes various MUC1 glycopeptides for their ability to elicit a humoral response. The 5E5 antibody generated in this study has proven effective in targeting tumours in multiple settings.

249. Tarp, M. A. et al. Identification of a novel cancerspecific immunodominant glycopeptide epitope in the MUC1 tandem repeat. Glycobiology 17, 197-209 (2007).

250. Posey, A. D. Jr. et al. Engineered CAR T cells targeting the cancer-associated Tn-glycoform of the membrane mucin MUC1 control adenocarcinoma. Immunity $\mathbf{4 4}$ 1444-1454 (2016)

251. Pule, M. A. et al. Virus-specific T cells engineered to coexpress tumor-specific receptors: persistence and antitumor activity in individuals with neuroblastoma. Nat. Med. 14, 1264-1270 (2008).

252. Mount, C. W. et al. Potent antitumor efficacy of anti-GD2 CAR T cells in H3-K27M ${ }^{+}$diffuse midline gliomas. Nat. Med. 24, 572-579 (2018).

253. Makovitzky, J. The distribution and localization of the monoclonal antibody-defined antigen 19-9 (CA19-9) in chronic pancreatitis and pancreatic carcinoma. An immunohistochemical study. Virchows Arch. B Cell Pathol. Incl. Mol. Pathol. 51, 535-544 (1986).

254. Loy, T. S., Sharp, S. C., Andershock, C. J. \& Craig, S. B. Distribution of CA 19-9 in adenocarcinomas and transitional cell carcinomas. An immunohistochemical study of 527 cases. Am. J. Clin. Pathol. 99, 726-728 (1993).

255. Ragupathi, G. et al. Synthesis of sialyl Lewis ${ }^{a}$ sLe $^{a}$ CA 19-9) and construction of an immunogenic sLe vaccine. Cancer Immunol. Immunother. $\mathbf{5 8}$ 1397-1405 (2009).

256. Sawada, R. et al. Human monoclonal antibodies to sialyl-Lewis (CA19.9) with potent CDC, ADCC, and antitumor activity. Clin. Cancer Res. 17, 1024-1032 (2011)

257. Viola-Villegas, N. T. et al. Applying PET to broaden the diagnostic utility of the clinically validated CA 19.9 serum biomarker for oncology. J. Nucl. Med. 54, 1876-1882 (2013)

258. Houghton, J. L. et al. Site-specifically labeled CA19. 9-targeted immunoconjugates for the PET, NIRF, and multimodal PET/NIRF imaging of pancreatic cancer. Proc. Natl Acad. Sci. USA 112, 15850-15855 (2015).

259. Poty, S. et al. Leveraging bioorthogonal click chemistry to improve 225Ac-radioimmunotherapy of pancreatic ductal adenocarcinoma. Clin. Cancer Res. 25 868-880 (2019)

260. O'Reilly, E. A. et al. Phase I dose escalation study of ${ }^{177} \mathrm{Lu}$-HuMab-5B1 (MVT-1075) in combination with MVT-5873 as radioimmunotherapy (RIT) in subjects with relapsed/refractory pancreatic cancer or other CA 19-9+ malignancies [abstract CT 140]. Cancer Res. 78, CT140 (2018).

261. Johannes, L., Jacob, R. \& Leffler, H. Galectins at a glance. J. Cell Sci. 131, jcs208884 (2018).

262. Girard, A. \& Magnani, J. L. Clinical trials and applications of galectin antagonists. Trends Glycosci. Glycotechnol. 30, SE211-SE220 (2018)

263. Varki, A. Omics: account for the "dark matter" of biology. Nature 497, 565 (2013).

264. Lee, H.-H. et al. Removal of $\mathrm{N}$-linked glycosylation enhances PD-L1 detection and predicts anti-PD-1/PDL1 therapeutic efficacy. Cancer Cell 36, 168-178.e4 (2019).

265. Steentoft, C. et al. Mining the O-glycoproteome using zinc-finger nuclease-glycoengineered SimpleCell lines. Nat. Methods 8, 977-982 (2011).

266. Steentoft, C. et al. Precision mapping of the human $O$-GalNAc glycoproteome through SimpleCell technology. EMBO J. 32, 1478-1488 (2013).

267. McKitrick, T. R. et al. Antibodies from lamprey as smart anti-glycan reagents (SAGRs) - perspectives on their specificity, structure and glyco-genomics. Biochemistry 59, 3111-3122 (2020).
268. Kaltgrad, E. et al. Anti-carbohydrate antibodies elicited by polyvalent display on a viral scaffold. ChemBioChem 8, 1455-1462 (2007).

269. Woods, R. J. \& Yang, L. Glycan-specific analytical tools US Patent 9,926,612 (2009).

270. Spiciarich, D. R. et al. A novel germline variant in CSF3R reduces $\mathrm{N}$-glycosylation and exerts potent oncogenic effects in leukemia. Cancer Res. 78, 6762-6770 (2018).

271. Mende, M. et al. On-chip neo-glycopeptide synthesis for multivalent glycan presentation. Chem. Eur. J. 26, 9954-9963 (2020).

272. Narimatsu, Y. et al. An atlas of human glycosylation pathways enables display of the human glycome by gene engineered cells. Mol. Cell 75, 394-407.e5 (2019).

273. Briard, J. G., Jiang, H., Moremen, K. W., Macauley, M. S. \& Wu, P. Cell-based glycan arrays for probing glycan-glycan binding protein interactions. Nat. Commun. 9, 880 (2018).

274. Kalas, V. et al. Structure-based discovery of glycomimetic FmlH ligands as inhibitors of bacterial adhesion during urinary tract infection. Proc. NatI Acad. Sci. USA 115, E2819-E2828 (2018).

275. Wun, T. et al. Phase 1 study of the E-selectin inhibitor GMI 1070 in patients with sickle cell anemia. PLoS ONE 9, e101301 (2014).

276. Kirsten, A. et al. Efficacy of the pan-selectin antagonist bimosiamose on ozone-induced airway inflammation in healthy subjects - a double blind, randomized placebo-controlled, cross-over clinical trial. Pulm. Pharmacol. Ther. 24, 555-558 (2011).

277. Cheadle, C. et al. Effects of anti-adhesive therapy on kidney biomarkers of ischemia reperfusion injury in human deceased donor kidney allografts Clin. Transplant. 25, 766-775 (2011).

278. Stähli, B. E. et al. Effects of the P-selectin antagonist inclacumab on myocardial damage after percutaneous coronary intervention according to timing of infusion: insights from the SELECT-ACS trial. J. Am. Heart Assoc. 5, e004255 (2016).

279. Bross, P. F. et al. Approval summary: gemtuzumab ozogamicin in relapsed acute myeloid leukemia Clin. Cancer Res. 7, 1490-1496 (2001).

280. Sievers, E. L. et al. Efficacy and safety of gemtuzumab ozogamicin in patients with CD33-positive acute myeloid leukemia in first relapse. J. Clin. Oncol. 19 3244-3254 (2001).

281. Petersdorf, S. H. et al. A phase 3 study of gemtuzumab ozogamicin during induction and postconsolidation therapy in younger patients with acute myeloid leukemia. Blood 121, 4854-4860 (2013).

282. Castaigne, S. et al. Effect of gemtuzumab ozogamicin on survival of adult patients with de-novo acute myeloid leukaemia (ALFA-0701): a randomised, open-label, phase 3 study. Lancet 379, 1508-1516 (2012).

283. Renneville, A. et al. Clinical impact of gene mutations and lesions detected by SNP-array karyotyping in acute myeloid leukemia patients in the context of gemtuzumab ozogamicin treatment: results of the ALFA-0701 trial. Oncotarget 5, 916-932 (2014).

284. NextCure. NextCure provides an interim update of the phase 2 portion of the NC318 monotherapy phase $1 / 2$ trial and announces departure of Chief Medical Officer. GlobeNewswire News Room http://www. globenewswire.com/news-release/2020/07/13/ 2061067/0/en/NextCure-Provides-an-Interim-Update of-the-Phase-2-Portion-of-the-NC318-MonotherapyPhase-1-2-Trial-and-Announces-Departure-of-ChiefMedical-Officer.html (2020)

285. Ibrahim, N. K. et al. Survival advantage in patients with metastatic breast cancer receiving endocrine therapy plus sialyl Tn-KLH vaccine: post hoc analysis of a large randomized trial. J. Cancer 4, 577-584 (2013).

286. Morse, M. A. et al. Novel adenoviral vector induces T-cell responses despite anti-adenoviral neutralizing antibodies in colorectal cancer patients. Cancer Immunol. Immunother. 62, 1293-1301 (2013).

287. Berek, J. et al. Oregovomab maintenance monoimmunotherapy does not improve outcomes in advanced ovarian cancer. J. Clin. Oncol. 27, 418-425 (2009).
288. Battaglia, A. et al. Translational immune correlates of indirect antibody immunization in a randomized phase II study using scheduled combination therapy with carboplatin/paclitaxel plus oregovomab in ovarian cancer patients. Cancer Immunol. Immunother. 69, 383-397 (2020)

289. Brewer, M. et al. Front-line chemo-immunotherapy with carboplatin-paclitaxel using oregovomab indirect immunization in advanced ovarian cancer: a randomized phase II study. Gynecol. Oncol. 156, 523-529 (2020)

290. Baz, R. C., Zonder, J. A., Gasparetto, C., Reu, F. J. $\&$ Strout, V. Phase I study of anti-GM2 ganglioside monoclonal antibody BIW-8962 as monotherapy in patients with previously treated multiple myeloma. Oncol. Ther. 4, 287-301 (2016).

291. Tarhini, A. A. et al. Safety and efficacy of the antiganglioside GD3 antibody ecromeximab (KW2871) combined with high-dose interferon- $a 2 b$ in patients with metastatic melanoma. Melanoma Res. 27, 342-350 (2017).

292. Sabbatini, P. et al. Abagovomab as maintenance therapy in patients with epithelial ovarian cancer: a phase III trial of the AGO OVAR, COGI, GINECO and GEICO - the MIMOSA study. J. Clin. Oncol. 31, 1554-1561 (2013).

293. Buzzonetti, A. et al. Immunological response induced by abagovomab as a maintenance therapy in patients with epithelial ovarian cancer: relationship with survival - a substudy of the MIMOSA trial. Cancer Immunol. Immunother. 63, 1037-1045 (2014).

294. Alfonso, S. et al. A randomized, multicenter, placebocontrolled clinical trial of racotumomab-alum vaccine as switch maintenance therapy in advanced non-smal cell lung cancer patients. Clin. Cancer Res. 20, 3660-3671 (2014)

295. Cacciavillano, W. et al. A phase I study of the antiidiotype vaccine racotumomab in neuroblastoma and other pediatric refractory malignancies. Pediatr. Blood Cancer 62, 2120-2124 (2015).

296. Louis, C. U. et al. Antitumor activity and long-term fate of chimeric antigen receptor-positive $T$ cells in patients with neuroblastoma. Blood 118, 6050-6056 (2011).

297. Toubai, T. et al. Siglec-G represses DAMP-mediated effects on T cells. JCI Insight 2, e92293 (2017).

298. Crocker, P. R., Paulson, J. C. \& Varki, A. Siglecs and their roles in the immune system. Nat. Rev. Immunol. 7, 255-266 (2007).

299. Longenecker, B. M., Reddish, K., Koganty, R. \& MacLean, G. D. Specificity of the IgG response in mice and human breast cancer patients following immunization against synthetic sialyl-Tn, an epitope with possible functional significance in metastasis. Adv. Exp. Med. Biol 353, 105-124 (1994).

\section{Acknowledgements}

Work from the authors' laboratory was supported by a grant from the National Institutes of Health (CA227942). B.A.H.S. was supported by a Predoctoral Fellowship from the National Institutes of Health (F30CA232541) and the Stanford School of Medicine Medical Scientist Training Program. The authors thank M. Gray and S. Wisnovsky for critical reading of the manuscript.

\section{Author contributions}

The authors contributed to all aspects of the article.

\section{Competing interests}

C.R.B. is a co-founder of Redwood Bioscience, Enable Biosciences, Palleon Pharmaceuticals, InterVenn Bio, Lycia Therapeutics and OliLux Biosciences, and a member of the Board of Directors of Eli Lilly. B.A.H.S. is a shareholder of GlycoMimetics.

\section{Publisher's note}

Springer Nature remains neutral with regard to jurisdictional claims in published maps and institutional affiliations.

\section{RELATED LINKS}

Consortium for Functional Glycomics:

https://functionalglycomics.com

GlyCosmos: https://glycosmos.org

GlyGen: https://glygen.org

(c) Springer Nature Limited 2021, corrected publication 2021 